Portland State University

PDXScholar

Winter 3-20-2015

\title{
Development of an Optical Method for the Detection of Homocysteine as a Disease Biomarker Using Fluorescein-Aldehydes
}

Aabha Barve

Portland State University

Follow this and additional works at: https://pdxscholar.library.pdx.edu/open_access_etds

Part of the Chemistry Commons

Let us know how access to this document benefits you.

\section{Recommended Citation}

Barve, Aabha, "Development of an Optical Method for the Detection of Homocysteine as a Disease Biomarker Using Fluorescein-Aldehydes" (2015). Dissertations and Theses. Paper 2221.

https://doi.org/10.15760/etd.2218

This Dissertation is brought to you for free and open access. It has been accepted for inclusion in Dissertations and Theses by an authorized administrator of PDXScholar. Please contact us if we can make this document more accessible: pdxscholar@pdx.edu. 
Development of an Optical Method for the Detection of Homocysteine as a Disease Biomarker Using Fluorescein-Aldehydes

by

Aabha Barve

A dissertation submitted in partial fulfillment of the requirements for the degree of

Doctor of Philosophy

in

Chemistry

Dissertation Committee:

Robert M. Strongin, Chair

Reuben H. Simoyi

Jon Abramson

Mark Woods

Portland State University

2015 


\begin{abstract}
Homocysteine is a natural occurring aminothiol. It is an intermediate product in the metabolism of methionine. Methionine is an essential amino acid required for protein synthesis. Metabolic irregularities disrupt homocysteine levels in plasma. Elevated homocysteine levels are directly linked to folate and cobalamin (vitamin B12) deficiencies, and are an independent risk factor for cardiovascular diseases. High homocysteine levels have also been associated with Alzheimer's, osteoporosis, renal failure, cancer, birth defects and pregnancy complications. The association of elevated homocysteine levels with cardiovascular disease and other diseases has generated great interest in the detection of homocysteine.
\end{abstract}

An optical method for the detection of homocysteine has been developed using fluorescein mono- and dialdehydes. Selectivity for homocysteine was achieved based on the characteristic differences between 5- and 6-membered ring heterocyclic amines formed upon the reaction with fluorescein mono- and dialdehydes. 6-membered ring homocysteine-derived thiazinane-4-carboxylic acids were found to be more basic than 5membered cysteine-derived thiazolidine-4-carboxylic acids. Fluorescence enhancement in response to homocysteine was thus attained by tuning $\mathrm{pH}$ and excitation wavelengths. Furthermore, the design and synthesis of a more sensitive fluorophore, fluorescein tri aldehyde has been accomplished based on the aforementioned findings to enable the detection of homocysteine at physiological levels. Calculations of Mulliken charges revealed that the formation of thiazinanes results in modulation of the electron density on the fluorophore leading to higher fluorescence. 


\section{ACKNOWLEDGEMENTS}

I would like to express my deepest appreciation to my thesis advisor and committee chair, Dr. Robert M. Strongin, for providing me the opportunity to be a part of his research group and his support and encouragement. Without his guidance and persistent help this research would not have been possible.

I would like to show my gratitude towards my committee members, Dr. Mark woods, Dr. Reuben H. Simoyi and Dr. Jon Abramson for their invaluable suggestions and immense support during my research. I highly appreciate their patience and time for reading my dissertation. I would also like to thank Dr. Shankar Rananavare for his help and suggestions in my research.

I would like to thank my group members, Dr. Mark Lowry, Dr. Jorge Escobedo and Dr. Joseph Rajan for their help and many insightful scientific discussions during my graduate studies. I would like to thank my former and fellow colleagues Lei Wang, Jialu Wang, Shelly Chu and Lovemore Hakuna for their help and emotional support.

Finally, I would like to thank my parents, siblings and friends for their love, support and encouragement. A very special thanks to my fiancé Santosh Kumar for his love and support. I am very thankful to my friends Rekha Sharma, Aparna Gurijala, Renu Singh, Ajay Malpani and Megha Khandelwal for being with me through the good time and bad. 


\section{TABLE OF CONTENTS}

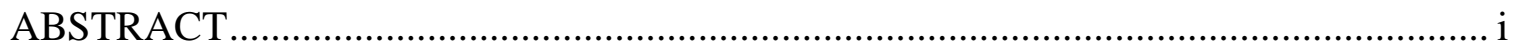

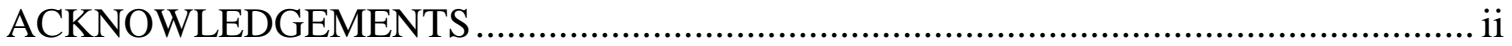

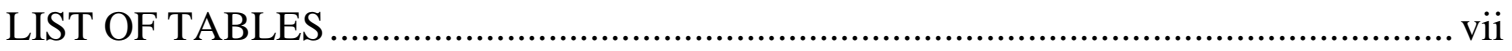

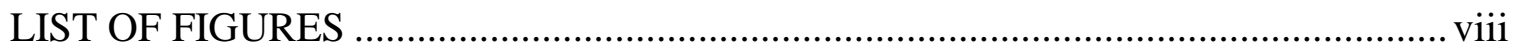

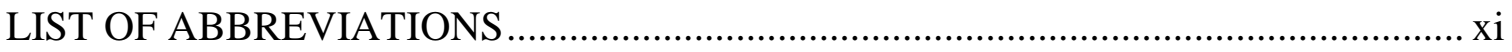

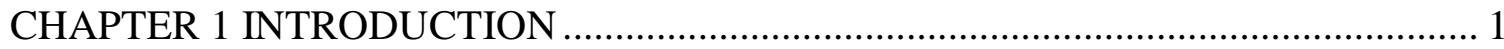

$1.1 \mathrm{Hcy}$, Cys and GSH: structural features and functions. ............................................ 1

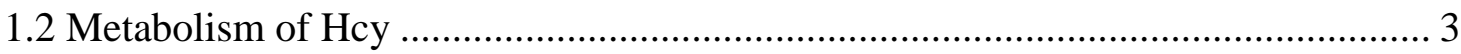

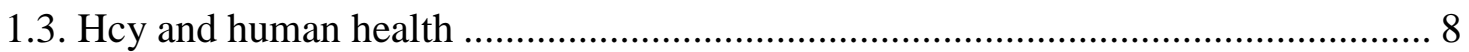

1.3.1 Hcy: A biomarker or a risk factor!.................................................................. 13

CHAPTER 2 AN OVERVIEW - TECHNIQUES INVOLVED IN HCY DETECTION 17

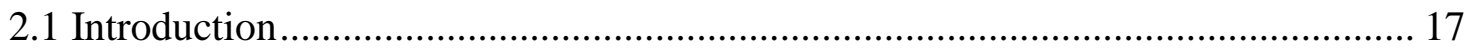

2.2 Existing methods for the detection of Hcy .................................................... 17

2.3 Methods based on electrochemistry and nano materials ........................................ 19

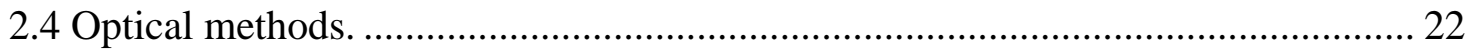

2.4.1 Optical detection based on the redox chemistry of Hcy .................................. 22

2.4.2 Methods for detection of Cys and Hcy based on Schiff base formation and subsequent cyclization to form a heterocycle. ......................................................... 24 


\section{CHAPTER 3 SELECTIVE DETECTION OF HCY USING FLUORESCEINE}

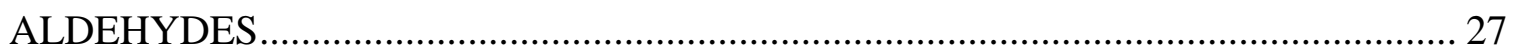

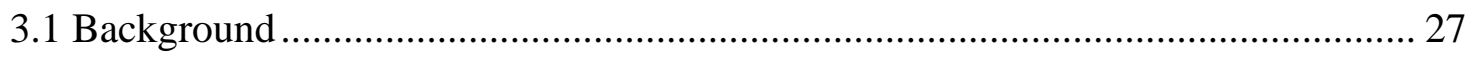

3.2 Mechanism of signal transaction in aldehyde bearing fluorophore probes upon

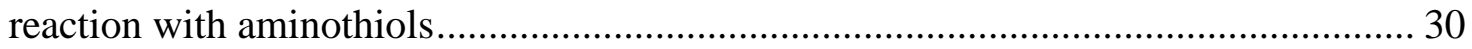

3.3 Previous work- response of fluorescein aldehydes to Cys and Hcy ..................... 31

3.4 Present work - results and discussion........................................................ 34

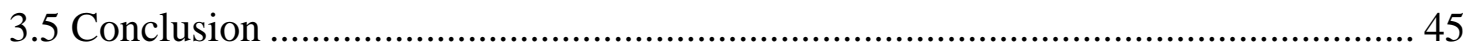

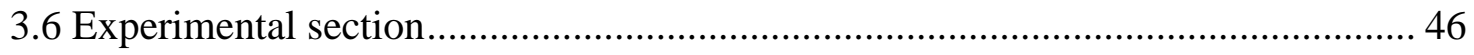

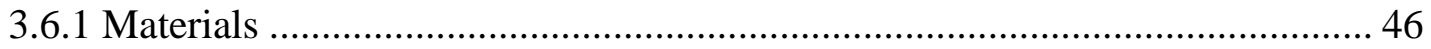

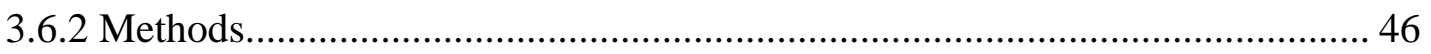

3.6.3 Spectrophotometric measurement...................................................... 47

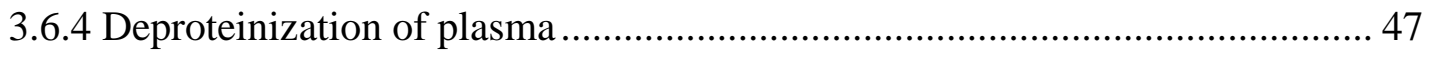

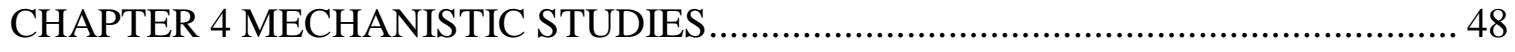

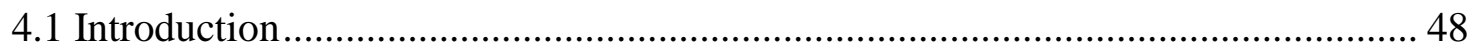

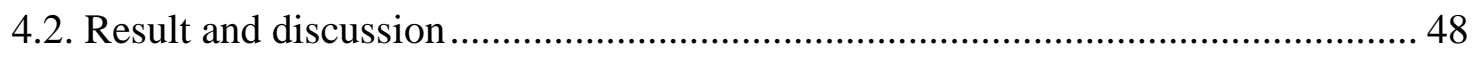

4.2.1 Synthesis of Cys- and Hcy-derived analogs 4.1, 4.3, 4.5, 4.2, 4.4 and 4.6..... 49

4.2.1 Estimated $\mathrm{p} K_{\mathrm{a}}$ values of Cys- and Hcy-derived analogs 4.1, 4.3, 4.5, 4.2, 4.4

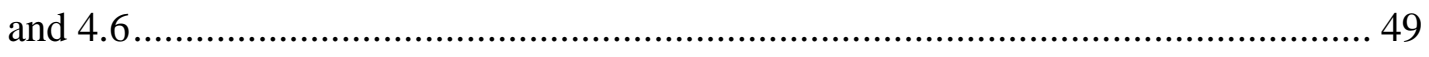

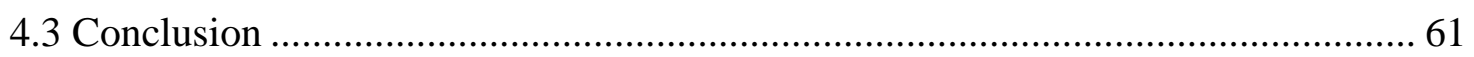




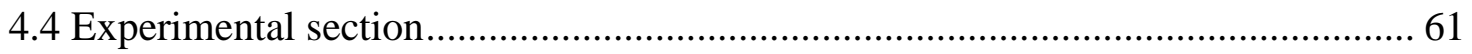

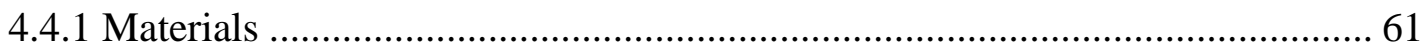

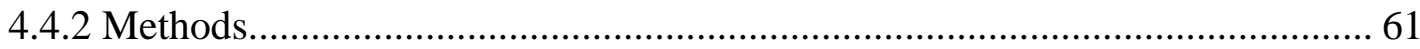

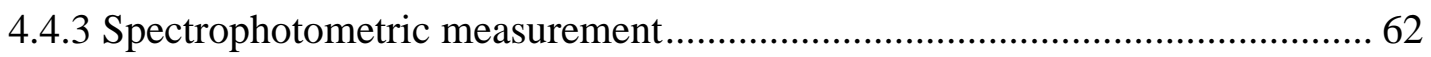

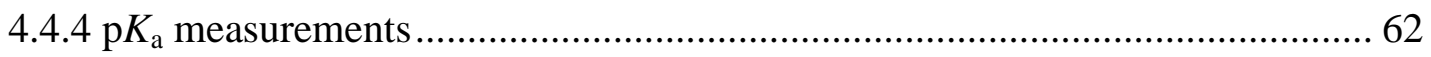

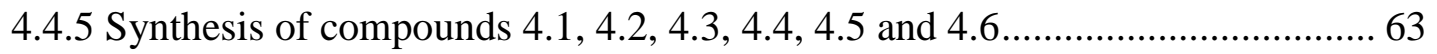

CHAPTER 5 SYNTHESIS OF FLUORESCEIN TRI ALDEHDYE AND ITS

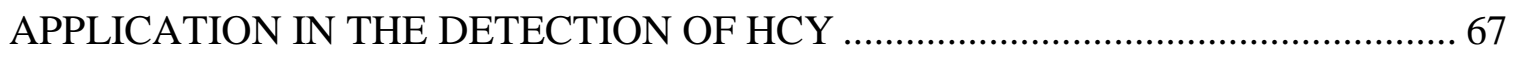

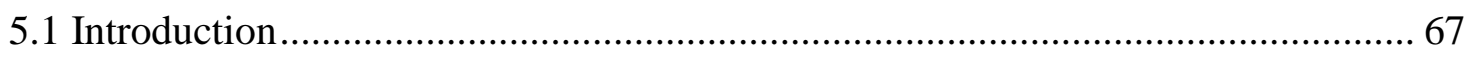

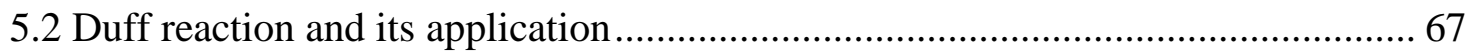

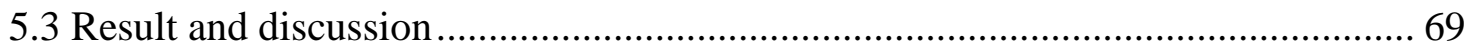

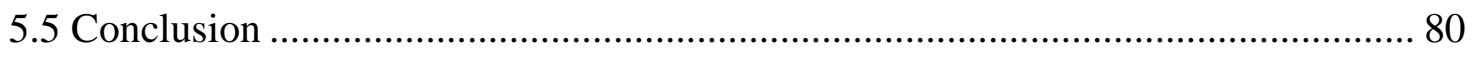

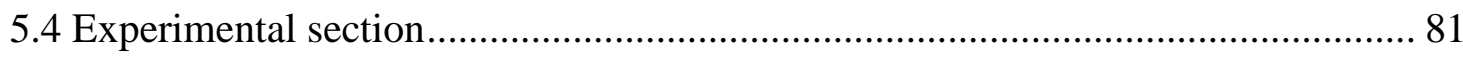

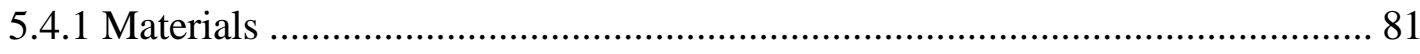

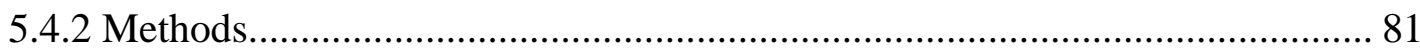

5.4.3 Spectrophotometric measurement ................................................... 82

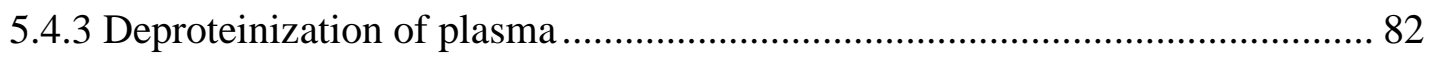

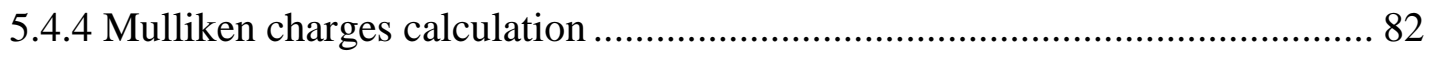

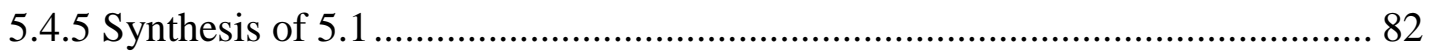


APPENDIX A : CHARACTERIZATION OF COMPOUNDS 4.1 AND 4.2 …............ 95

APPENDIX B : CHARACTERIZATION OF COMPOUND 4.3 AND 4.4 .................. 98

APPENDIX C : CHARACTERIZATION OF COMPOUND 4.5 AND 4.6................. 101

APPENDIX D : CHARACTERIZATION OF COMPOUNDS 5.1 ............................ 104

APPENDIX E : COLORIMETRIC RESPONSE OF THIOLS TOWARDS 5.1 .......... 106

APPENDIX F : ENERY MINIMIZED SIMULATED 3D STRUCTURE OF 5.1, 5.1A

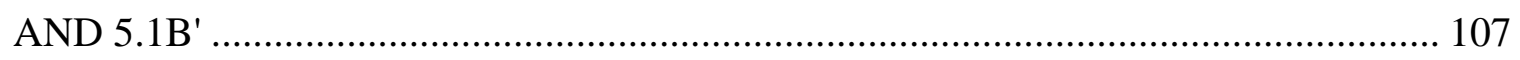




\section{LIST OF TABLES}

Table 4.1. Estimated $\mathrm{p} K_{\mathrm{a}}$ values of the protonated amine moiety of 2-substituted thiazolidine/thiazinane-4-carboxylic acids. 51

Table 5.1 Comparison Mulliken charges on the ' $\mathrm{N}$ ' and ' $\mathrm{S}$ ' of Cys and Hcy derived heterocycles formed upon reaction with 5.1

Table 5.2 Comparison Mulliken charges on the phenolate ' $\mathrm{O}$ ' and ether ' $\mathrm{O}$ ' of 5.1 and Cys and Hcy derived heterocycles formed upon reaction with 5.1 80 


\section{LIST OF FIGURES}

Figure 1-1. Structures of selected biological thiols ..................................................... 1

Figure 1-2. Homocysteine-methionine metabolism............................................. 5

Figure 1-3. Redox and methylation reaction mechanism of methionine synthase: ........... 7

Figure 2-1. Structure of desyl derivative probe DN-2 …....................................... 24

Figure 2-2. Structure of phosphorescence sensor for Hcy based on iridium (III) complex, $\operatorname{Ir}(\mathrm{pba})_{2}(\mathrm{acac})(\mathrm{Hpba}=4-(2-\mathrm{pyridyl})-$ benzaldehyde; $\mathrm{acac}=$ acetylacetone $) \ldots \ldots \ldots \ldots \ldots \ldots . . . . . .25$

Figure 2-3. Structures of P-Hcy-1 and P-Hcy-2. ................................................. 25

Figure 2-4. Structure of aldehyde bearing bodipy based sensor for Hcy detection ......... 26

Figure 3-1. General reaction scheme for reaction of carbonyl with Cys and Hcy........... 27

Figure 3-2. Mechanism of signal transduction in generic aldehyde-bearing aminothiol

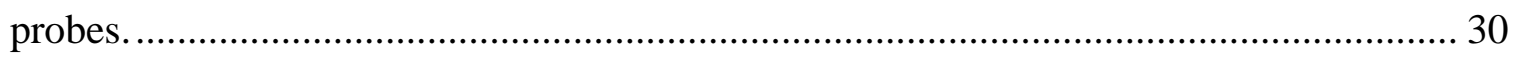

Figure 3-3. Change in the absorbance spectra of 3.3 upon addition of $\mathrm{Cys}$ in buffer, $\mathrm{pH}$

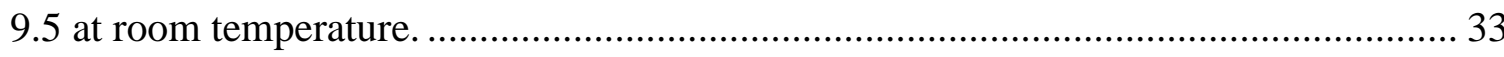

Figure 3-4. Quenching of the fluorescence emission of 3.3 upon addition of Cys, excited

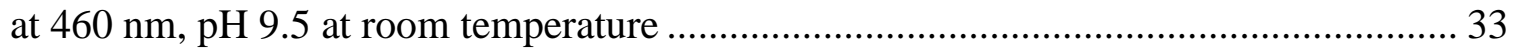

Figure 3-5. Quenching of the fluorescence emission of 3.3 upon addition of Hcy, excited

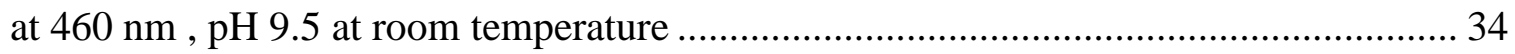

Figure 3-6. Optical sensing behavior of 3.1 towards Hcy and Cys at $\mathrm{pH} 9.5 \ldots \ldots \ldots \ldots \ldots . . . . . . .36$

Figure 3-7. Optical sensing behavior of 3.1 towards Hcy and Cys at $\mathrm{pH} 5.5 \ldots \ldots \ldots \ldots \ldots . . . . . . .36$

Figure 3-8. Optical sensing behavior of 3.1 towards Hcy and Cys at $\mathrm{pH}$ 6.0................. 37

Figure 3-9. Optical sensing behavior of 3.1 towards Hcy and Cys at $\mathrm{pH} 9.5 \ldots \ldots \ldots \ldots \ldots . . . . . . . . . .38$ 
Figure 3-10. Optical sensing behavior of 3.1 towards Hcy and Cys at $\mathrm{pH} 5.5$ 39

Figure 3-11. Optical sensing behavior of 3.1 towards Hcy and Cys at $\mathrm{pH} 6.0$........ 39

Figure 3-12. Optical sensing behavior of 3.1 towards Cys and Hcy as compared to other biologically relevant species 40

Figure $3-13 . \mathrm{H}^{1} \mathrm{NMR}$ of $3.1,3.1$ in the presence of Hcy (3 equiv) and 3.1 in presence of Cys (3 equiv) at $\mathrm{pH} 6.0$. 41

Figure 3-14. $\mathrm{H}^{1}$ NMR of 3.1 and 3.1 in the presence of Gly (3 equiv) at $\mathrm{pH} 6 \ldots \ldots \ldots \ldots . . . . .42$

Figure 3-15. Optical sensing behavior of 3.3 towards Hcy and Cys at $\mathrm{pH} 6.0 \ldots \ldots \ldots \ldots \ldots . . . . . .43$

Figure 3-16. Optical sensing behavior of 3.3 towards Hcy and Cys at $\mathrm{pH}$ 6.0............... 43

Figure 3-17. Optical sensing behavior of 3.3 towards Cys and Hcy at their biological concentrations at $\mathrm{pH} 6.0$. 44

Figure 3-18. Spectral response of 3.3 towards increasing levels of Hcy in phosphate buffer (100 mM, pH 6.0) 44

Figure 3-19. Optical sensing behavior of 3.3 towards Cys and Hcy in deproteinized bovine plasma at $\mathrm{pH} 6.0$ 45

Figure 4-1. Average of triplicates of (a) $\mathrm{pH}$ titration curve and (b) derivatives of 4.1 and 4.2. 52

Figure 4-2. Average of triplicates of (a) $\mathrm{pH}$ titration curve and (b) derivatives of 4.3 and 4.4 53

Figure 4-3. Average of triplicates of (a) $\mathrm{pH}$ titration curve and (b) derivatives of 4.5 and 4.6. 54

Figure 4-4. ${ }^{1} \mathrm{H} \quad \mathrm{NMR}$ of salicylaldehyde-Cys derived thiazolidines 4.1 and ix 
salicylaldehyde-Hcy derived thiazinanes 4.2 in $\mathrm{D}_{2} \mathrm{O}: \mathrm{H}_{2} \mathrm{O}$

Figure 4-5. Time dependent fluorescence spectral changes and enhancement factor (inset) of fluorescence of 3.1 with Cys and Hcy,(a) pH 5.5, (b) pH 6.0, (c) pH 6.5, (d) pH 7.0, (e) $\mathrm{pH}$ 7.4. (f) comparison of fluorescence response of 3.1 towards Cys and Hcy at different $\mathrm{pH}$

Figure 5-1. Optical sensing behavior of 5.1 towards Hcy and Cys at $\mathrm{pH}$ 6.0................. 71 Figure 5-2. Comparison of magnitude of response of Hcy towards (a) 5.1, (b) 3.3, (c) 3.1. 72

Figure 5-3. Optical sensing behavior of 5.1 towards Cys and Hcy at their biological concentrations at $\mathrm{pH} 6.0$. 73

Figure 5-4. Optical sensing behavior of 5.1 towards Hcy and Cys with and without

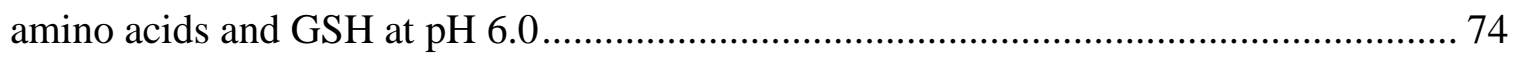

Figure 5-5. (a) and (b)- Spectral response of 5.1 towards increasing levels of Hcy in phosphate buffer (100 mM, pH 6.0 at $2 \mathrm{~h})$. 75

Figure 5-6. Optical sensing behavior of 5.1 towards Cys and Hcy in deproteinized plasma at $\mathrm{pH}$ 6.0.after $2 \mathrm{~h}$. 76

Figure 5-7. Optical sensing behavior of 5.1 towards Cys and Hcy in deproteinized plasma at $\mathrm{pH}$ 6.0.after $2 \mathrm{~h}$. 77

Figure 5-8. Optical sensing behavior of 5.1 towards Cys and Hcy in buffer at different $\mathrm{pH}$, after $2 \mathrm{~h}$. 78 Figure 5-9. Predominant species of compounds 5.1, 5.1a and 5.1b at $\mathrm{pH}$ 6.0. Calculated Mulliken charges are shown for the oxygen atoms in the fused ring system. 80 


\section{LIST OF ABBREVIATIONS}

$\begin{array}{ll}\text { Hcy } & \text { Homocysteine } \\ \text { Cys } & \text { Cysteine } \\ \text { GSH } & \text { Glutathione } \\ \text { Met } & \text { Methionine } \\ \text { SAHH } & \text { S-adenosylhomocysteine hydrolase } \\ \text { SHA } & \text { S-adenosyl-Hcy } \\ \text { MAT } & \text { Methionine adenosyltransferase } \\ \text { MTHFR } & \text { Methylenetetrahydrofolate reductase } \\ & \end{array}$

S-AdoMet S-adenosylmethione

BMT Betaine methyl transferase

S-AdoHcy S-adenosylhomocysteine

SAC S-adenosyl-cysteine

CVD Cardiovascular diseases

$\begin{array}{ll}\text { AD } & \text { Alzheimer's disease } \\ \text { NTD } & \text { Neural tube defects }\end{array}$




$\begin{array}{ll}\text { TG } & \text { Thyroglobulin } \\ \text { SAC } & \text { S-adenosyl-cysteine } \\ \text { LDA } & \text { Lactate degydrogenase } \\ \text { MSN } & \text { Mesoporus silica nanoparticle } \\ \text { PEI } & \text { Polyethyleneimine } \\ \text { RSL } & \text { Resonance light scattering technique } \\ \text { MWCNT } & \text { Multiwalled carbon nanotubes } \\ \text { CPE } & \text { Carbon paste electrode } \\ \text { HBA } & \text { Homocysteine biosensor array } \\ \text { PET } & \text { Photoinduced electron transfer } \\ \text { ICT } & \text { Intramolecular charge transfer } \\ \text { AAOx } & \text { D-amino acid oxidase } \\ \text { SAH } & \text { S-adenosylhomocysteine }\end{array}$




\section{CHAPTER 1 INTRODUCTION}

The low molecular weight thiols homocysteine (Hcy), cysteine (Cys) and glutathione (GSH) play a crucial role in metabolism and homeostasis. They are vital cell components that serve as antioxidants to maintain the redox balance in the human body. Aberrant levels in their concentrations results in metabolic disturbances that are linked to several diseases [1].

\subsection{Hcy, Cys and GSH: structural features and functions.}

Hcy is a sulfur containing non-essential amino acid. It is a metabolic intermediate derived from the essential sulfur containing amino acid methionine (Met). Hcy shares structure resemblance with another low molecular weight thiol, Cys, with the exception that it contains one more methylene group in its side chain, as shown in Figure 1-1. Thiol-like properties of Hcy are common to GSH and Cys.

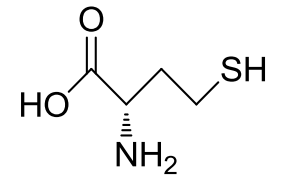

Homocysteine (Hcy)

1.1<smiles>CSCC[C@H](N)C(=O)O</smiles>

Methionine (Met)

1.2<smiles>N[C@@H](CS)C(=O)O</smiles>

Cysteine (Cys)

1.3

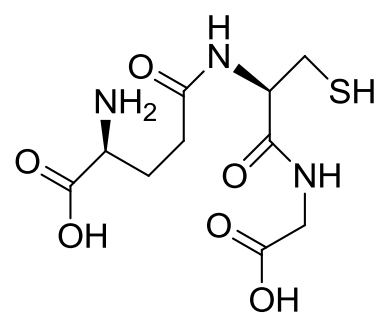

Glutathione (GSH)

1.4

Figure 1-1. Structures of selected biological thiols

Hcy is present in various forms in human plasma. Total Hcy is the sum of all different species of Hcy i.e. protein bound, oxidized and reduced or free forms and it is 
referred as tHcy [2]. The major form is disuflude bound to proteins, mainly albumin. The protein bound form of Hcy constitutes 70-80 \% of total Hcy. Other oxidized forms such as Hcy-Hcy (Hcy disulfide) accounts for 5-10\%, Hcy-Cys disulfide accounts for 5$10 \%$ of the tHcy, and reduced Hcy sulfhydril accounts for less than $1 \%$ in human plasma. In general, the levels of tHcy in a healthy humans is approximately $5-15 \mu \mathrm{M}$, and increases with ageing. The condition in which the level of Hcy in human plasma rises above $15 \mu \mathrm{M}$ is called 'hyperhomocysteinemia'. There are three stages of hyperhomocysteinemia; mild, in which the Hcy level is $15-30 \mu \mathrm{M}$; moderate, in which the level is $30-100 \mu \mathrm{M}$ and for the level above $>100 \mu \mathrm{M}$ of Hcy, it is termed as severe hyperhomocysteinemia [3].

Cys is the lowest molecular weight biological thiol. Among the three major biological thiols, cysteine is the most abundant extracellular thiol. It varies from 150-300 $\mu \mathrm{M}[4,5]$. Cys is produced during Hcy metabolism. Therefore, Hcy and Cys levels are highly related to each other. Cys plays an essential role in protein synthesis, redox chemistry and peptide cross-linking, detoxification and other metabolic processes [6, 7].

GSH is a tripeptide wherein glycine and Cys are linked by normal peptide linkage and amine group of Cys is attached to the carbonyl group of glutamate side chain via gamma peptide linkage. Thus, GSH is indirectly linked to homocysteine metabolism. It is known for its antioxidant properties. It is also involved in gene expression, cell proliferation and apoptosis [8]. GSH concentrations are very high in cells. They range from 1 to $5 \mathrm{mM}$, whereas its concentration in plasma is 1 to $6 \mu \mathrm{M}[5,8]$. 


\subsection{Metabolism of Hcy}

The metabolism of Hcy is intricately linked to the metabolic pathway of methionine, one of the essential amino acids [9]. Hcy is thus a vital part of cellular homeostasis in human body. Methionine is essential for protein synthesis; it acts as a methyl donor for the synthesis of a wide range of vital methylated compounds such as DNA, RNA etc. [10]. Hcy is the key intermediate of the transsulfuration pathway to produce several other sulfur-bearing amino acids such as, cystathionine, Cys, taurine, GSH, etc. [11]. Hcy is the foremost source of sulfur for inorganic sulfate. It also is linked to polyamine biosynthesis. Furthermore, Hcy plays a crucial part in folate metabolism, as well as in the catabolism of choline and betaine [10].

Hcy metabolism is shown in Figure 1-2. Hcy levels depend on the proper functioning of the enzymes involved in its metabolism. These include enzymes involved in the remethylation reaction pathway to form methionine (Met), such as betaine methyltransferase (BMT), S-adenosylhomocysteine hydrolase (SAHH), methionine synthase (MS), methionine adenosyltransferase (MAT) and $S$-adenosylmethione $(S$ AdoMet)-dependent methyl transferases e.g., glycine methyltransferase. Methionine synthase depends on methionine synthase reductase, vitamin B12 and 5methyltetrahydrofolate obtained from methylenetetrahydrofolate reductase (MTHFR). A second pathway in Hcy metabolism is transsulphuration to produce cystathione, Cys and inorganic sulphates. This latter pathway mainly involves the enzyme cystathionine $\beta$ synthase (CBS) [12]. 
In the remethylation step, Hcy is converted to Met by a complex 5methyltetrahydrofolate- dependent reaction [13]. 5-methyl tertrahydrofolate is produced by 5,10-methylenetetrahydrofolate in the presence of MTHFR. The remethylation reaction is catalyzed by MS. This enzyme gets reductively methylated by methionine synthase reductase. The synthesis of methionine synthase reductase requires cobalamine (vitamin B12) and S-AdoMet. Additionally, Hcy can be remethylated to Met in a process promoted by betaine via betaine methyl transferase (BMT). Remethylating enzyme BMT is only found in liver, kidney and brain. MS, however, it has a wide tissue distribution [14].

Met is transformed to its active form $S$-AdoMet. This reaction is catalyzed by methionine adenosyl transferase (MAT) [13]. S-AdoMet acts as a methyl donor for the production of a large number methylated biomolecules such as methylated DNA, RNA, lipids and proteins [14]. To date, $39 \mathrm{~S}$-AdoMet dependent methyl transferases have been discovered in mammals [1]. After donating a methyl group, $S$-AdoMet becomes $S$ adenosylhomocysteine ( $S$-AdoHcy). To complete the Hcy metabolism cycle, $S$-AdoHcy undergoes hydrolysis to produce Hcy and adenosine. The enzyme Ado-Hcy hydrolase catalyzes this hydrolysis [14]. S-AdoMet also undergoes decarboxylation to provide a propyl amine moiety for the synthesis of spermine and spermidine[13]. However, this reaction consumes less than $10 \%$ of the total $S$-AdoMet[15]. (Figure 1-3) 


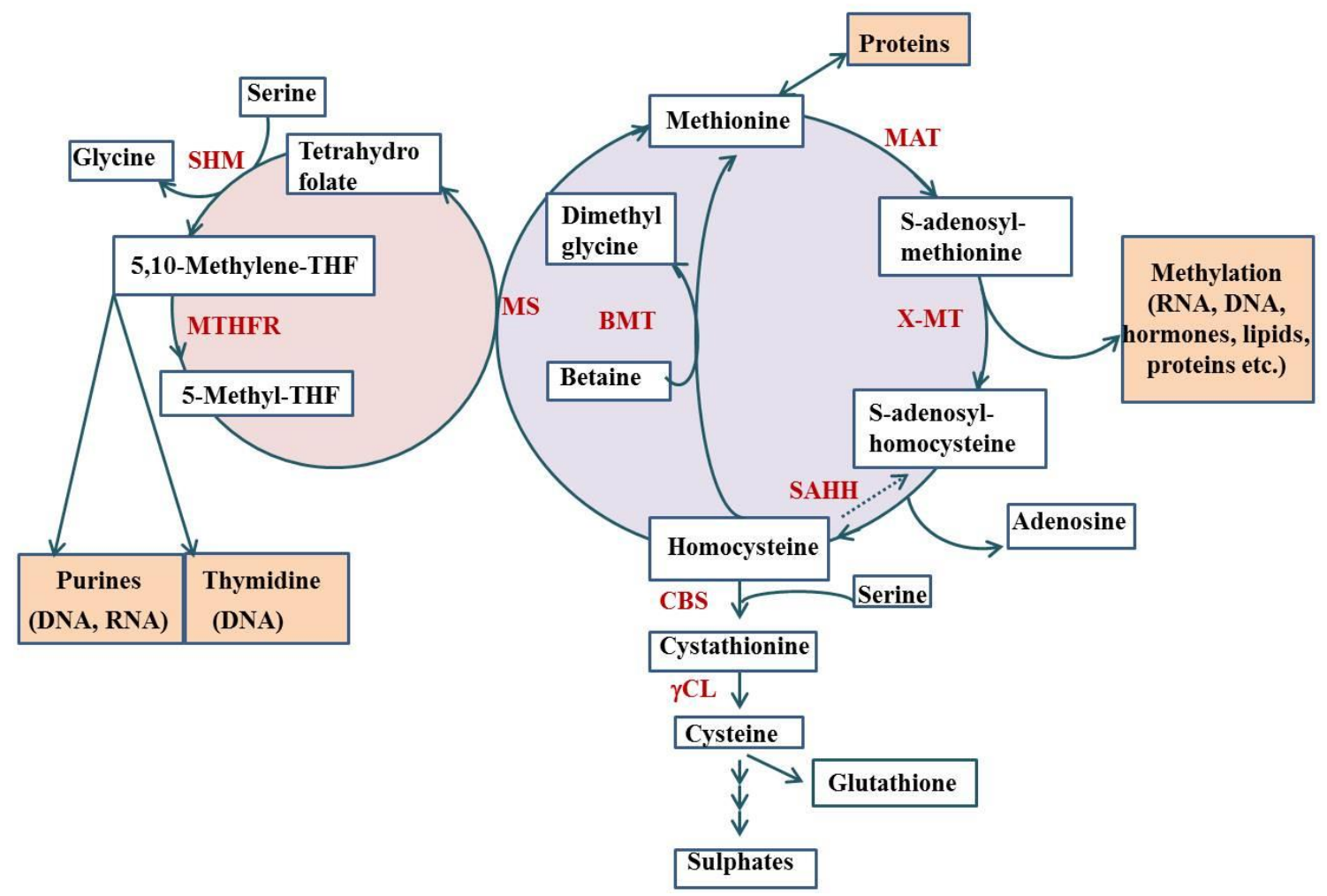

Figure 1-2. Homocysteine-methionine metabolism.

Enzymes involved in in Hcy metabolism : MAT-methionine adenosyltransferase, X-MT-various $S$-AdoMet dependent methyltransferases, SAHH-S-adenosylhomocysteine hydrolase, MS-methionine synthase, BMT-betaine methyltransferase, MTHFR methylenetetrahydrofolate reductase, CBS cystathioni ne $\beta$-synthase, $\gamma \mathrm{CL}, \gamma$-cystathionase, SHM serine hydroxymethylase. This figure was adopted from [14] and redrawn with some modifications.

In the alternate Hcy transsulfuration [11] pathway, the first step involves condensation of Hcy with serine to produce cystathionine. This condensation takes place in the presence of cystathionine $\beta$-synthase (CBS). Pyridoxal 5'phosphate (vitamin $\mathrm{B}_{6}$ ) is a cofactor for CBS. In the second step, cystathionine converts to Cys and a by-product $\alpha$ oxo butyrate. The enzyme $\beta$ - cystathionase catalyzes this step and, like CBS, requires pyridoxal 5'phosphate [14]. Cys is essential for the synthesis of the antioxidant glutathione. By a variety of enzymatic reactions and oxidation, cysteine produces 
inorganic sulfates [16].

1.2.1 Summary of enzymes involved in the regulation of Met and Hcy

(1). ATP: L-Methionine $S$-Adenosyltransferase: This enzyme facilitates the formation of vitally important $S$-AdoMet by catalyzing the transfer of adenosyl moiety from ATP to Met [14]. This reaction takes place in the presence of $\mathrm{Mg}^{2+}$ and $\mathrm{K}^{+}$[17]. Two of the forms of $S$-AdoMet are specific to liver i.e. a tetramer MAT(I), which is an $\alpha$ form and a dimer MAT(III), which is a $\beta$ form. The gene MATIA encodes both forms in the liver. This gene is capable of reacting with high Met immediately.

(2). S-AdoMet-dependent methyltransferases (glycine N-methyltransferase GNMT): GNMT is one of the $S$-AdoMet-dependent methyltransferases that converts glycine to sarcosine by the transfer of a methyl group from $S$-AdoMet [14]. By donating a methyl group, $S$-AdoMet transforms to $S$-AdoHcy. $S$-AdoHcy is an inhibitor of the enzyme MS. Any disturbance in the ratio of $S$-AdoMet to $S$-AdoHcy affects the activity of MS [14].

(3). S-AdoHcy Hydrolase: This enzyme has a binding site for adenosine. Therefore, it facilitates $S$-AdoHcy hydrolysis to form Hcy and release adenosine [9].

(4). Methionine Synthase (5-Methyltetrahydrofolate: Homocysteine Methyltransferase ): This enzyme catalyzes the remethylation reaction to form Met [9]. MS assists the transfer of the methyl group from 5-methyl THF to Hcy to form Met. MS maintains the folate and Met cycle to endow enough Met for $S$-AdoMet-dependent transmethylation reactions [14]. This enzyme encompasses zinc and four domains to bind Hcy, S-AdoMet, cobalmine cofactor and methylene tetrahydrofolate [18]. 
(5). Methionine Synthase Reductase (Methionine Synthase Cob(II)alamine Reductase): MS would be inactive if the cobalamine factor exists as cob(II)alamine [14]. To activate methionine synthase, $\operatorname{cob}(\mathrm{II})$ amine needs to be reduced to $\operatorname{cob}(\mathrm{I})$ alamine. Reduction requires conversion of $S$-AdoMet to $S$-AdoHcy. This overall process is expedited by the enzyme methionine synthase reductase [14]. A complete reaction mechanism is described in Figure1-4.

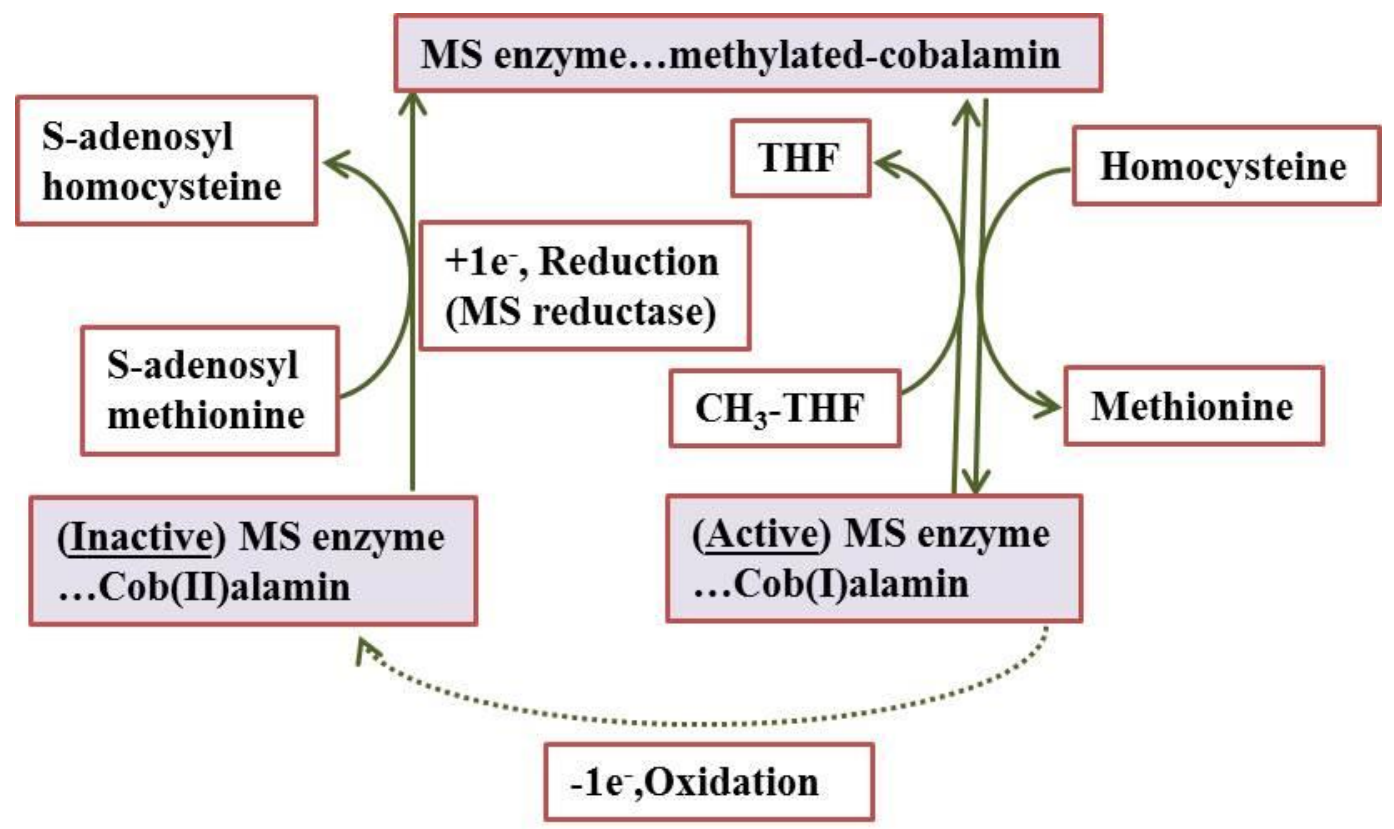

Figure 1-3. Redox and methylation reaction mechanism of methionine synthase: methionine synthase (MS) reductase; and tetrahydrofolate (THF). This figure was adopted form [14] and redrawn with some modifications.

(6). Betaine Homocysteine Methyltransferase (BMT): This enzyme also transforms Hcy to Met [14]. Betaine acts as a methyl donor in the process [13]. Betaine is the product of the catabolism of choline [13]. Betaine methyltransferase is mainly present in the liver and the kidney. 
(7) 5,10 Methylenetetrahydrofolate Reductase (MTHFR): 5-methyltetrahydrofolate is synthesized from 5,10-methylenetetrahydrofolate with the help of MTHFR [9]. This NADPH-associated reduction process provides a methyl group for vital compounds such as DNA and RNA and controls the folate coenzyme entry in the remethylation pathway for Hcy metabolism [14].

(8). Cystathionine $\beta$-synthase (CBS): L-cystathionine, the precursor for the synthesis of Cys, is produced by the condensation of Hcy and serine [14]. This condensation is expedited by CBS which is a cytosolic pyridoxal 5' phosphate-requiring enzyme. This enzyme mainly occurs in human liver [14].

\subsection{Hcy and human health}

As described in the previous section, Hcy is the key intermediate in the Met and Cys synthesis. Any alternation in these two metabolic pathways i.e. remethylation and transsulfuration, may result in abnormal levels of Hcy. Elevated levels of Hcy are directly linked to a number of pathologies mainly cardiovascular diseases [19], Alzheimer's [20], birth defects and pregnancy complications [21], osteoporosis[22], renal failure [23], cancer [24], inflammatory bowel disease [25], and cancer[24]. Normal Hcy levels can be disturbed by several factors such as a deficiency of enzymes involved in Hcy metabolism (for example cystathionine $\beta$-synthase (CBS), MTHFR, MS)[11], inadequacy of vitamin $\mathrm{B}_{6}, \mathrm{~B}_{12}$ and/or folic acid [2], overburdening of dietary methionine and buildup of excessive reactive oxygen species (ROS) [3]. Other factors that affect Hcy homeostasis include heavy smoking, caffeine and alcohol consumption, specific drugs, renal dysfunction, life style, age and gender [26]. A deficiency of folate or defects in MTHFR 
alter the formation of 5-methyltetrahydrofolate that results in lower concentrations of $S$ AdoMet and overloading of Hcy for the transsulfuration pathway. Furthermore, insufficient levels of $S$-AdoMet also suppress the transsulfuaration pathway, and this overall process leads to the accumulation of excessive Hcy in the cells, followed by its transfer to the blood stream producing hyperhomocysteinemia [11]. It is also caused by defects in CBS, responsible for transsulfuration pathway, which forces Hcy to proceed via remethylation to produce excess $S$-AdoMet. This eventually leads to feedback inhibition of MTHFR impeding the remethylation process. This causes severe hyperhomocysteinemia wherein the entire Hcy metabolism is impaired [11]. A number of diseases associated with hyperhomocysteinemia are listed below.

\section{Cardiovascular diseases (CVD)}

Hcy has been established as an independent risk factor for cardiovascular diseases. A number of published studies indicate the direct link between CVD and elevated levels of Hcy [27-30]. According to an early study by WHO, CVD mortality rate and Hcy levels are closely related to each other.

In 1969, McCully published a report about two patients, 2 months and 8 years old, with homocystinuria. Homocystinuria is a form of very severe hyperhomocysteinimia wherein homocysteine overload leads to its excretion in urine. McCully's young patients suffered from premature atherosclerosis due to a deficiency of CBS [31]. Since that time, a wide variety of studies have been published suggesting modestly higher level of Hcy are a risk factor for atherosclerosis [32]. An association 
between plasma Hcy and mortality rate was published by Refsum et al. Their study revealed that the mortality rate was $24.7 \%$ in CVDs patient with plasma Hcy $>15 \mu \mathrm{M}$ [19]. Recently, Tentolouris et al. indicated that acute Met-induced hperhomocysteinemia affects myocardial performance and impairs aortic distensibility [27].

The occurrence of hyperhomocysteinemia is assessed to be $5 \%$ in the general population and $13 \%$ to $47 \%$ among patients suffering from symptomatic atherosclerotic vascular disease [26]. A meta-analysis of cross-sectional epidemiologic studies revealed that a $60 \%$ higher occurrence of ischemic heart disease was noticed with increase in each $5 \mu \mathrm{M}$ concentration level of plasma Hcy [33]. Cross-sectional studies and prospective studies both confirm that the incidence of myocardial infarction was increased by 3.4 fold when the concentration of Hcy was more than $16 \mu \mathrm{M}$. The mortality rates of CVD patients was 4.5 fold higher at a Hcy concentration higher than $20 \mu \mathrm{M}$ [34].

A multivariate analysis conducted by Boutouyrie et al. indicated that out of Hcy, Cys and GSH, only Hcy was directly linked with carotid artery remodeling, suggesting that Hcy is the only plasma thiols that acts as an independent risk factor for CVD [35]. Meta-analysis studies presented a correlation of plasma Hcy concentration with ischaemic heart disease, deep vein thrombosis, pulmonary embolism and stroke [32]. Both genetic and prospective studies revealed lowering Hcy concentration by $3 \mu \mathrm{M}$ reduced the risk of ischaemic heart diseases by $16 \%$, deep vein thrombosis by $25 \%$ and stroke by $24 \%$ [32]. Also, a prospective study conducted on women with a risk of myocardial infarction found that fasting Hcy levels are positively related with myocardial infarction risk in women [36]. 


\section{Alzheimer's disease (AD)}

Hyperhomocysteinemia has been also considered to be an independent risk factor for cognitive impairment, dementia and Alzheimer's disease (AD) [20]. According to the National Health and Nutrition Examination Survey (NHANES III), hyperhomocysteinem ia is directly linked to weak memory in elderly people. A survey was conducted on participants over 60 years of age. Participants with greater Hcy levels and lower folate levels received a lower score on short delayed recall tests [37].

AD has been associated with an increased level of Hcy, along with a deficiency of vitamin $\mathrm{B}_{6}, \mathrm{~B}_{12}$ and folic acid [38]. Elevated levels of Hcy and $S$-AdoHcy deter the remethylation processes of Met and $S$-AdoMet. This affects the methylation of various vital components such as DNA and protein, eventually damaging the vascular structure, neurotoxicity and causing apoptosis.

According to Lehman et al. unusual high levels of Hcy were found in patients suffering from AD as compared to a control group [39]. Ueland et al. published a study that presented considerably higher levels of Hcy along with a deficiency of folate and vitamin $\mathrm{B} 12$ in the $\mathrm{AD}$ patients. It also revealed that slight increases in Hcy levels have a strong effect on the risk of $\mathrm{AD}$, and are 4.5 times greater in patients with Hcy levels $\geq 14 \mu \mathrm{M}$ compared to patients with $\leq 11 \mu \mathrm{M}$ [40]. Another case study conducted at the interval of 8 years on 1092 elderly patient stated that risk of AD was increased by $40 \%$ with $5 \mu \mathrm{M}$ increases in Hcy concentrations, whereas risk was doubled at Hcy concentrations $\geq 14 \mu \mathrm{M}[20]$. 


\section{Neural tube defects (NTD)}

It is well known that the intake of folic acid during pregnancy can reduce the risk of neural tube birth defects. Levels of folate and vitamin $\mathrm{B}_{12}$ were found to be lower in the women carrying fetuses with NTD than the women with normal fetuses [41]. However, despite folate and vitamin B12 supplements, the risk of NTD remains elevated indicating that other metabolic factors are also responsible for this defect [42]. A case study reported by Scott et al. showed abnormal levels of Hcy present in the women with NTD fetuses. According to the authors, the abnormal levels were related to the defects in the enzyme methionine synthase [43]. This enzyme is necessary for methylation reaction such as DNA and myelin a basic protein, which may be a possible mechanism for NTD. Another factor responsible for NTD is the C677T and A1298C mutations in the (MTHFR) gene [44]. This can be regulated by folate supplement. However MTHFR polymorphism is a moderate risk factor for NDT in comparison to the methionine synthase.

\section{Osteoporosis}

In a 2005 review Herrmann et al. described a direct link between osteoporosis and Hcy levels. They explained that Hcy is not merely a risk indicator, it is also involved in bone metabolism [22]. A study conducted by Mudd et al. shows that 'bone mineral density' (BMD) was found to be lower in patients suffering from homocystinuria. Moreover, a risk of osteoporosis was found to be $50 \%$ by the age of 16 [45]. Studies conducted on large populations revealed that increases in Hcy levels elevate the risk of fragile bone 
fractures [46, 47] Abnormal skeletal growth, skeletal deformities, an elongated appendicular skeleton and flattening of the vertebral bodies have been observed in homcystinuric patients [48-50]. According to a double-blind placebo-controlled intervention trial conducted by Sato et al. "Hcy lowering therapy treatment $(5 \mathrm{mg}$ of folate and $1500 \mu \mathrm{g}$ of vitamin B12) was found to be effective in reducing the hip fracture rate in hemiplegic stroke patients [51]. The role of Hcy in osteoporosis is not clearly understood. It is believed that Hcy can affect bone metabolism in different ways; for instance, it can inhibit osteoblast formation and accelerate the osteoclast formation thereby affecting bone resorption. It can also lead to decreased bone blood flow. It inhibits collagen cross-linking, thereby reducing bone extracellular matrix (ECM) quality $[22]$.

In addition to the aforementioned disorders, Hcy has been linked to inflammatory bowel disease [25], diabetes [52] and cancer [24].

\subsubsection{Hcy: A biomarker or a risk factor!}

Several clinical studies have successfully demonstrated a strong link between Hcy with CVD [19]. However, it has been a subject of debate from decades, whether Hcy is merely a biomarker or in fact a risk factor [53]. A proper mechanism for the role of Hcy in CVD has not been clearly understood. The efficiency of folic acid supplementation in stroke prevention was examined by a meta-analysis study [54]. The results indicated that folic acid supplementation may effectively reduce the risk of stroke for the patient [54]. A randomize controlled trial was conducted by Hess et al. on 553 patients to study the effect of Hcy lowering therapy by a combined supplement of folic acid, vitamin B6 and 
B12. The results revealed that after percutaneous coronary intervention, the frequency of major adverse events was substantially reduced [55]. Improvement in the stroke mortality was also reported in a government study after folic acid fortification in United States and Canada [56].

Nevertheless, another meta-analysis of randomized and controlled trial conducted by Saver $e t$ al. showed that folic acid and vitamin B12 combined together provided a very mild benefit to prevent primary stroke in male patient [57]. Similarly, McQueen et al. investigated the efficacy of Hcy-lowering therapy on stroke risk, severity and disability. Their 5 year study on 5522 adults with CVD demonstrated that a combined supplement of folate and vitamin B decreased the frequency of overall stroke but stroke severity and disability remained unaffected [58]. On the other hand, supplementation of vitamin B12 along with folate as Hcy-lowering therapy for secondary prevention in patients that suffered from acute mycardinal infarction was published by Rasmussen et al. Their investigation revealed Hcy-lowering therapy had no impact on the risk of recurring CVD after myocardial infarction, in fact vitamin B12 had an adverse effect [59]. Similar cases were reported by Ebbing et al. where secondary prevention by folic acid and vitamin B supplementation in patients with coronary artery disease or aortic valve stenosis was found to be ineffective on CVD and total mortality [60]. Possible reasons for the failure of Hcy lowering therapy were explained by Blom et al. These include (1) the duration of these trials and interventions were not long enough to decide whether Hcy lowering therapy is helpful to prevent the risk of CVD. Most of these trials were conducted for less than 5 years. Since atherosclerotic plaque develops 30-40 years from initial growth to 
clinical trials, Hcy lowering therapy may require a much longer period of trial than a relatively few years of study[61]. Reason two is that the majority of interventions understudied patients with greater levels of homocysteinimea (> $20 \mu \mathrm{M})$, as mostly patients with just slightly higher levels of Hcy were included in the trials. Reason 3 is that the adverse effects of folate and vitamin B supplements were not taken into consideration in aggravating CVD. Fourth, a better understanding of the role of Hcy in damaging the vascular system is needed so that a proper study and treatment can be designed, apart from folate and Vitamin B supplementation. A fifth reason given is that Hcy lowering therapy was found to be ineffective because patients already had advanced CVD with a vascular system so impaired that folate and vitamin B supplementation was insufficient or too late to control the disease [61].

Regardless of whether Hcy is a biomarker or risk factor, a strong correlation between Hcy and CVD as well as other diseases generates a great demand to determine Hcy levels. Therefore, in this study, a method to detect Hcy has been developed. 
The main objectives of this project are:

1. Development of an optical method and design of a sensor for selective detection of Hcy.

2. To detect Hcy at its physiological levels in addition to the elevated levels.

3. To achieve a selective response of Hcy in presence of other related potentially interfering analytes, especially Cys, as well as in biological media.

This thesis has been divided into five chapters. After an introduction in the first chapter, an overview of the current state of the art of techniques for Hcy detection is described in the second chapter. The third chapter explains the development of a novel optical method for the selective detection of Hcy using aldehyde bearing flurophores as sensors. In the fourth chapter, the mechanism behind the selectivity for Hcy is described. The fifth chapter includes the design and synthesis of a novel aldehyde bearing flurophore to achieve a sensitive and selective fluorescent signal in response to Hcy at biologicallyrelevant concentrations. 


\section{CHAPTER 2 AN OVERVIEW - TECHNIQUES INVOLVED IN HCY DETECTION}

\subsection{Introduction}

As describes in chapter one, elevated levels of Hcy are linked to a number of diseases, especially cardiovascular diseases. The association of Hcy levels with such life threatening diseases has generated a great interest in the scientific world to develop different methodologies for detection of this biomarker[62]. For example, high performance liquid chromatography (HPLC) [63-65], liquid chromatography/mass spectroscopy (LCMS) [66, 67], electrochemical [68-70], enzymatic [71, 72], and immunoassay [73] [72] and optical methods [74-79] have been employed to detect Hcy.

\subsection{Existing methods for the detection of Hcy}

In current diagnostic laboratories, techniques such as HPLC [80], LCMS [81], enzymatic procedures [82-84], and immunoassays [85-87] are more prevalent for detection of Hcy. Their popularity is due to the sensitive and precise measurements of Hcy. However, these techniques also suffer from some disadvantages. For example, HPLC and UHPLC involve an additional derivatization step with a suitable reagent, and also require thorough sample preparation and labor intensive work with expensive instruments $[2,62$, 88-90]. LC/MS involved complicated sample preparation methods and expensive instruments $[67,91]$.

The first immunoassay method was developed by Shipchandler and Moore in 1995 [92]. tHcy is reduced to free Hcy by a suitable reducing agent. Next, Hcy is 
enzymatically transformed to $S$-adenosyl-Hcy (SAH) by the action of $S$-adenosyl-Hcy hydrolase (SAHH). Anti SAH antibodies are used for the immunoassay of SAH via different techniques such as fluorescence polarization immunoassay (FPIA), chemiluminescence immunoassay (ICL), enzyme-linked immunoassay (EIA), the immune precipitation assay (IP) [93], For instance, Zappacosta et al. used anti-S-AdoHcy antibodies bound to polystyrene particles to bind SAH [73]. SAH had to compete for anti-SAH antibodies with thyroglobulin (TG) conjugated $S$-adenosyl-cysteine (SAC). The presence of SAH caused a weaker aggregation of polystyrene particles. In absence of SAH, TG-conjugated SAC induces a complete aggregation of polystyrene particles. The signal is measured by the scattered light which is inversely associated to SAH content [73]. However, the accuracy and adequate specificity of immunoassay techniques have been questioned in the past [94-96]. These methods suffer from the interferences such as effects of anticoagulants, icterus, hemolysis, lipemia, and sample storage [94, 95, 97]. Apart from that, analyte dependent interferences are produced by the interaction of sample component with one or more antibodies such as human anti-animal antibodies, auto-analyte, heterophilic antibodies, rheumatoid factor and other proteins [94, 95]. These interferences may lead to false results.

In enzymatic procedures, cystathionine - $\beta$-synthase (CBS) was used to synthesize cystathionine from Hcy and serine [71]. With the help of $\gamma$-cystathionase lyase, cystathionine was converted to Cys, ammonina and pyruvate. Using lactate degydrogenase (LDA), the reduction of pyruvate was carried out along with the oxidation of NADH to NAD. The oxidation of NADH is measured by the spectroscopic methods 
[71]. Immunoassays and enzymatic procedures also require fragile and relatively expensive biological material such as antibodies and other biomolecules. Therefore, their proper washing, handling and storage is necessary [2, 83]. Regardless of these complications, enzymatic procedures are the more commonly used methods on the clinical level compared to immunoassays, HPLC and LCMS. The requirements of small amounts of reagents, less complicated procedures, sensitivity and high output make enzymatic procedure a method of interest for Hcy detection for regular clinical applications $[71,73,83]$. However, a comparative study of all these techniques for tHcy determination shows imprecision and variations in the results [98].

\subsection{Methods based on electrochemistry and nano materials}

Other techniques for Hcy detection have been reported in the literature that includes, the use of nano particles $[99,100]$ and electrochemical techniques $[69,88,100,101]$ etc. Recently, a silica nanoparticle based sensor was reported by Wu et al. [102]. They developed a mesoporus silica nanoparticle (MSN) based nanostructure as fluorescence sensor for detection of Hcy. They prepared a fluorescence sensor by embedding the anthracene nitroolefin inside the MSNs. In the absence of biothiols, the electron deficient nitroolefin moiety quenches the fluorescence of electron rich anthrancene scaffold via intramolecular charge transfer (ICT). Later, Michael addition of thiols to the nitoolefin moiety prevents ICT, resulting in fluorescence enhancement. Thus the probe acts as a fluorescence sensor for biological thiols. Selectivity for Hcy was achieved with the help of covalently bound polyethylene glycol (PEG 5000) chains on the surface of the MSNs. Based on the polarity and the size of the molecules, these chains serve as a barrier for the 
diffusion of different biological thiols inside the mesoporus nanoparticle. According to them, relative lower content of polar groups and smaller size make Hcy best candidate among all biological thiols, to pass through the barrier fastest and give a fluorescence turn on signal by Michael addition reaction. However size and the polarity of Cys is similar to that of Hcy but no explanation was given why Cys was not able to pass the barrier. The sensor responded well towards Hcy, however equimolar concentrations of other thiols such as Cys and GSH were used in the detection method. Therefore, Cys is expected to cause interference at physiological levels, making the sensor ineffective for specific responses to Hcy in plasma.<smiles>O=[N+]([O-])C/C=C/c1c2ccccc2cc2ccccc12</smiles>

2.1

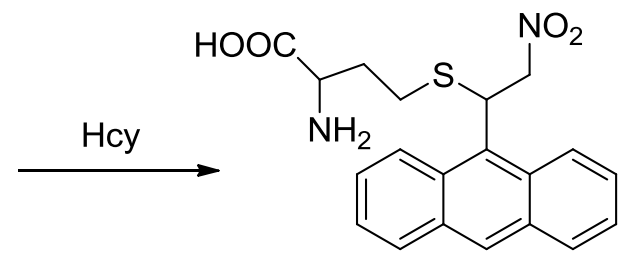

2.2

Scheme 2-1. Michael addition of Hcy on the nitroloefin moiety of 2.1 to prevent ITC that results in the fluorescence of 2.2 .

Yan et al. designed polyethyleneimine capped Ag-nanoclusters for Hcy detection by resonance light scattering technique (RSL) [99]. Hcy served as a bridge between the $\mathrm{Ag}$ core and polyethyleneimine (PEI) chains. This linking was due to the affinity of SH group of Hcy for the Ag core and the ionic interaction of the carboxylate group of Hcy with hyperbranched PEI chains. This resulted in the formation of a Ag-nanocluster assembly. These nanoclusters interacted with one another to produce oscillation coupling, enhancing the RSL signal. This assembly showed selectivity for Hcy over Cys and 
glutathione. However the instability of the Ag-particles makes it difficult to run the Hcy assay in practice [103].

Several electrochemical detection techniques for Hcy detection have also been reported in the literature $[69,88,100,101]$. For example, Campton et al. achieved responses for Hcy by an electrocatalytic reaction and 1,4 Michael addition of Hcy with catechol using a modified carbon nanotube glassy carbon electrode (CNT-GCE) [68, 69]. Though the electrochemical detection of Hcy was carried out in the presence of Cys, GSH and ascorbic acid using carbon electrode, the response for Hcy was not achieved at a physiological level in the presence of other thiols and amino acids as well as in any biological media [68].

Kerman et al. developed another electrochemical method wherein electrodepositi on of gold on carbon nanotubes was employed for the enhanced electrochemical detection of Hcy. They recorded the response of Hcy at very high concentrations (mM level), and no information was given about other interfering thiols, amino acids and biological media [100].

On the other hand, an amperometric Hcy biosensor array (HBA) was developed by Ching et al. for the determination of Hcy. They fabricated amperometric HBA with a D-amino acid oxidase (AAOx) immobilized on a screen printed carbon electrode[104]. Silver-silver chloride $(\mathrm{Ag}-\mathrm{AgCl})$ was used as a reference electrode. Detection sensitivity was found to be the best with 8 working electrodes. Though this method was sensitive, it involved several steps and was found to be time consuming. Moreover, they do not report 
the response of Cys and GHS, capable of undergoing the same oxidation mechanism as Hcy, eventually causing interference with the response of Hcy. (Scheme 2-2)

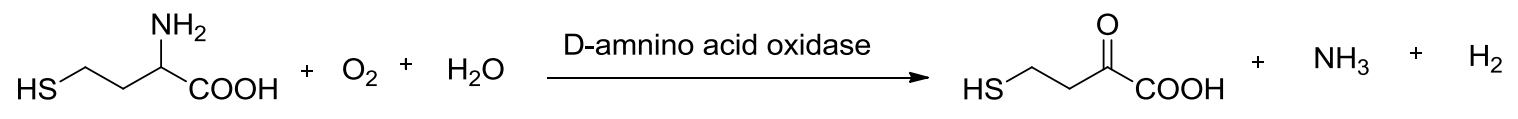

Scheme 2-2. The enzymatic oxidation of homocysteine by D-amino acid oxidase to produce $\mathrm{H}_{2} \mathrm{O}_{2}$

\subsection{Optical methods.}

Optical methods have received a great deal of attention for the detection of biological thiols [74-79]. The popularity of these methods is due to sensitivity, relative ease, and low cost; however, to date there have been relatively few optical methods, especially fluorescence methods, reported that can reliably distinguish Hcy over Cys, GSH and other amino acids [105-110].

\subsubsection{Optical detection based on the redox chemistry of Hcy}

Our group has published a photochemical method for the detection of homocysteine in whole plasma using viologens as redox based indicators [106, 107]. This mechanism, as shown in Scheme 2-3, relies on the reduction of viologens by the $\alpha$-amino carbon centered radical of Hcy generated by intramolecular hydrogen atom transfer (HAT) of its thiyl radical $[106,107]$. Addition of Hcy to a solution of viologen resulted in change in the absorbance spectra the viologen. 


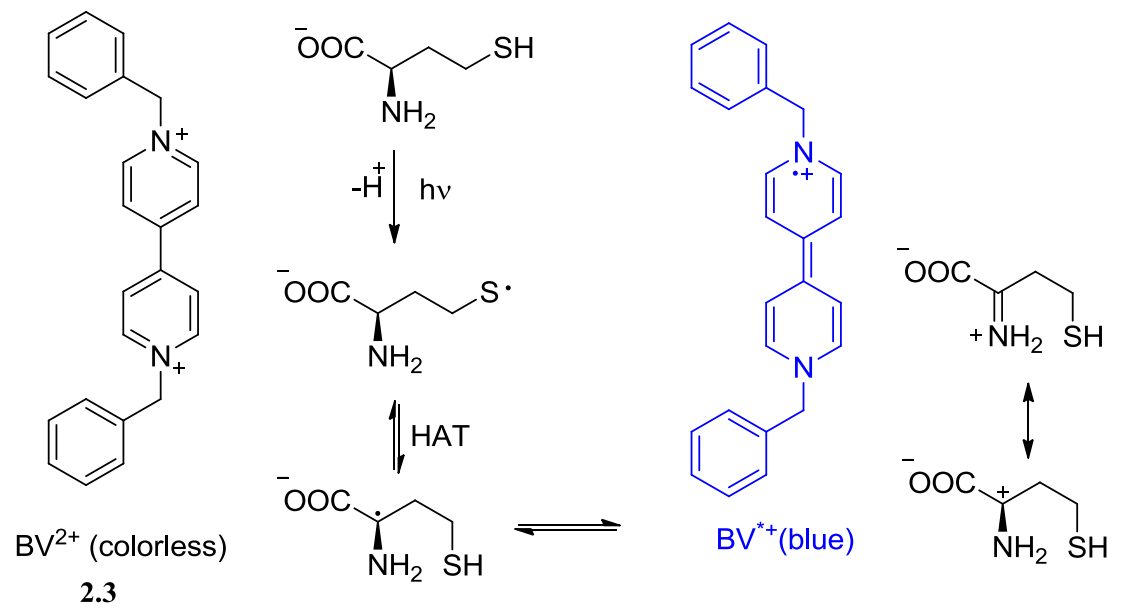

Scheme 2-3. Mechanism for the detection of Hcy involving by generation of thiyl radical, hydrogen atom transfer and reduction of $\mathrm{BV}^{2+}$

Lately, Wang et al. also published a redox based fluorometric detection of homocysteine using a dansyl derivative as fluorescence probe [108] (Figure 2-1). The selectivity for Hcy was proposed due to the oxidation of dansyl derivative probe DN-2 by Hcy. Selectivity of the probe for Hcy over Cys was due to the formation of a favorable five membered intermediate derived from Hcy, as opposed to the strained four membered ring derived from Cys. They claimed the selectivity of Hcy over Cys and GSH, nonetheless the response of Hcy in presence Cys and GSH towards the probe, had a relatively very high fluorescence enhancement than the Hcy itself (almost two folds). Under physiological conditions, where levels of Cys are 15-20 times higher than Hcy, it would be confusing to decide whether the high response is from Hcy or Cys. 

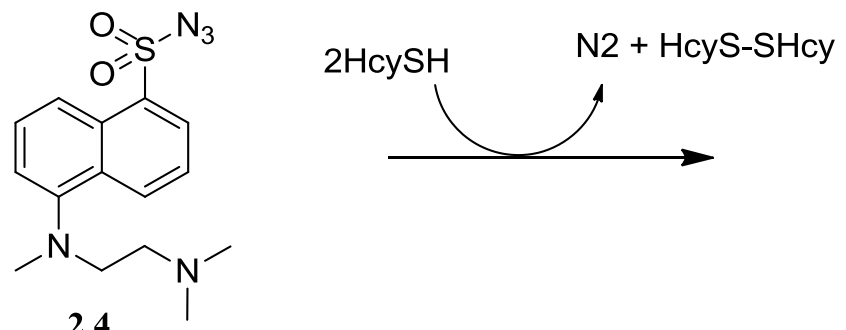

Figure 2-1. Structure of desyl derivative probe DN-2

\subsubsection{Methods for detection of Cys and Hcy based on Schiff base formation and subsequent cyclization to form a heterocycle.}

It is well know that, Cys and Hcy form thiazolidine and thiazinane heterocycles upon reaction with aldehyde moiety (for more details refer chapter 4). Based on this concept, some research groups have reported the detection of Hcy over Cys using aldehyde bearing fluorophores $[105,109,110]$. Huang et al. reported a phosphorescence sensor for Hcy detection based on an iridium (III) complex. Figure 2-2). Photoinduced electron transfer (PET) from Cys-derived thiazolidine was believed to be responsible for specificity of iridium (III) complex towards Hcy over Cys. Enhancement of the photoluminescence upon addition of Hcy and quenching of the optical response with respect to Cys was obtained. This complex produced a very good signal for Hcy, nevertheless a response was achieved at a very high concentration $(400 \mu \mathrm{M})$, far more than the physiological levels, and the use of excess of DMSO (90\%) as a reaction medium makes it inapplicable in the biological sample.[109] 


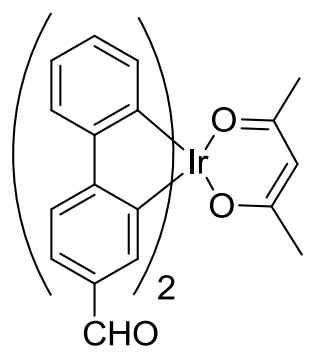

2.6

Figure 2-2. Structure of phosphorescence sensor for Hcy based on iridium (III) complex, $\operatorname{Ir}(\mathrm{pba})_{2}(\mathrm{acac})$ $($ Hpba $=4-(2-$ pyridyl $)$-benzaldehyde; acac $=$ acetylacetone $)$

Yoon et al. reported aldehyde bearing pyrene probes (P-Hcy-1 and P-Hcy-2) for the selective detection of Hcy [105] (Figure 2-3). Addition of Hcy to a solution of pyrene aldehdyes resulted in fluorescence enhancement. They stated that the distinct fluorescence response of the probes towards Hcy and Cys was due to intramolecular charge transfer (ICT) and photoinduced electron transfer (PET). However, the response of Hcy at physiological levels in the presence of other interfering thiols was not reported.

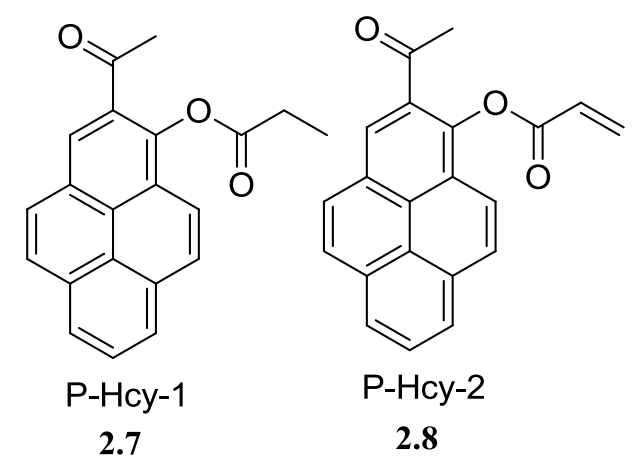

Figure 2-3. Structures of P-Hcy-1 and P-Hcy-2.

Recently, an aldehyde bearing bodipy based turn on NIR fluorescent probe containing a partially exposed aldehyde group at the meso position for the detection of 
Hcy over Cys was published [110] (Figure 2-4). At the equimolar concentration of Hcy and Cys, after four hours, a 30 fold increase in the fluorescence was obtained for Hcy and a 9 folds increase in the fluorescence for Cys was observed. Under physiological conditions where Cys levels are 15-20 times higher than Hcy; hence, Cys will interfere with the selectivity for Hcy. This makes the sensor unsuitable for Hcy detection in the biological samples.

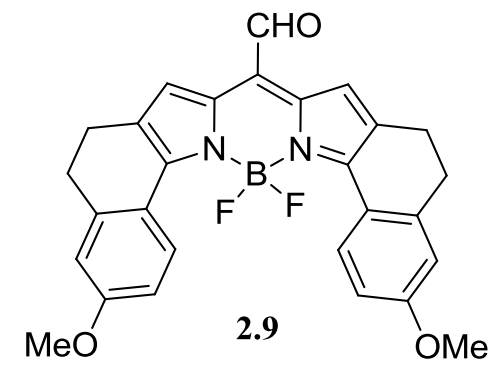

Figure 2-4. Structure of aldehyde bearing bodipy based sensor for Hcy detection

Keeping the above information in mind, it is safe to say that it has been very challenging to design a molecule and develop a method which can deliver a distinctive response to Hcy in the presence of other biological thiols and amino acids at physiologically-relevant levels. 


\section{CHAPTER 3 SELECTIVE DETECTION OF HCY USING FLUORESCEINE}

\section{ALDEHYDES}

\subsection{Background}

It has been known for almost 90 years that Cys reacts with aldehydes and forms thiazolidines [111]. Aldehyde-functionalized probes have received a great deal of attention for the optical detection of aminothiols and amino acids [76-78, 105, 112-114] First aldehyde-bearing fluorophore for the detection of Cys and Hcy was developed by our group in 2004 [76]. These reactions are based on the well-known cyclization of the aldehyde group with aminothiols to form thiazinane/thiazolidine heterocycles, as shown in the Figure 3-1. The formation of these heterocycles affords a change in the electronic properties of the chromophore and gives a different optical response than the molecule itself.

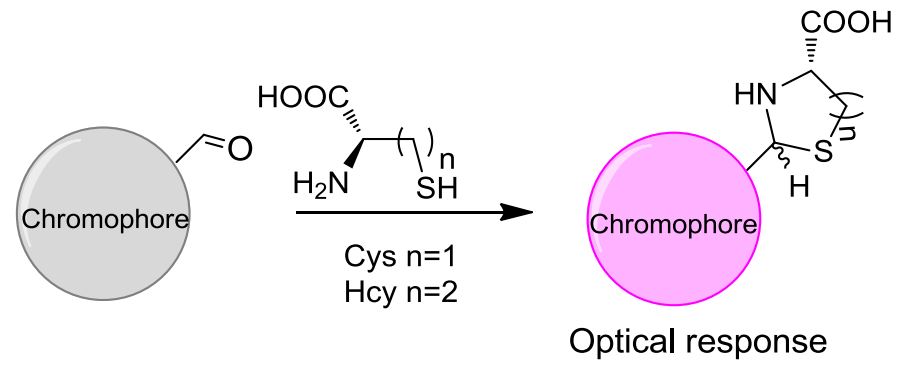

Figure 3-1. General reaction scheme for reaction of carbonyl with Cys and Hcy

Interestingly, this class of probes has responded to their respective analytes via either fluorescence quenching or fluorescence enhancement on a case by case basis. For instance, Glass et al. reported the detection of amino acids using aldehyde bearing 
coumarin probes, wherein the reaction of the aldehyde with amino acids to form imines produced an enhancement of fluorescence [112]. Concurrently, Strongin and co-workers. presented the detection of biological thiols with aldehyde bearing fluorophores [76, 77] based upon the well-known reaction of aldehydes with $N$-terminal cysteine residues to form heterocycilic thiazolidines [115] and $N$-terminal homocysteine residues to form heterocyclic thiazinanes. They reported the fluorescence quenching of fluorescein aldehyde probes due to the formation of thiazolidines/thiazinanes heterocycles, upon reaction of Cys and Hcy [76]. Afterwards, several groups have implemented this concept of aldehyde bearing probes for the detection of Cys and Hcy [75]. For instance, Kim et al. observed the fluorescence quenching of an aldehyde bearing amino coumarin based fluorophore in response to Cys/Hcy [113]. Hoang et al, reported an aldehyde bearing hydroxy coumarin [114] in which addition of Cys/Hcy resulted in enhancement of the fluorescence.

Another point of interest is that these aldehyde-based probes [76-78, 105, 112$114,116]$ have generally responded to the entire classes of analytes including amino acids[112] or biological thiols [113, 114] without specificity for individual analytes within each class. It is therefore of great interest and utility to develop a better understanding of the mechanisms behind different signal transduction in these related aldehyde-based probes. Such knowledge will lead to improved probes with increased sensitivity for the selected aminothiols of interest, specifically for Hcy over Cys.

Besides understanding the mechanism of signal transduction for respective analytes, it is equally important to focus on the difference in the spectroscopic responses 
of the probe itself and the probe-analyte complex with respect to excitation wavelength $\left(\lambda_{\text {ex }}\right)$. In general, fluorescence responses of an analyte-indicator complexes are observed at an excitation wavelength that corresponds to the absorption maximum of the dye or indicator. However, the chosen excitation wavelength may not give the optimal response, since it corresponds to the maximum absorption of the dye in the absence of analyte [112]. In 2010, Strongin et al. had reported the optimum excitation wavelength for $\alpha, \beta-$ unsaturated aldehyde-based sensor for the detection of biological thiols, which was different than the maximum absorption of sensor[78].

Usually, selective detection is obtained due to the specific and distinctive interactions of analytes with sensors or receptors. However, different analytes or biomolecules present in biological media may interact with the indicator through similar supramolecular or covalent interactions. Therefore, the presence of these indicator-bound species may interfere with the selective detection of the desired analyte. To overcome this problem, Strongin et al. studied a simple approach for the selective detection of a target biomolecule [117]. This new approach is based on the concept that the structural differences among various complexes which were formed by the interaction of various analytes with the same sensor may produce distinctive absorption and emission responses. This potentially allows a multianalyte detection via a single optical indicator. Based on this concept, a tunable detection of specific saccharides was achieved with the help of the single optical indicator by the judicious selection of excitation and emission wavelengths[117]. For instance, selective detection of fructose and ribose derivatives was attained at different excitation and emission wavelengths as a function of time. A 
rhodamine boronic acid was used as an indicator in that study.

\subsection{Mechanism of signal transaction in aldehyde bearing fluorophore probes upon reaction with aminothiols}

It is important to note the differences in the reaction of aldehyde-bearing probes with aminothiols compared to amino acids. Amino acids react to form Schiff bases [112] whereas, aminothiols such as Cys and Hcy react to form heterocyclic thiazolidines and thiazinanes respectively [76]. These differences result in unique optical responses towards aminothiols. The mechanism of signal transduction in fluorescein aldehyde probes upon their reaction with aminothiols was investigated in this work.

(a)

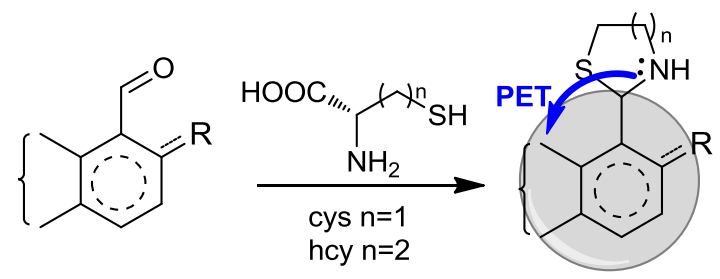

(b)

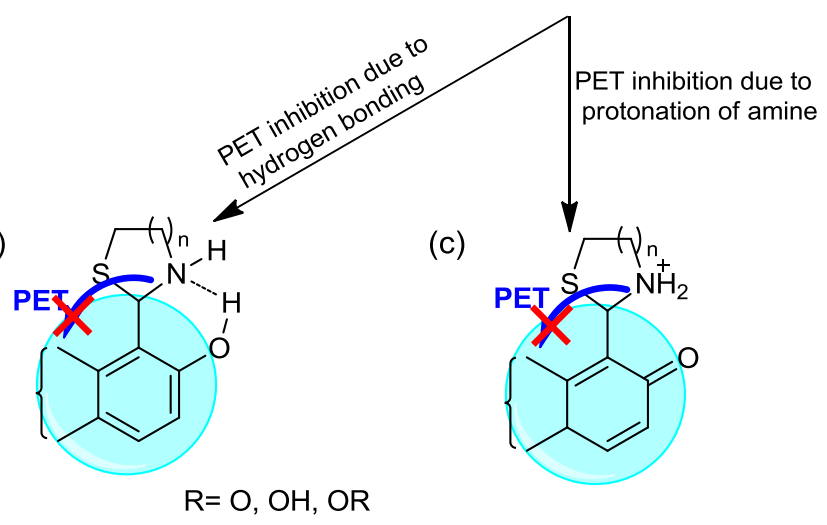

Figure 3-2. Mechanism of signal transduction in generic aldehyde-bearing aminothiol probes.

(a) PET-based fluorescence quenching following reaction of Cys/Hcy with the aldehyde group. (b) PET inhibition through hydrogen bonding between the amine-containing heterocycle and adjacent groups. (c) PET inhibition through protonation of the amine-containing heterocycle.

There are several phenomena that impact the fluorescence response of aldehyde- 
bearing probes. Figure 3-2 depicts the reaction of Cys/Hcy with the aldehyde group of a generic aldehyde-bearing probe. The mechanistic understanding described herein, has led to control over signal transduction in such a way that the probe can be tuned to respond to Cys/Hcy through either quenching or enhancement. Importantly, the response can be controlled in such a manner that Hcy is detected selectively over Cys.

It is well established that the free electrons of the amino group in the heterocycle can quench the fluorescence of the probe (Figure 3-2a) through photo induced electron transfer (PET) [113]. PET-induced responses have been modulated through tuning the functionality of the fluorescent probes [118],[114]. For example, hydrogen bonding in aqueous media between the amine-containing heterocycles and adjacent groups (Figure 3-2b) has been reported to inhibit PET leading to fluorescence enhancement upon reaction with both Cys and Hcy with a coumarin aldehyde [114]. Conversely, PET inhibition leading to selective fluorescence enhancement for Hcy/Cys can be achieved via a mechanism involving protonation of the amino group of the heterocycle. (Figure 3-2c)

In this work, the above mentioned concepts were implemented based on the structural differences between the complexes of fluorescein dialdehyde (FDA) or /fluorescein monoaldehyde (FMA) with Cys and Hcy. Via different signal transduction mechanisms, a specific response for Hcy was achieved by varying the excitation and emission wavelengths as a function of time at specific $\mathrm{pH}$ values.

\subsection{Previous work- response of fluorescein aldehydes to Cys and Hcy}

Previously, in 2004, Strongin et al. investigated the reaction of 3.1(FMA), and 3.3 (FDA) 
with Cys and Hcy at pH 9.5 [76, 77]. As described below in Scheme 3-1, this is a very simple method for the detection of Cys or Hcy and doesn't involve any complicated biochemical techniques or preparative separation $[76,77]$. This protocol was developed on the same aforementioned concept i.e. the reaction of aldehyde with $\mathrm{N}$ - terminal Cys residue to form thiazolidines $[115,119]$.<smiles>O=Cc1c(O)ccc2c(-c3ccccc3C(=O)[O-])c3ccc(=O)cc-3oc12</smiles>

FMA

3.1<smiles>O=Cc1c2oc3c(C=O)c(O)ccc3c(-c3ccccc3C(=O)[O-])c-2ccc1=O</smiles>

FDA

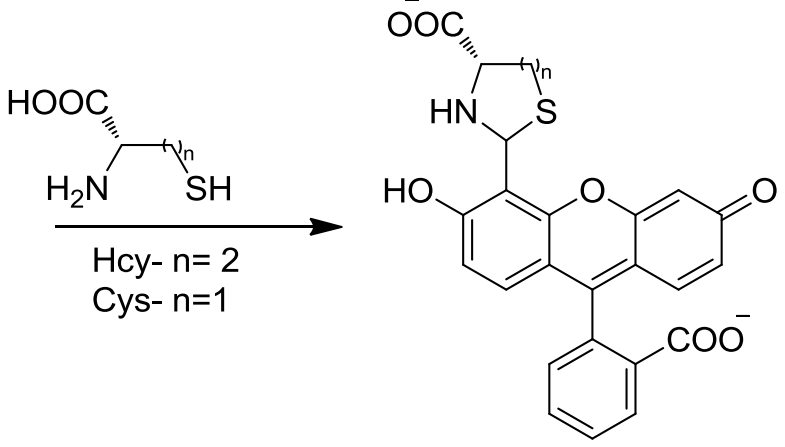

3.2a, $n=1$ and 3.2b, $n=2$<smiles>O=C([O-])c1ccccc1-c1c2ccc(=O)c(C3N[C@H](C(=O)[O-])CS3)c-2oc2c(C3N[C@@H](C(=O)[O-])CS3)c(O)ccc12</smiles>

3.4a, $n=1$ and 3.4b, $n=3$

Scheme 3-1. Reaction of FMA (3.1) and FDA (3.3) with Cys and Hcy to generate thiazolidines/ thiazinanes heterocycles respectively.

In Scheme 3-1, as shown above, the addition of Cys and Hcy to a solution of $\mathbf{3 . 3}$ results in a change in solution color from yellow to orange. Optical studies have shown that the 
addition of Cys to the solution of $\mathbf{3 . 3}$ produces a red shift in the absorption spectrum from $480 \mathrm{~nm}$ to $495 \mathrm{~nm}$ which is shown in the Figure 3-3. Further, addition of Cys and Hcy to a solution of $\mathbf{3 . 3}$ has also been shown to result in a monitorable fluorescence quenching (excited at $460 \mathrm{~nm}$ ) due to the formation of thiazolidines/thiazinanes as shown in Figure 3-4 and Figure 3-5. Moreover, NMR spectra proved the formation of thiazolidines/ thiazinanes in this reaction [76]. "Figure 3-3, Figure 3-4 and Figure 3-5 were adapted with permission from [76] Copyright (2004) American Chemical Society."

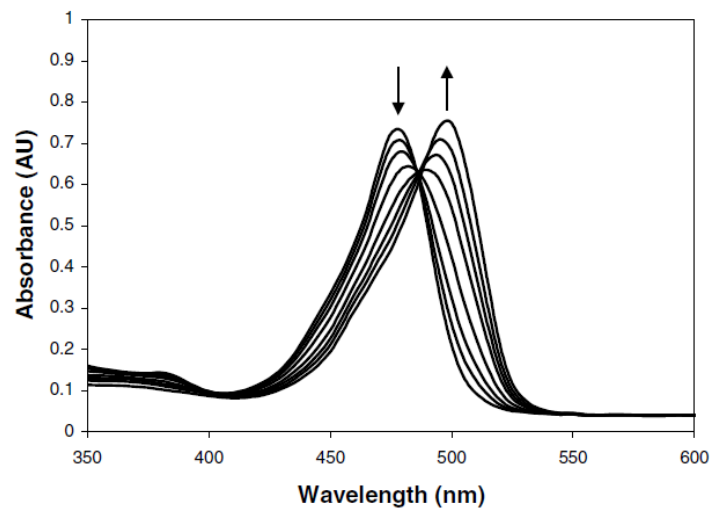

Figure 3-3. Change in the absorbance spectra of 3.3 upon addition of Cys in buffer, $\mathrm{pH} 9.5$ at room temperature.

Each spectrum was acquired after $5 \mathrm{~min}$. As the concentration of Cys increases, a red shift from $480 \mathrm{~nm}$ to $495 \mathrm{~nm}$ was observed.

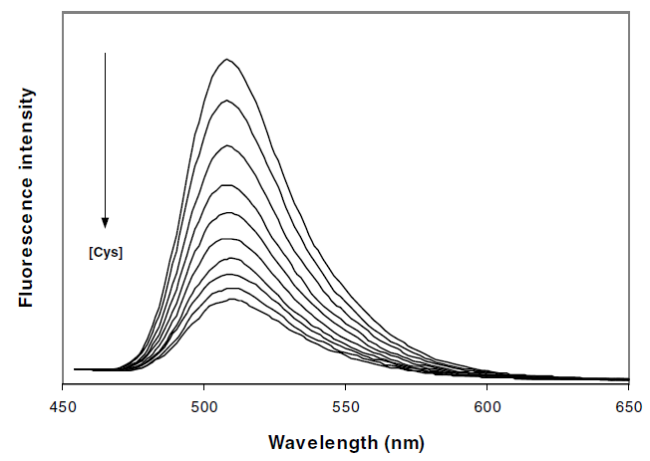

Figure 3-4. Quenching of the fluorescence emission of $\mathbf{3 . 3}$ upon addition of Cys, excited at $460 \mathrm{~nm}, \mathrm{pH} 9.5$ at room temperature 


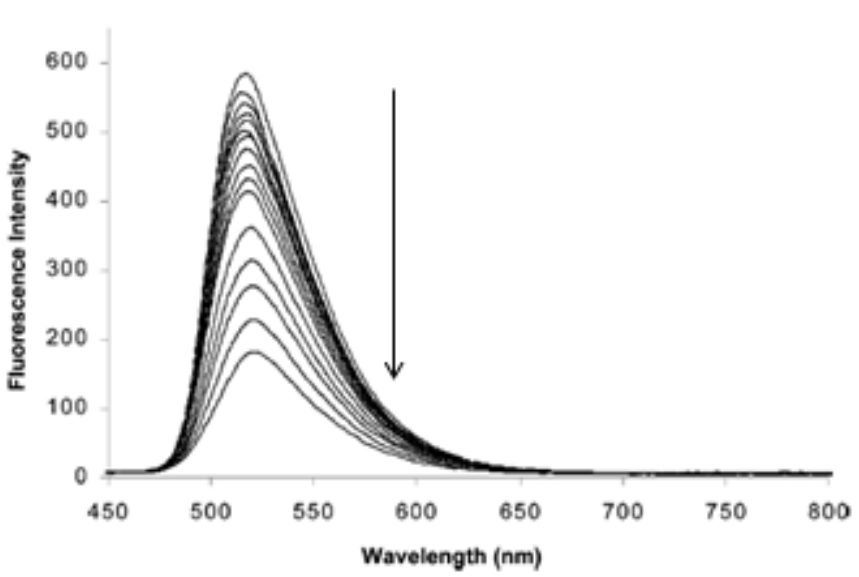

Figure 3-5. Quenching of the fluorescence emission of $\mathbf{3 . 3}$ upon addition of Hcy, excited at $460 \mathrm{~nm}, \mathrm{pH}$ 9.5 at room temperature

In these optical studies, under basic conditions (at $\mathrm{pH} 9.5$ ) both Cys and Hcy displayed the same behavior towards 3.1 and 3.3 i.e. quenching of the fluorescence emission of fluorescein aldehydes. This was attributed to the photoinduced electron transfer (PET) of the lone pairs present on the nitrogen atom of heterocycles derived from Cys and Hcy.

\subsection{Present work - results and discussion}

In the current study, the objective was to optimize the system to develop a simple, convenient and inexpensive fluorescence method to serve as a sensitive analytical tool for the detection of Hcy. It was hypothesized that at sufficiently low $\mathrm{pH}$, the amine of the heterocycles, which formed upon reaction with the probe, would be protonated, thereby inhibiting PET and leading to florescence enhancement. Moreover, we anticipated that the protonated amino groups in the thiazinane and thiazolidine would have different $\mathrm{pKa}$ values due to hybridization differences as a function of ring sizes. Hence, it was decided to study of response Hcy and Cys towards $\mathbf{3 . 1}$ and $\mathbf{3 . 3}$ at different $\mathrm{pH}$ values. 
The behavior of the reaction products was found to vary at different $\mathrm{pH}$, as shown in Figure 3-6, Figure 3-7 and Figure 3-8. At higher pH (9.5), Hcy and Cys both exhibited expected quenching of the fluorescence of $\mathbf{3 . 1}$ as both retain their amine lone pairs. At lower $\mathrm{pH}$ (5.5 and 6.0), Hcy enhanced the fluorescence of the fluorophore. However Cys displayed fluorescence quenching (Figure 3-8) at $\mathrm{pH} 6.0$ (at $\mathrm{pH}=5.5$ there was no signal change). These results suggest that at $\mathrm{pH}=6$ the amine of the Hcy thiazinane was protonated (PET quenching off) and that of the cysteine thiazolidine was neutral (lone pairs retained and PET quenching on).

In the case of a 5-memebered Cys-derived thiazolidine ring, the $\mathrm{C}-\mathrm{N}-\mathrm{C}$ bond angle is smaller than that in a 6-membered Hcy-derived thiazinane ring. This results in greater \% S-character of the $\mathrm{N}-\mathrm{H}$ bond in the thiazolidines, rendering them less basic than the thiazinanes[120-122] 
(a) $\quad \lambda_{\mathrm{ex}} 480 \mathrm{~nm}$ at $\mathrm{pH} 9.5$

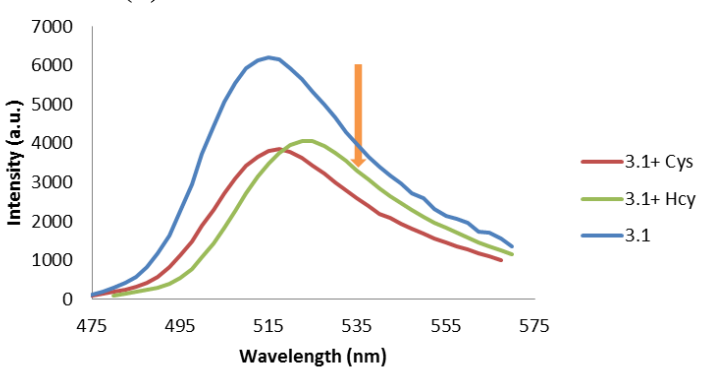

(b) $\lambda_{e x} 480$ and $\lambda_{e m} 515 \mathrm{~nm}$ at pH 9.5

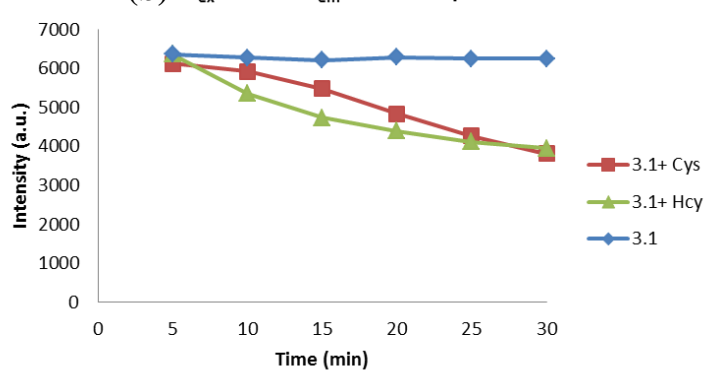

Figure 3-6. Optical sensing behavior of $\mathbf{3 . 1}$ towards Hcy and Cys at $\mathrm{pH} 9.5$

(a) fluorescence spectral changes of $\mathbf{3 . 1}$ with Hcy and Cys after 30 min. (b) Time dependent fluorescence spectral changes of 3.1 with Hcy and Cys. Solutions are composed of $4 \mu \mathrm{M}$ of $\mathbf{3 . 1}$ with $1 \mathrm{mM}$ of analyte in carbonate buffer (100 mM, pH 9.5) DMSO 99:1 at $20^{\circ} \mathrm{C}, \lambda_{\mathrm{ex}}=480 \mathrm{~nm}$ and $\lambda_{\mathrm{em}}=515 \mathrm{~nm}$.
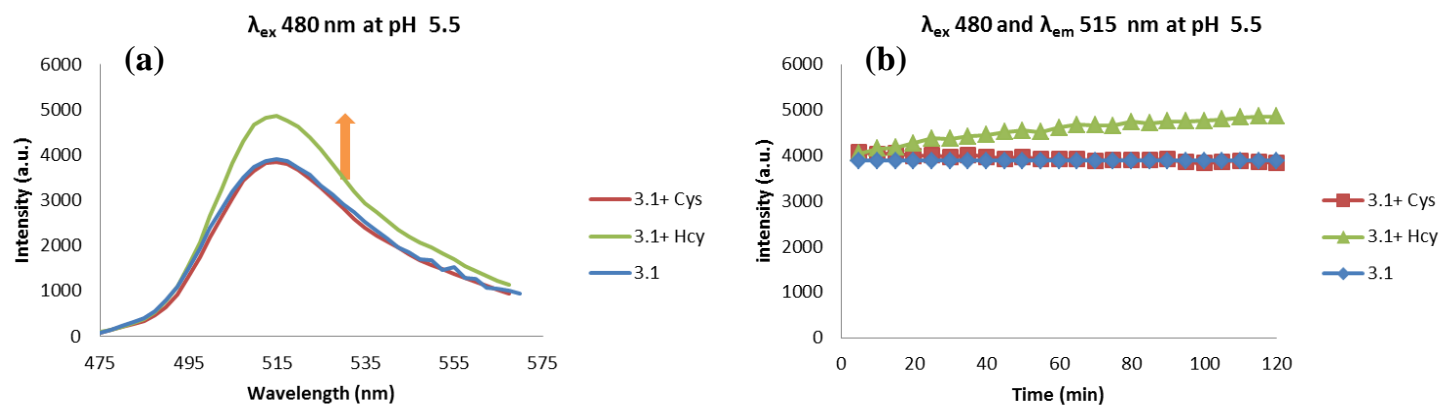

Figure 3-7. Optical sensing behavior of 3.1 towards Hcy and Cys at $\mathrm{pH} 5.5$.

(a)fluorescence spectral changes of $\mathbf{3 . 1}$ with Hcy and Cys after 2h. (b) Time dependent fluorescence spectral changes of 3.31 with Hcy and Cys. Solutions are composed of $4 \mu \mathrm{M}$ of 3.1 with $1 \mathrm{mM}$ of analyte in phosphate buffer $\left(100 \mathrm{mM}\right.$, pH 5.5) DMSO 99:1 at $20^{\circ} \mathrm{C}, \lambda_{\mathrm{ex}}=480 \mathrm{~nm}$ and $\lambda_{\mathrm{em}}=515 \mathrm{~nm}$. 

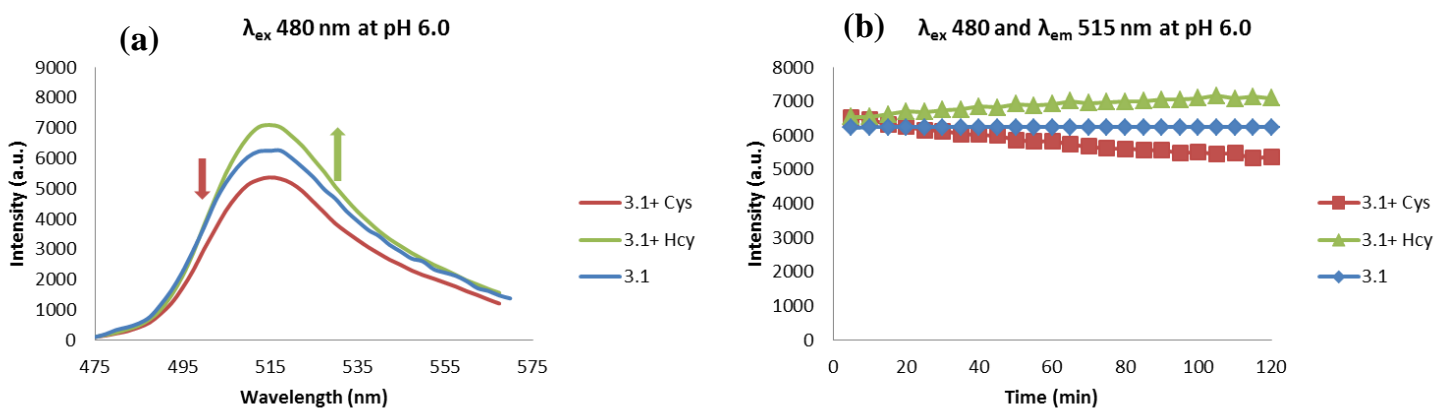

Figure 3-8. Optical sensing behavior of 3.1 towards Hcy and Cys at $\mathrm{pH}$ 6.0.

(a) Fluorescence spectral changes of $\mathbf{3 . 1}$ with Hcy and Cys after 2h. (b) Time dependent fluorescence spectral changes of $\mathbf{3 . 1}$ with Hcy and Cys. Solutions are composed of $4 \mu \mathrm{M}$ of $\mathbf{3 . 1}$ with $1 \mathrm{mM}$ of analyte in phosphate buffer (100 mM, pH 6.0) DMSO 99:1 at $20^{\circ} \mathrm{C}, \lambda_{\mathrm{ex}}=480 \mathrm{~nm}$ and $\lambda_{\mathrm{em}}=515 \mathrm{~nm}$.

The hypothesis and results showed that lowering the $\mathrm{pH}$ of the reaction medium results in the enhancement of the fluorescence of $\mathbf{3 . 1}$ in the presence of Hcy. After studying the responses to thiols as a function of $\mathrm{pH}$, a study was conducted to explore the response of 3.1 towards Hcy and Cys at a different excitation wavelengths. It was again hypothesize that the fluorescence response would be maximum when excited at wavelength which is near the absorption maxima of the reaction product, instead of the absorption maxima of the probe itself. Based on this concept, maximum response for the detection of amino acids and Cys as well as tunable detection of saccharides[117] have been reported in the literature $[78,112,117]$. Absorbance spectra of 3.1, show that the addition of Hcy or Cys to a solution of 3.1, produces a red shift from $480 \mathrm{~nm}$ to 495 as a result of the formation of thiazinane/thiazolidine heterocycles ( 
Figure 3-9) [76].

To prove this second hypothesis, the optical response of Cys and Hcy towards 3.1 was monitored at higher excitation wavelengths, i.e. $\lambda_{\mathrm{ex}}$ at $495 \mathrm{~nm}$, near the absorption maxima of the heterocyclic reaction product. On exciting at $495 \mathrm{~nm}$, enhancement in the fluorescence of 3.1 in response to Hcy was found to be 2 to 3 fold higher than the excitation at lower wavelength (at $480 \mathrm{~nm}$, lambda max of the probe itself) as shown in Figure 3-10. Another interesting observation was that, on adjusting the $\mathrm{pH}$ from 5.5 to 6.0, the signal is modulated such that Hcy enhances the fluorescence of $\mathbf{1}$ while there is minimal change upon reaction with Cys, as shown in Figure 3-11. These observations led to a new method to achieve a maximum response of Hcy over Cys via adjusting the $\mathrm{pH}$ of the reaction medium and the excitation wavelength. In the present case, the best parameters are $\mathrm{pH} 6.0$ and excitation wavelength, $\lambda_{\mathrm{ex}}$ of $495 \mathrm{~nm}$.

(a)

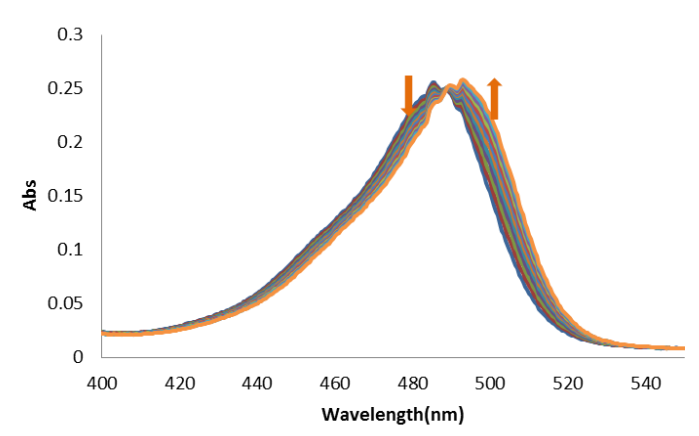

(b)

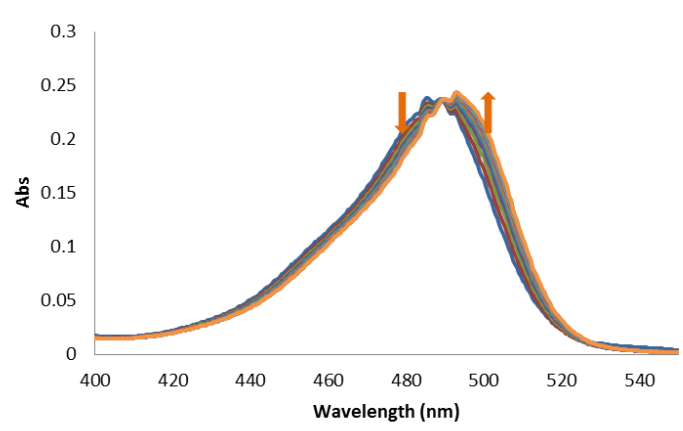

Figure 3-9. Optical sensing behavior of $\mathbf{3 . 1}$ towards Hcy and Cys at $\mathrm{pH} 9.5$.

(a) Time dependent absorption spectral changes of $\mathbf{3 . 1}$ with Hcy over $30 \mathrm{~min}$. (b) Time dependent absorption spectral changes of 3.1 with Cys over 30 min. Solutions are composed of $4 \mu \mathrm{M}$ of 3.1 with 1 $\mathrm{mM}$ of analyte in carbonate buffer (100 mM, pH 9.5) DMSO 99:1 at $20^{\circ} \mathrm{C}$ 
(a) $\quad \lambda_{\mathrm{ex}} 495 \mathrm{~nm}$ at pH 5.5

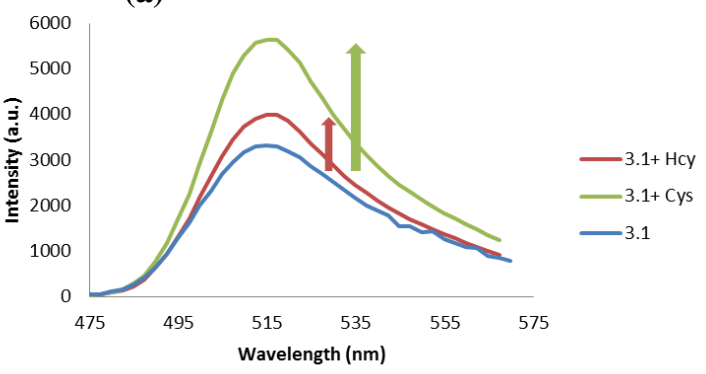

(b) $\lambda_{\text {ex }} 495$ and $\lambda_{e m} 515 \mathrm{~nm}$ at pH 5.5

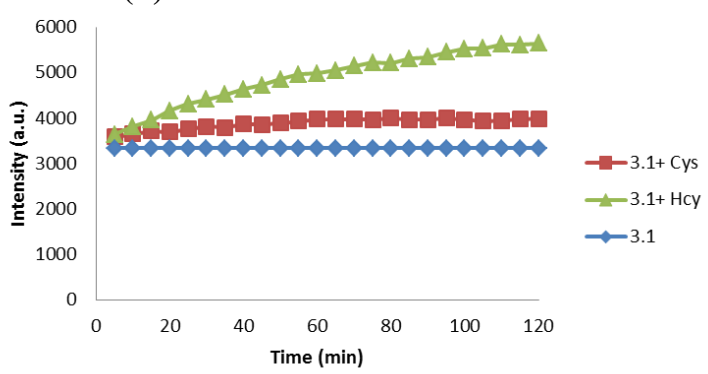

Figure 3-10. Optical sensing behavior of $\mathbf{3 . 1}$ towards Hcy and Cys at $\mathrm{pH}$ 5.5.

(a) Fluorescence spectral changes of 3.1 with Hcy and Cys after 2h. (b) Time dependent fluorescence spectral changes of 3.1 with Hcy and Cys. Solutions are composed of $4 \mu \mathrm{M}$ of $\mathbf{3 . 1}$ with $1 \mathrm{mM}$ of analyte in phosphate buffer (100 mM, pH 5.5) DMSO 99:1 at $20^{\circ} \mathrm{C}, \lambda_{\mathrm{ex}}=495 \mathrm{~nm}$ and $\lambda_{\mathrm{em}}=515 \mathrm{~nm}$.
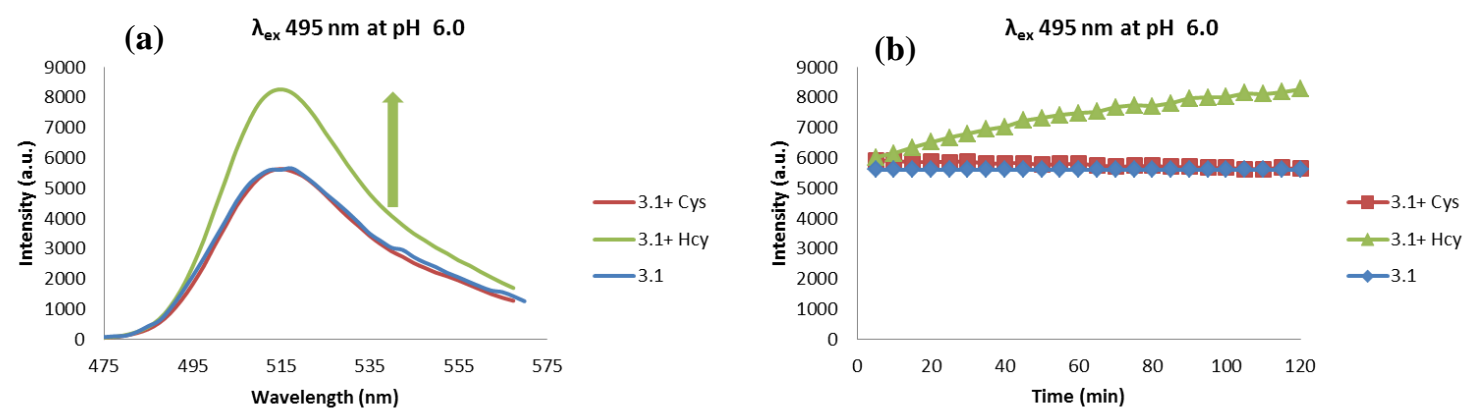

Figure 3-11. Optical sensing behavior of 3.1 towards Hcy and Cys at $\mathrm{pH}$ 6.0.

(a) Fluorescence spectral changes of 3.1 with Hcy and Cys after 2h. (b) Time dependent fluorescence spectral changes of $\mathbf{3 . 1}$ with Hcy and Cys. Solutions are composed of $4 \mu \mathrm{M}$ of $\mathbf{3 . 1}$ with $1 \mathrm{mM}$ of analyte in phosphate buffer (100 mM, pH 6.0) DMSO 99:1 at $20^{\circ} \mathrm{C}, \lambda_{\mathrm{ex}}=495 \mathrm{~nm}$ and $\lambda_{\mathrm{em}}=515 \mathrm{~nm}$.

The response of $\mathbf{3 . 1}$ towards GSH and various amino acids at $\mathrm{pH} 6.0$ was also investigated. As shown in the Figure 3-12, it was found that only Hcy promotes fluorescence enhancement. 


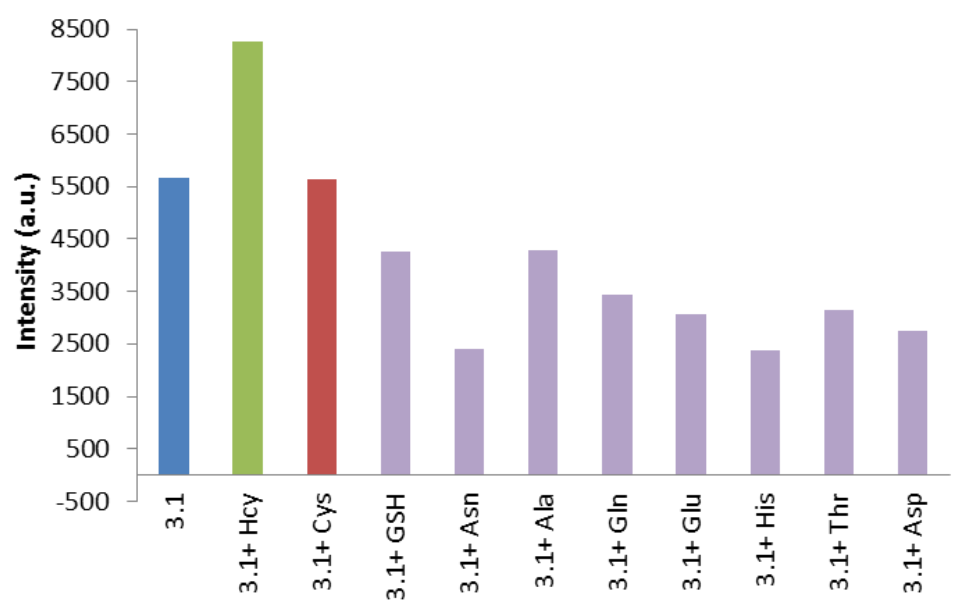

Figure 3-12. Optical sensing behavior of 3.1 towards Cys and Hcy as compared to other biologically relevant species.

Fluorescence response of $\mathbf{3 . 1}$ upon addition of different analytes (Cys, Hcy, GSH,Asn, Ala, Gln, Thr, Asp, Arg, His, Glu, $1 \mathrm{mM}$ ). All Solutions are composed of $4 \mu \mathrm{M}$ of 3.1 with $1 \mathrm{mM}$ analyte in phosphate buffer (100 mM, pH 6.0):DMSO 99:1 at $20^{\circ} \mathrm{C}, \lambda_{\mathrm{ex}}=495 \mathrm{~nm} \lambda_{\mathrm{em}}=515 \mathrm{~nm}$

${ }^{1}$ HNMR study of $\mathbf{3 . 1}$ in the presence of Hcy and Cys under these conditions also confirms the formation of thiazinane and thiazolidine, upon reaction of Cys and Hcy with 3.1. Figure 3-13 shows disappearance of aldehyde resonance at $10.39 \mathrm{ppm}$ and appearance of methine resonance at $6.81 \mathrm{ppm}$ substantiate formation of these heterocycles. Whereas, ${ }^{1} \mathrm{H}$ NMR experiment of $\mathbf{3 . 1}$ with glycine shows the formation of a Schiff base (an imine ), in the Figure 3-14, the Schiff base resonance at $9.11 \mathrm{ppm}$ along with CHO resonance at 10.38 ppm shows the Schiff base formation was in equilibrium with the 3.1. 


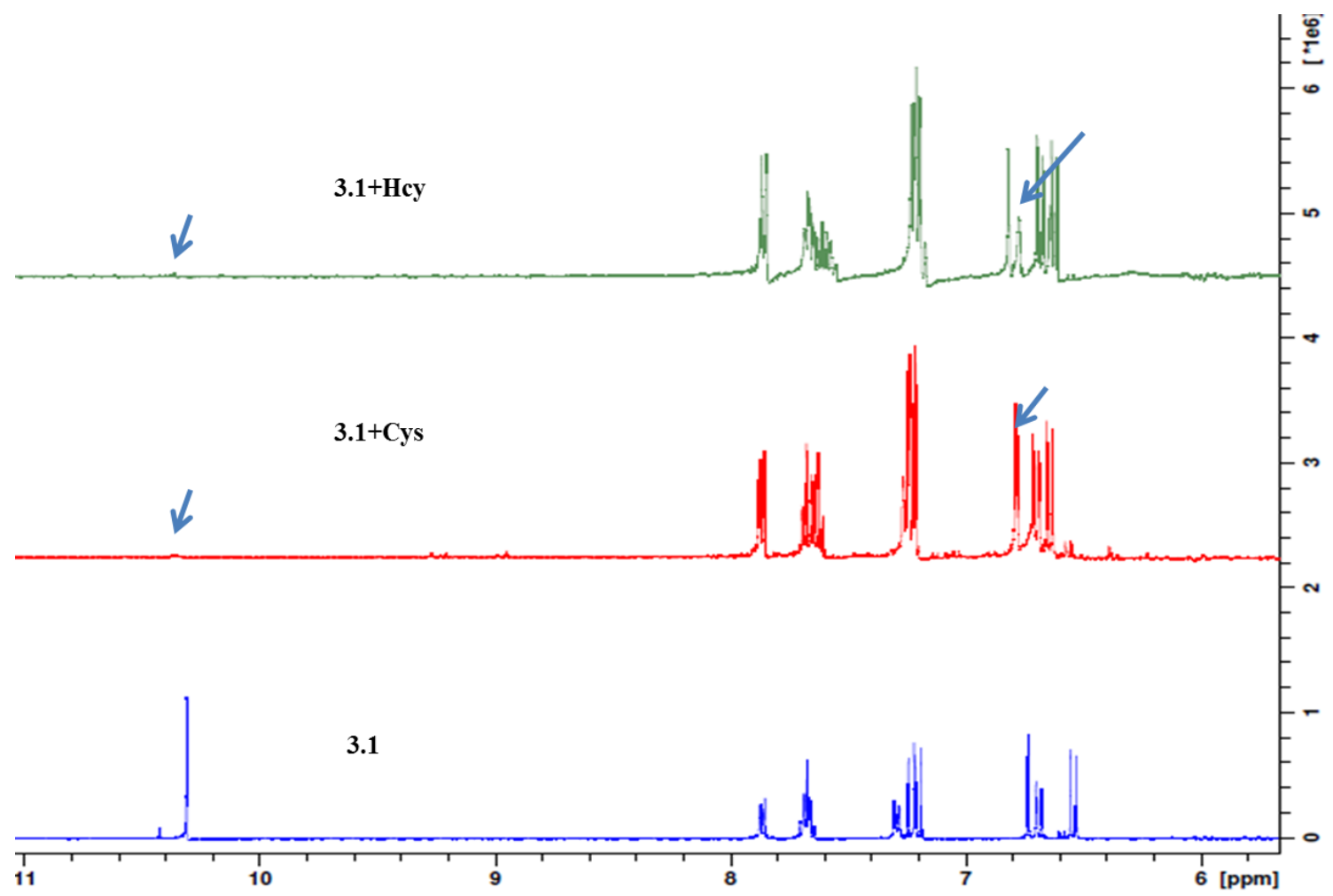

Figure 3-13. $\mathrm{H}^{1}$ NMR of 3.1, 3.1 in the presence of Hcy ( 3 equiv) and 3.1 in presence of Cys (3 equiv) at pH 6.0. 


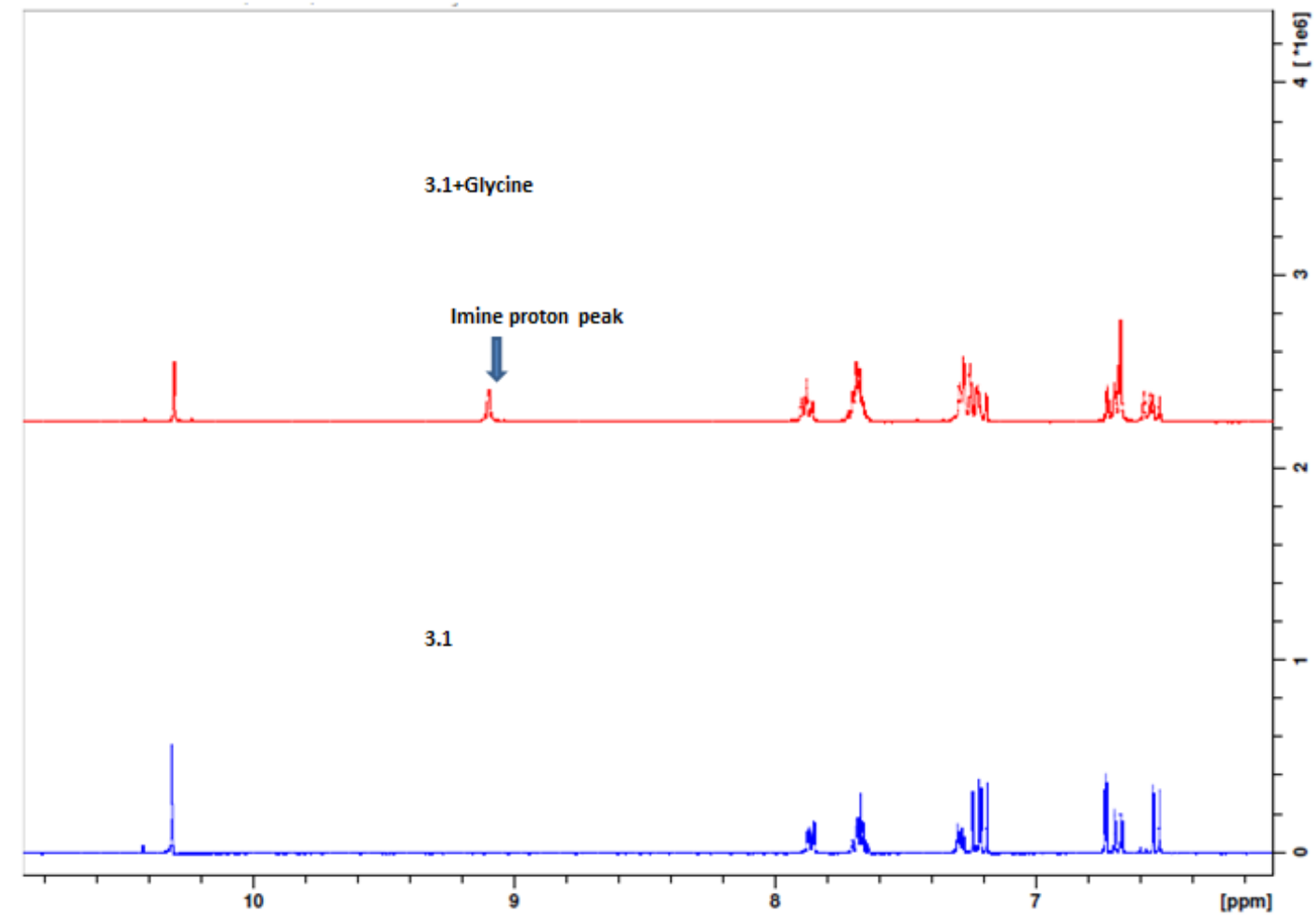

Figure 3-14. $\mathrm{H}^{1} \mathrm{NMR}$ of $\mathbf{3 . 1}$ and $\mathbf{3 . 1}$ in the presence of Gly (3 equiv) at $\mathrm{pH} 6$.

Although highly selective for Hcy over Cys, $\mathbf{3 . 1}$ was not sensitive enough to produce an appreciable response of Hcy at the lower levels. Therefore, it was decided to study the response of Hcy and Cys towards 3.3, i.e. fluorescein dialdehdye.

The absorption spectra of $\mathbf{3 . 3}$ in the presence of Hcy and Cys are analogous to those using 3.1, including a red shift in the absorption maxima upon addition of Hcy and Cys from 480nm to $495 \mathrm{~nm}$ (Figure 3-15). Further, on exciting at a higher wavelength $\left(\lambda_{\text {ex }}=495 \mathrm{~nm}\right), \mathbf{3 . 3}$ produces a $>5$ fold enhancement in the fluorescence upon addition of Hcy (Figure 3-16). The signals using 3.3 were approximately twice as intense as from 3.1. The response of $\mathbf{3 . 3}$ towards Hcy was easily observed in as little as $15 \mathrm{~min}$ and 
plateaus near 45 min.
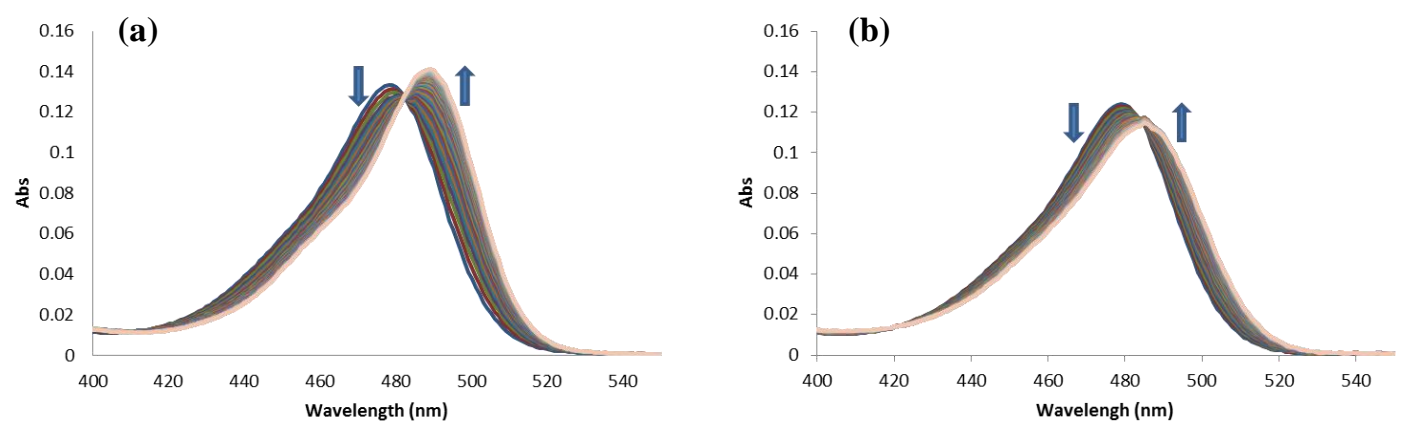

Figure 3-15. Optical sensing behavior of $\mathbf{3 . 3}$ towards Hcy and Cys at $\mathrm{pH}$ 6.0.

(a) Time dependent absorption spectral changes of $\mathbf{3 . 3}$ with Hcy over 2h. (b) Time dependent absorption spectral changes of $\mathbf{3 . 3}$ with Cys over $2 \mathrm{~h}$. Solutions are composed of $4 \mu \mathrm{M}$ of $\mathbf{3 . 3}$ with $1 \mathrm{mM}$ of analyte in Phosphate buffer (100 mM, pH 9.5) DMSO 99:1 at $20^{\circ} \mathrm{C}$
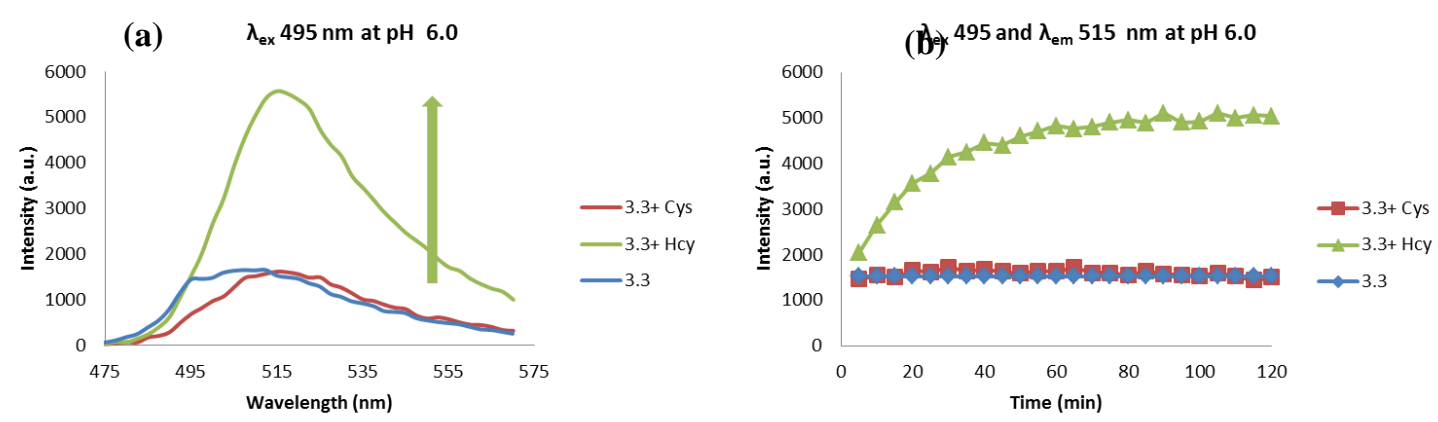

Figure 3-16. Optical sensing behavior of $\mathbf{3 . 3}$ towards Hcy and Cys at $\mathrm{pH}$ 6.0.

(a) Fluorescence spectral changes of $\mathbf{3 . 3}$ with Hcy and Cys after $2 \mathrm{~h}$. (b) Time dependent fluorescence spectral changes of $\mathbf{3 . 3}$ with Hcy and Cys. Solutions are composed of $4 \mu \mathrm{M}$ of $\mathbf{3 . 3}$ with $1 \mathrm{mM}$ of analyte in phosphate buffer (100 mM, pH 6.0) DMSO 99:1 at $20^{\circ} \mathrm{C}, \lambda_{\mathrm{ex}}=495 \mathrm{~nm}$ and $\lambda_{\mathrm{em}}=515 \mathrm{~nm}$.

Having identified the optimal conditions for the discrimination of Hcy over Cys, the response of the more sensitive dialdehyde $\mathbf{3 . 3}$ towards normal healthy concentrations of aminothiols in $\mathrm{pH} 6.0$ buffer was investigated. As shown in the Figure 3-17, No response 
was observed toward $250 \mu \mathrm{M}$ Cys, while $15 \mu \mathrm{M}$ Hcy resulted in a $\sim 10 \%$ increase in the fluorescence. The fluorescence response of $\mathbf{3 . 3}$ towards Hcy increased linearly with the increase in the Hcy concentration, and the limit of detection was found to be as low as 2.5 $\mu \mathrm{M}$ as shown in the Figure 3-18.

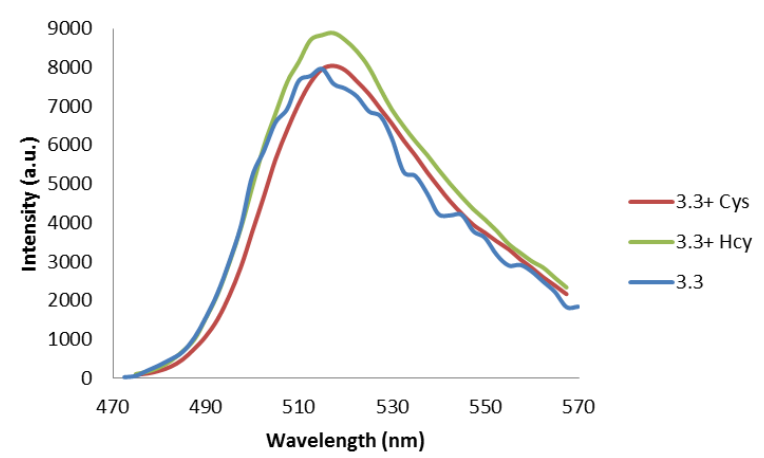

Figure 3-17. Optical sensing behavior of $\mathbf{3 . 3}$ towards Cys and Hcy at their biological concentrations at $\mathrm{pH}$ 6.0 .

Fluorescence spectra of $\mathbf{3 . 3}$ with Cys and Hcy after two hours. Solutions are composed of $30 \mu \mathrm{M}$ of $\mathbf{3 . 3}$ with $250 \mu \mathrm{M}$ of Cys and $15 \mu \mathrm{M}$ of Hcy in phosphate buffer (100 mM, pH 6.0):DMSO 99:1 at $20^{\circ} \mathrm{C}, \lambda_{\text {ex }}=$ $494 \mathrm{~nm}$.

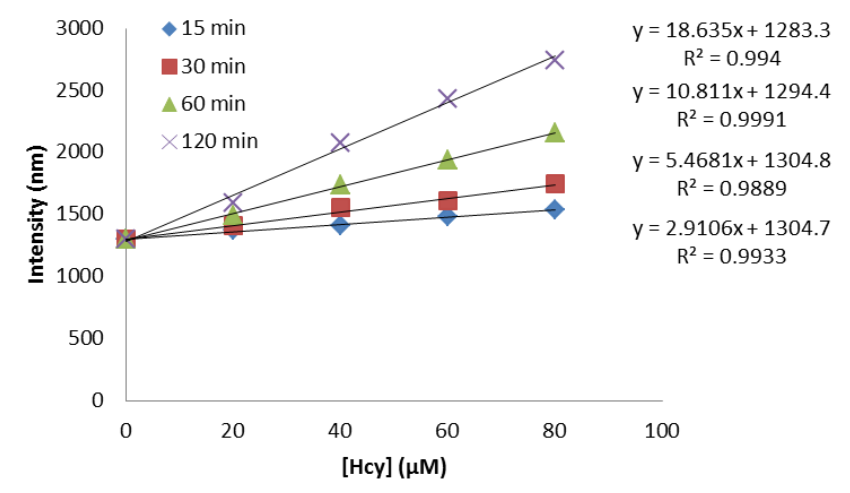

Figure 3-18. Spectral response of $\mathbf{3 . 3}$ towards increasing levels of Hcy in phosphate buffer (100 mM, pH 6.0).

Solutions are composed of $4 \mu \mathrm{M}$ of $\mathbf{3 . 3}$ with $0-80 \mu \mathrm{M}$ of Hcy in phosphate buffer (100 mM, pH 6.0):DMSO 99:1 at $20^{\circ} \mathrm{C}, \lambda_{\mathrm{ex}}=494 \mathrm{~nm}$ and $\lambda_{\mathrm{em}}=515 \mathrm{~nm}$. 
The response of $\mathbf{3 . 3}$ in deproteinized plasma at elevated levels of Hcy was also investigated. To measure a known amount of Hcy deproteinized plasma was spiked with Hcy $(100 \mu \mathrm{M})$. Under this condition, $\mathbf{3 . 3}$ functioned well in the presence of spiked Hcy. The response of physiological levels of Cys (i.e. $250 \mu \mathrm{M}$ ) towards $\mathbf{3 . 3}$ was insignificant as shown in the Figure 3-19.

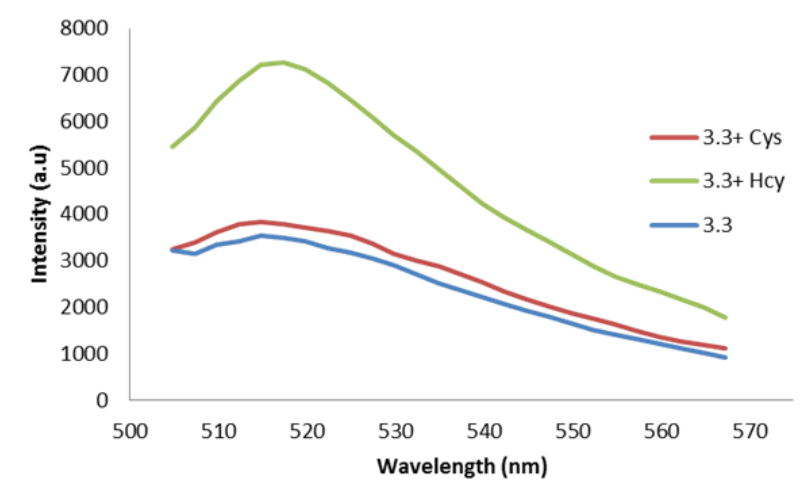

Figure 3-19. Optical sensing behavior of 3.3 towards Cys and Hcy in deproteinized bovine plasma at $\mathrm{pH}$ 6.0 .

Solutions are composed of $25 \mu \mathrm{M}$ of $\mathbf{3 . 3}$ with $250 \mu \mathrm{M}$ of Cys and $100 \mu \mathrm{M}$ of Hcy in phosphate buffer (100 $\mathrm{mM}, \mathrm{pH}$ 6.0):DMSO 99:1 at $20 \mathrm{oC}$ after $2 \mathrm{hr}, \lambda \mathrm{ex}=495 \mathrm{~nm}$.

\subsection{Conclusion}

In conclusion, the optimum conditions to attain the specific detection of Hcy via a characteristic fluorescence increase with 3.1 and 3.3 were identified. Under basic conditions, addition of Hcy and Cys to a solution of fluorescein aldehyde (3.1 or 3.3), resulted in fluorescence quenching due to the PET from the lone pair of electron, present on the nitrogen atom of heterocycles derived from Hcy and Cys. Whereas under acidic conditions, protonation of amine of Hcy/Cys derived heterocycles inhibits PET and produces fluorescence enhancement. $\mathrm{pH} 6.0$ was found to be the optimal $\mathrm{pH}$ for the 45 
detection of Hcy, at this $\mathrm{pH}$ the response to Hcy of $\mathbf{3 . 1}$ and $\mathbf{3 . 3}$ led to fluorescence enhancement, whereas the response to Cys was minimal.

Apart from the $\mathrm{pH}$ dependence, the detection of Hcy was also found to be wavelength dependent. The magnitude of the response was at the maximum when excited in the region near the absorption maxima of the analyte-probe complex $\left(\lambda_{\mathrm{ex}}=495 \mathrm{~nm}\right)$ rather than the absorption maxima of probe itself $\left(\lambda_{\mathrm{ex}}=480 \mathrm{~nm}\right)$. Fluorescein dialdehyde (3.3) was found to be more sensitive than fluorescein mono aldehyde (3.1). The reaction of $\mathbf{3 . 3}$ with Hcy resulted in more than a fivefold enhancement in fluorescence. $\mathbf{3 . 3}$ was also found to function in deproteinized plasma, detecting relatively high levels of Hcy $(100 \mu \mathrm{M})$.

\subsection{Experimental section}

\subsubsection{Materials}

All chemicals were purchased from Sigma Aldrich and used as received. Ultra-pure water $\left(18.2 \mathrm{M} \Omega \cdot \mathrm{cm}\right.$ at $\left.25^{\circ} \mathrm{C}\right)$ obtained from a Milli-Q direct water purification system was used to prepare all aqueous solutions. All spectroscopic measurements were carried out in DMSO:buffer (1:99) solutions. $\mathbf{3 . 1}$ and $\mathbf{3 . 3}$ were synthesized from the procedure reported in the literature based on the Reimer Tiemann reaction for formylation [77].

\subsubsection{Methods}

${ }^{1} \mathrm{H}-\mathrm{NMR}$ spectra were recorded on an ARX-400 Advance Bruker spectrometer performing at $400.13 \mathrm{MHz}\left({ }^{1} \mathrm{H}\right) \cdot \mathrm{D}_{2} \mathrm{O}: \mathrm{H}_{2} \mathrm{O}$ (1:9) solvent system was used as NMR solvent. All chemical shifts $(\delta)$ were reported in ppm using DSS (sodium 2,2-dimetyl-2- 
silapentane-5-sulfonate) as an internal standard $(\delta=0.000)$ for ${ }^{1} \mathrm{H}-\mathrm{NMR}$ studies.

\subsubsection{Spectrophotometric measurement}

UV-visible spectra were recorded on a Cary $50 \mathrm{UV}$-Vis spectrophotometer (Agilent Technologies). Fluorescence spectra were obtained on a Cary Eclipse fluorescence spectrophotometer (Agilent Technologies) with slit widths set at $5 \mathrm{~nm}$ for both excitation and emission, respectively. Fluorescence spectra were corrected for the wavelength dependent response of the R928 photomultiplier tube with the help of a manufacturer generated correction file. All spectrophotometric measurements were conducted at room temperature.

\subsubsection{Deproteinization of plasma}

Deproteinization of plasma was carried out by reconstituting the lyophilized bovine plasma with ultrapure water to $1 / 3$ of the reconstitution volume. Two equivalents of acetonitrile (2/3 of the reconstitution volume) were added. This solution was vortexed for 10 min. after letting the solution stand for 10 minutes, it was centrifuged at 4000 RPM for 30 minutes to pellet the proteins. The decanted supernatant was aliquoted into sample vials and re-lyophilized. The vials were then sealed and stored in a refrigerator $\left(4^{\circ} \mathrm{C}\right)$. 


\section{CHAPTER 4 MECHANISTIC STUDIES}

\subsection{Introduction}

Fluorescence enhancement due to PET Inhibition is a well-known phenomenon. [123] PET based fluorescence sensors have been widely used to detect an individual or a class of analytes [109, 113, 114, 123-125]. This effect has been observed in the case of fluorescein aldehydes. As seen in previous chapter, under acidic conditions, amine of Hcy-Cys derived heterocycles is protonated causing inhibition of PET and fluorescence enhancement. However, at an intermediate $\mathrm{pH}$, the response of Hcy was observed but Cys seems to give minimal or insignificant response.

\subsection{Result and discussion}

Here the objective was to understand the difference in the fluorescence response of Hcyderived thiazinane and Cys-derived thiazolidine which are formed upon reaction of Hcy and Cys with 3.1 and 3.3 respectively. The difference in the response of Hcy than Cys towards 3.1/3.3 was possibly due to the difference in the $\mathrm{pKa}$ value of protonated amine of Hcy-derived thiazinane and the Cys-derived thiazolidine. Since, the C-N-C bond angle for 5-memebered Cys-derived thiazolidine ring is smaller than the 6-membered Hcyderived thiazinane ring, it generates a greater $S$-character of the $\mathrm{N}-\mathrm{H}$ bond in the thiazolidines, making them less basic than the thiazinanes [120-122]. To prove this hypothesis, it was necessary to understand the difference in the basicity of amine of Hcy/Cys derived heterocycles. Previously, the basicity of the amine of thiazolidine-4caroboxylc acids has been studied [126-129] but the basicity of the amine of the Hcyderived thiazinane-4-carboxylic acids had not been reported. Therefore, a series of 5- 
and 6-membered 2-substituted thiazolidine/thiazinane $S$-4-carboxylic acids were synthesized as model compounds of $\mathbf{3 . 1}$ and $\mathbf{3 . 3}$.

\subsubsection{Synthesis of Cys- and Hcy-derived analogs 4.1, 4.3, 4.5, 4.2, 4.4 and 4.6}

To understand the difference in the basicity of 5- and 6-membered heterocyclic amines, the Cys- and Hcy-derived analogs 4.1, 4.3, 4.5, 4.2, 4.4 and 4.6 were synthesized. 4.1, 4.3 and 4.5 were prepared by the reaction of Cys with salicylaldehyde, benzaldehyde and formaldehyde respectively in aqueous medium at room temperature. Several attempts were made for the synthesis of Hcy derived heterocycles analogs 4.2, 4.4 and 4.6. Reaction of Hcy was carried out with salicylaldehyde, benzaldehyde and formaldehyde respectively in aqueous and/or ethanol reaction medium by changing the number of equivalents, water/EtOH ratio and time over a period of few hours to 3 days. 4.2 and 4.4 were obtained as colorless crystals from the reaction medium. However 4.6 remained soluble in the aqueous medium therefore ethanol was added to the reaction mixture and after 24 hours shiny colorless crystals of $\mathbf{4 . 6}$ were obtained.

\subsubsection{Estimated $\mathrm{p} K_{\mathrm{a}}$ values of Cys- and Hcy-derived analogs 4.1, 4.3, 4.5, 4.2, 4.4 and 4.6}

To confirm the hypothesis that the $\mathrm{pH}$ dependent Hcy enhancement was related to the difference in the basicity of 5- and 6-membered heterocyclic amines, the estimated $\mathrm{p} K_{\mathrm{a}}$ values of the protonated amine of the Cys- and Hcy-derived analogs were measured. The values are reported in the Table 4.1. estimated $\mathrm{pKa}$ values were calculated from the $\mathrm{pH}$ titration curves which are shown in Figure 4-1, Figure 4-2 and Figure 4-3. Cysderived 4.1, 4.3 and 4.5 are known $[130,131]$ and their previously published $\mathrm{p} K_{\mathrm{a}}$ values 
are in general agreement with those in Table 4.1. As seen in Table 4.1, the protonated amine $\mathrm{p} K_{\mathrm{a}}$ of 6-membered thiazinanes is higher than that of 5-membered thiazolidines by at least one unit. Therefore, based on the $\mathrm{p} K_{\mathrm{a}}$ of these analogs, we expect the protonated amine $\mathrm{p} K_{\mathrm{a}}$ of Hcy-derived 3.2b to be approximately 1 unit greater ( 6.7) than Cysderived 3.2a $(\sim 5.7)$. One unit difference in the $\mathrm{pKa}$ of amine of Hcy and Cys derived heterocyles will affect the ionization state of amine at a given $\mathrm{pH}$. For instance, at $\mathrm{pH} 6.0$ major species for the amine of Hcy-derived thiazinane would exist mainly as the ammonium ion whereas the amine of the Cys-derived thiazolidine would be at a nearly equal concentration to the ammonium form. 
Table 4.1. Estimated $\mathrm{p} K_{\mathrm{a}}$ values of the protonated amine moiety of 2-substituted thiazolidine/thiazinane-4carboxylic acids.

$\mathrm{p} K_{\mathrm{a} \text { exp },\left(\mathrm{p} K_{\mathrm{a} \text { lit }}\right)}$

${ }^{a} 4.1$ and 4.3 were found to be relatively unstable showing signs of decomposition in aqueous solution during the course of the titration (Figure 4-1, Figure 4-2and Figure 4-4 ).

${ }^{b}$ 4.2 and 4.4 showed no indication of decomposition (Figure 4-1, Figure 4-2 and Figure 4-4 ) 

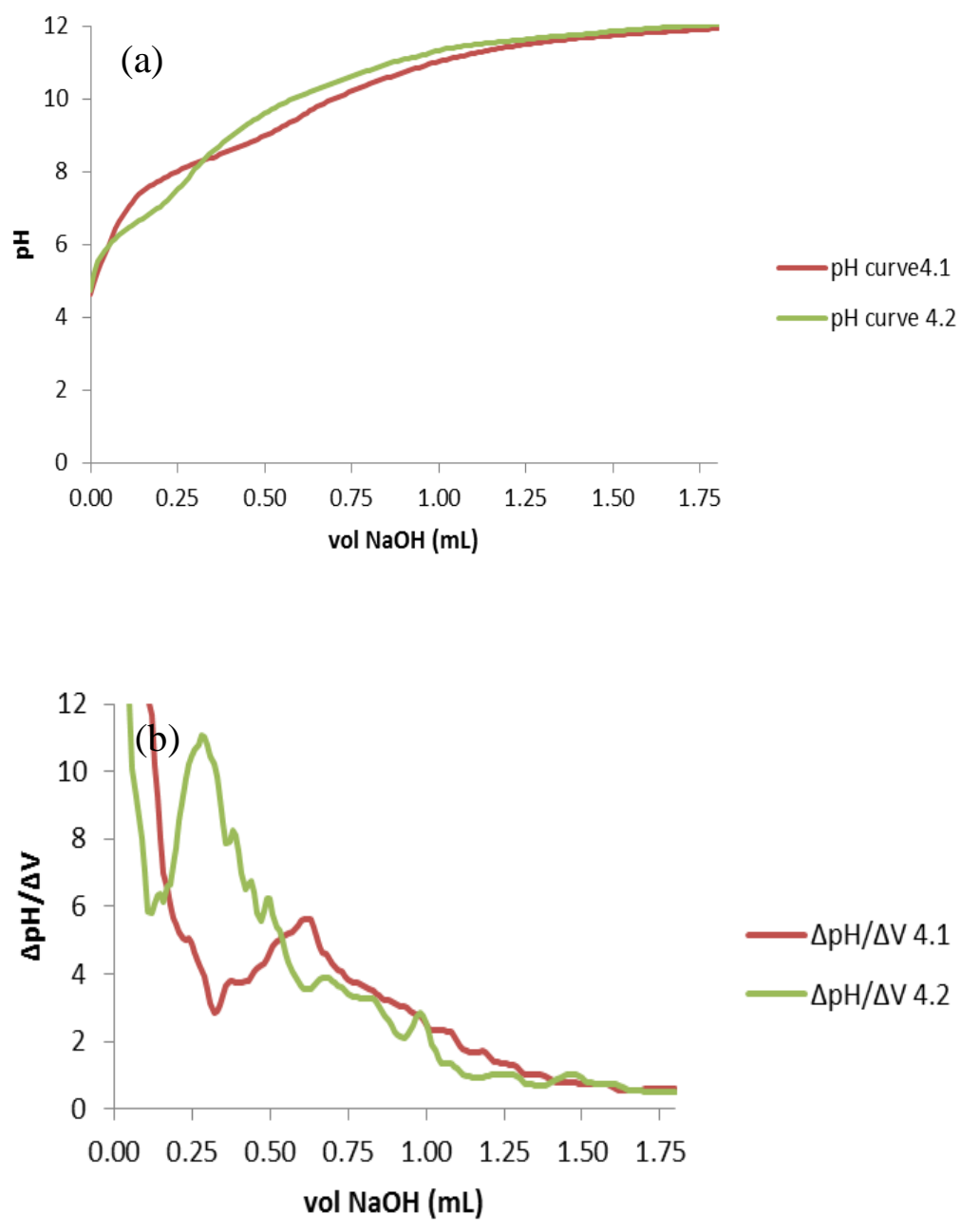

Figure 4-1. Average of triplicates of (a) $\mathrm{pH}$ titration curve and (b) derivatives of 4.1 and 4.2 

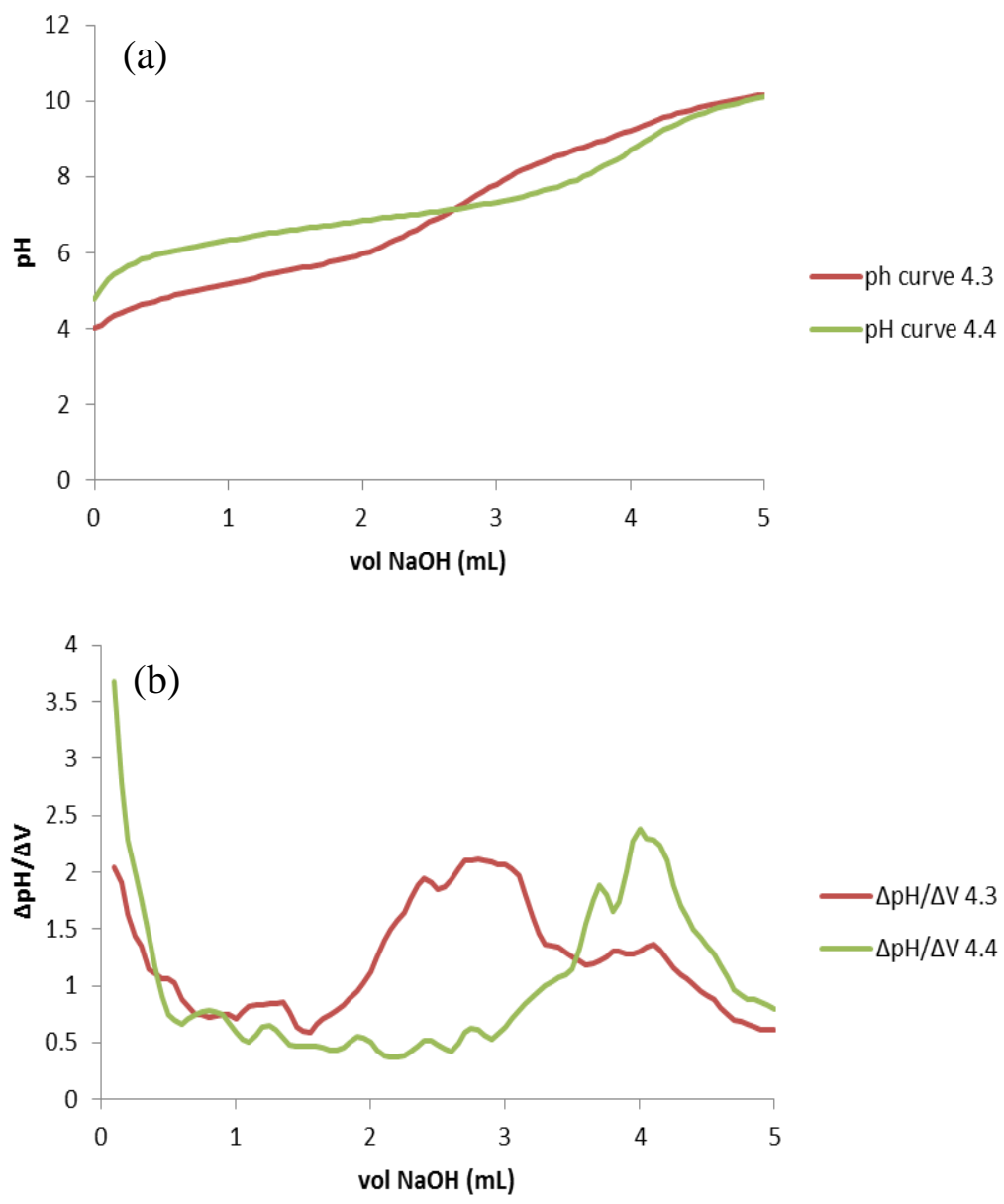

Figure 4-2. Average of triplicates of (a) $\mathrm{pH}$ titration curve and (b) derivatives of 4.3 and 4.4 

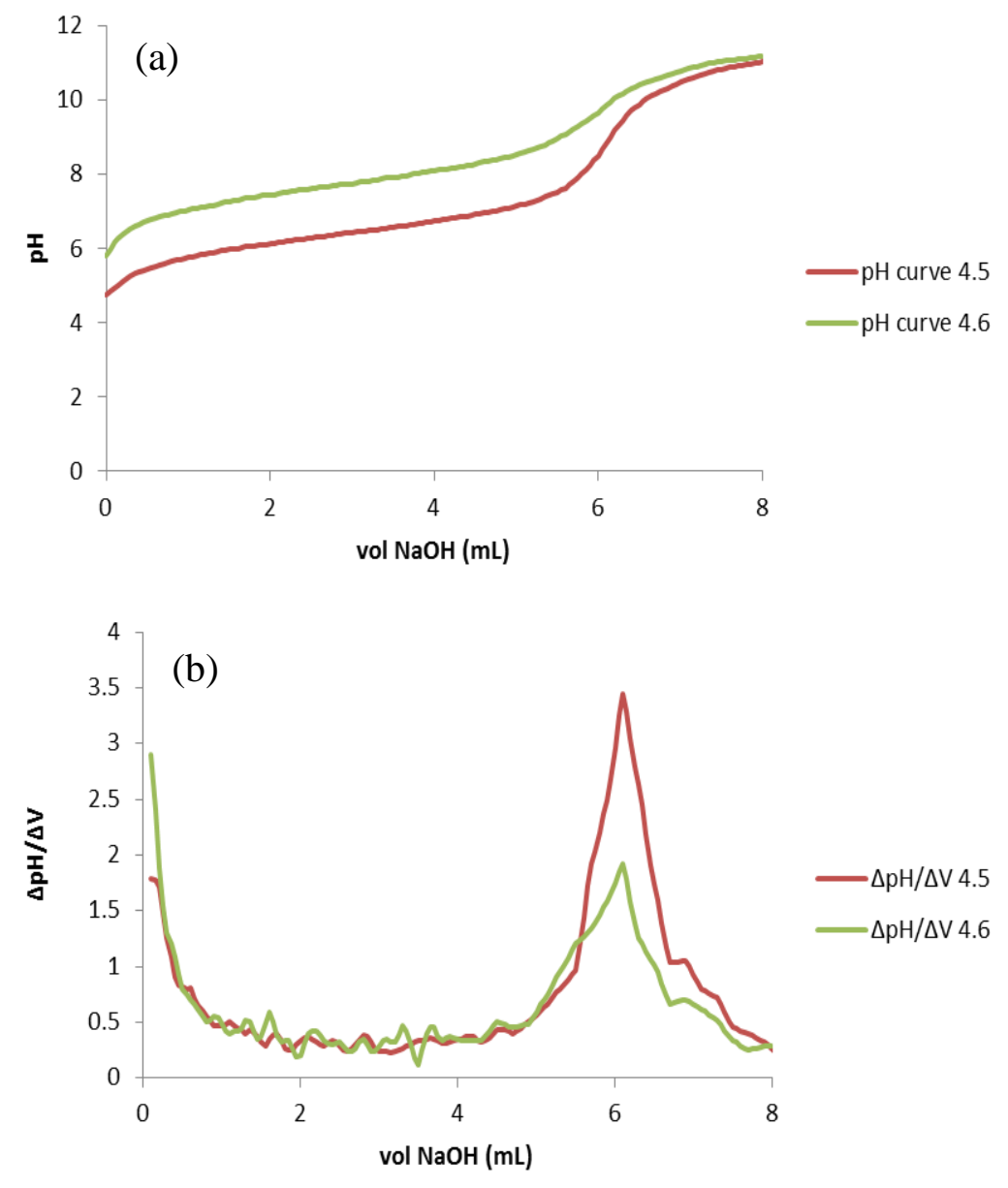

Figure 4-3. Average of triplicates of (a) $\mathrm{pH}$ titration curve and (b) derivatives of 4.5 and 4.6

From the $\mathrm{pH}$ titration of thiazolidine-4-carboxylic acids, derivatives $\mathbf{4 . 1}$ and $\mathbf{4 . 3}$ were found to be unstable in the aqueous solutions; however, thiazinane-4-carboxylic acids $\mathbf{4 . 2}$ and 4.4 appeared stable as shown in Figure 4-1 and Figure 4-2. Further, the stability of thiazolidines/thiazinane-4-carboxylic acids 4.1 and 4.2 were studied by ${ }^{1} \mathrm{HNMR}$ experiments. As shown in the , ${ }^{1}$ HNMR spectra of $\mathbf{4 . 1}$ and $\mathbf{4 . 2}$ were carried out in a mixture of $\mathrm{D}_{2} \mathrm{O}: \mathrm{H}_{2} \mathrm{O}$ (9:1). In the ${ }^{1} \mathrm{HNMR}$ of 4.1, the appearance of an aldehyde resonance at $9.88 \mathrm{ppm}$ shows that $\mathbf{4 . 1}$ decomposes and goes back to starting material i.e 
salicylaldehyde. On the other hand ${ }^{1}$ HNMR of $\mathbf{4 . 2}$ doesn't show any aldehyde proton peak and the presence of a methine resonance at $5.7 \mathrm{ppm}$ demonstrates the stability of this compound in aqueous medium, as shown in Figure 4.4. The instability of thiazolidine-4-carboxylic acids $\mathbf{4 . 1}$ and $\mathbf{4 . 3}$ in aqueous solutions has also been mentioned previously[130] (particularly in strongly basic and acidic medium [132]).

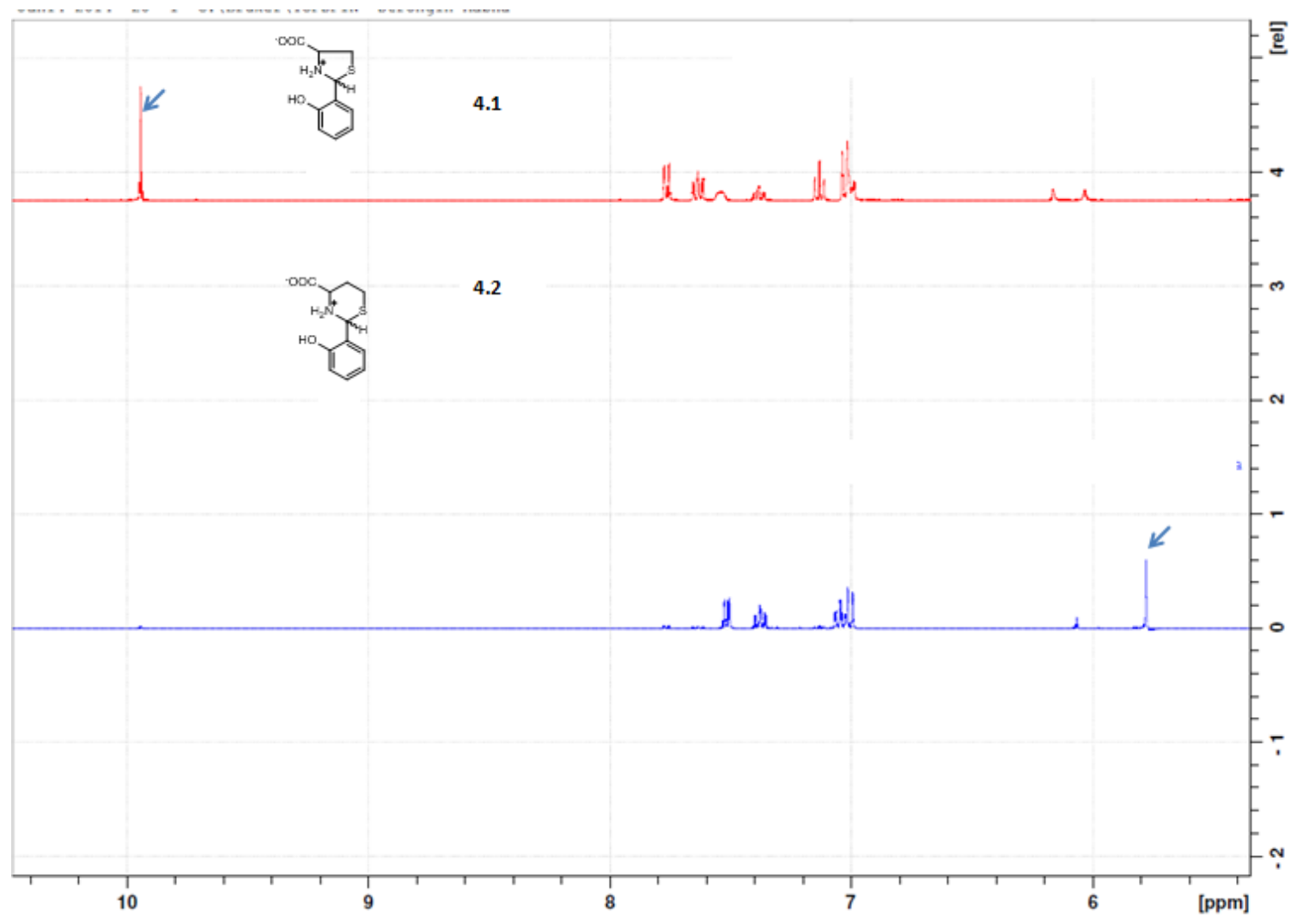

Figure 4-4. ${ }^{1} \mathrm{H}$ NMR of salicylaldehyde-Cys derived thiazolidines 4.1 and salicylaldehyde-Hcy derived thiazinanes 4.2 in $\mathrm{D}_{2} \mathrm{O}: \mathrm{H}_{2} \mathrm{O}$

Table 1 and $\mathrm{pH}$ titration curves (Figure 4-1, Figure 4-2 and Figure 4-3) show the higher basicity of the amine of the thiazinane-4-carboxylic acids than the amine of thiazolidine4-carboxylic acids at least by one unit. This difference in basicity results in the selectivity 
for Hcy over Cys. For the purpose of investigating the mechanism responsible for this unique selectivity, first the simpler monoaldehyde 3.1 was studied. The response of 3.1 towards Hcy and Cys over a range of $\mathrm{pH}$ values was investigated (Figure 4-5). From the $\mathrm{pH}$ dependent experiment, it is evident that, with a change in the $\mathrm{pH}$ values, the ratio of amine to ammonium ion in the Hcy/Cys derived heterocycles changes. That eventually affects the fluorescence response of 3.1 i.e. FMA (Figure 4-5). As the $\mathrm{pH}$ is lowered, the percent of ammonium ion species increases, consequently the fluorescence enhancement increases linearly as a result of PET inhibition by the ammonium ion. Due to the higher $\mathrm{p} K \mathrm{a}$ value of Hcy-derived thiazinane, there is a greater percent of ammonium ion species in the solution than the Cys-derived thiazolidines.

At the appropriate $\mathrm{pH}$, the ratio of ionization states of the amine moiety in thiazolidine 3.2a would be such that fluorescence quenching by the lone pair electrons is cancelled by PET inhibition from the ammonium species 3.2a' (Scheme 4-1). At this pH, the amine group in thiazinane $\mathbf{3 . 2 b}$ exists predominately as the more fluorescent ammonium 3.2 $\mathbf{b}^{\prime}$ (Scheme 4-1) because the $\mathrm{p} K_{\mathrm{a}}$ of $\mathbf{3 . 2} \mathbf{b}^{\prime}$ is greater than that of $\mathbf{3 . 2 \mathbf { a } ^ { \prime }}$. At $\mathrm{pH}$ 6.0, the reaction between 3.1 and Cys does not result in a change in fluorescence while reaction with Hcy results in fluorescence enhancement. 


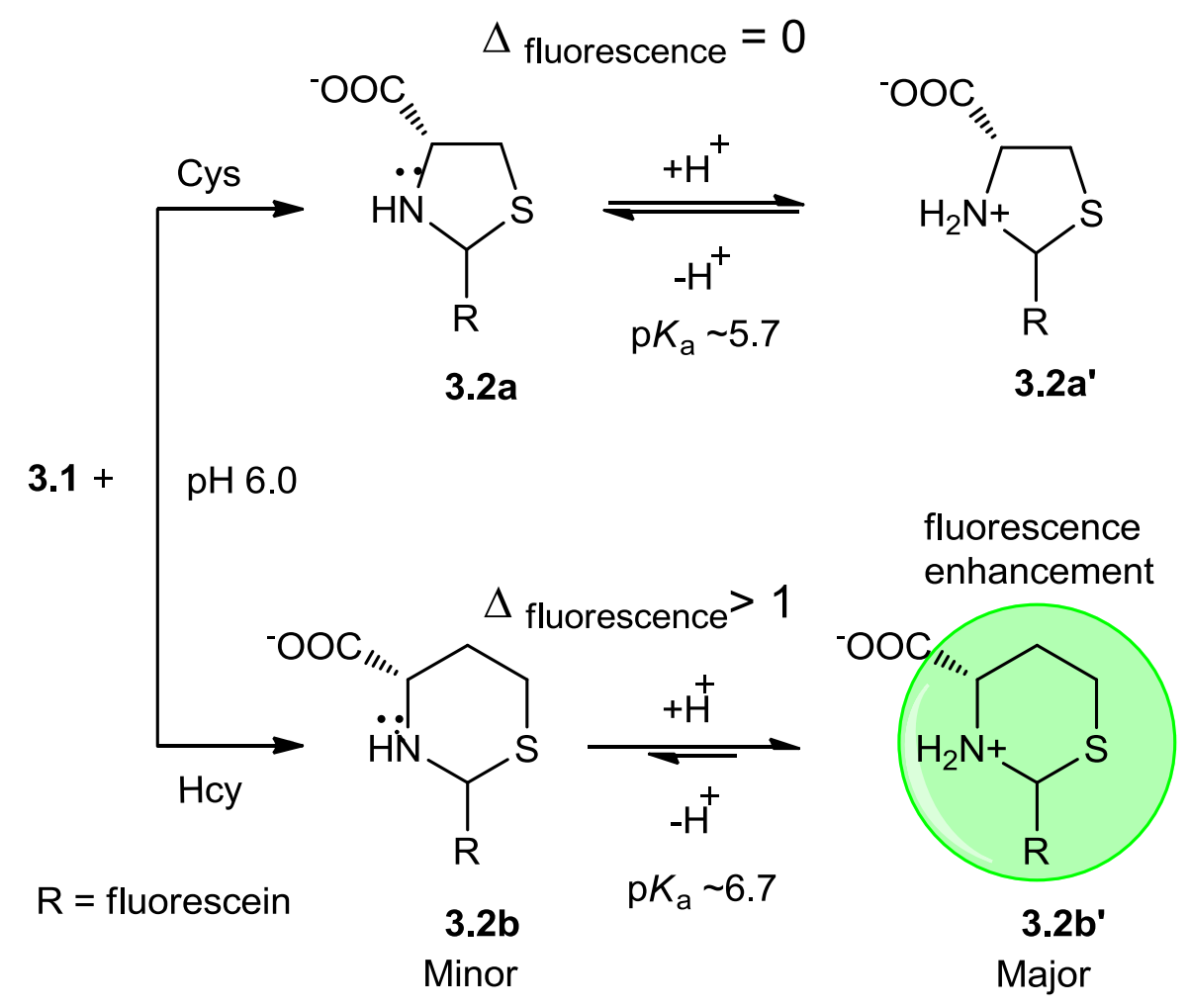

Scheme 4-1. Different ionization states of the the amine moieties in Cys- and Hcy-derived heterocycles at pH 6.0.

Thus $\mathrm{pH} 6.0$ is optimal for the detection of Hcy. Raising the $\mathrm{pH}$ increases the ratio of amine to ammonium which leads to quenching, while decreasing the $\mathrm{pH}$ leads to enhancement as clear from Figure 4-5. 

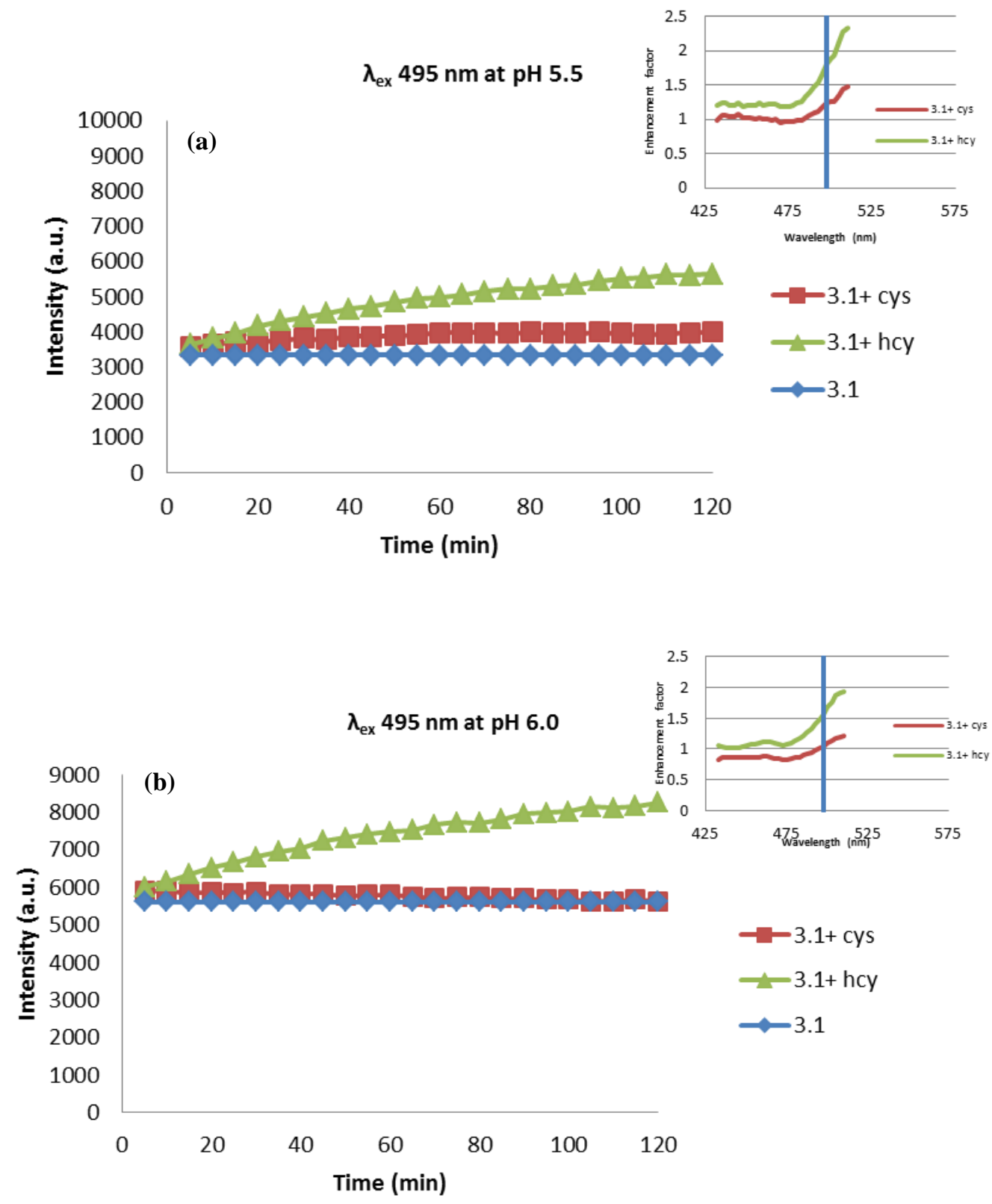

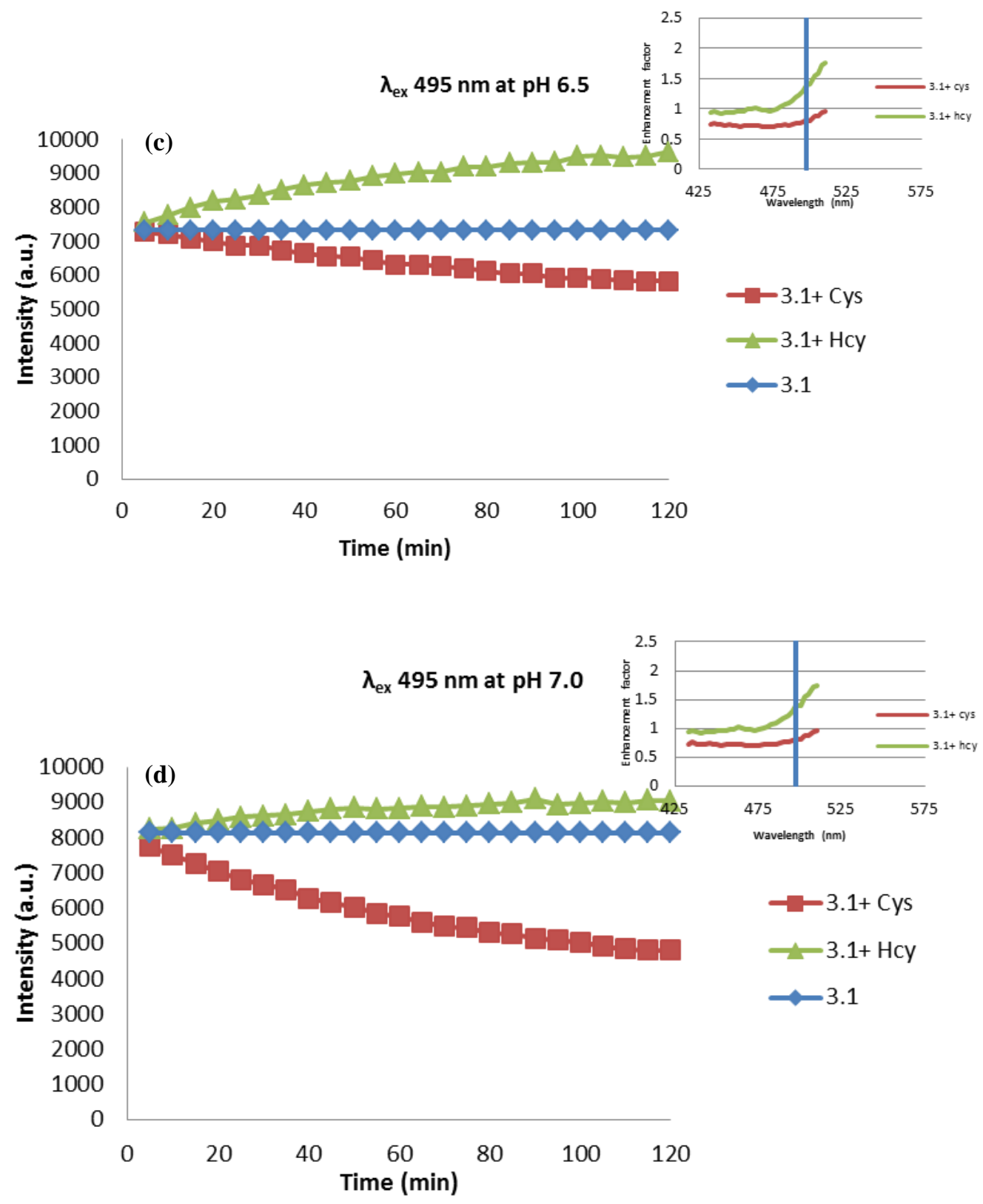

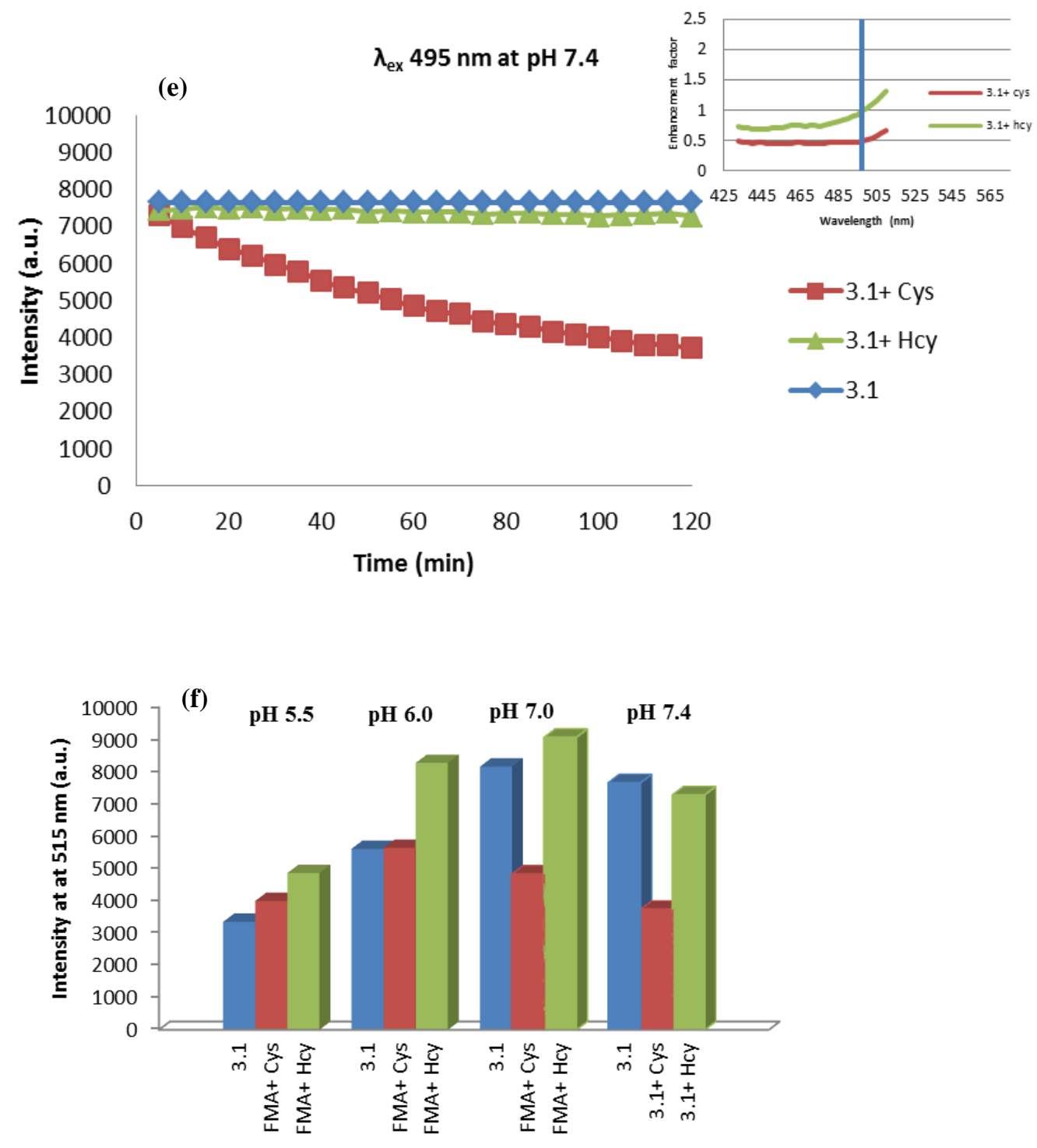

Figure 4-5. Time dependent fluorescence spectral changes and enhancement factor (inset) of fluorescence of 3.1 with Cys and Hcy,(a) pH 5.5, (b) pH 6.0, (c) $\mathrm{pH} 6.5$, (d) $\mathrm{pH} 7.0$, (e) $\mathrm{pH} 7.4$. (f) comparison of fluorescence response of $\mathbf{3 . 1}$ towards Cys and Hcy at different $\mathrm{pH}$.

Solutions are composed of $4 \mu \mathrm{M}$ of $\mathbf{3 . 1}$ with $1 \mathrm{mM}$ analyte in phosphate buffer (100 mM, pH 6.0):DMSO $99: 1$ at $20^{\circ} \mathrm{C}, \lambda_{\mathrm{ex}}=495 \mathrm{~nm}$ and $\lambda_{\mathrm{em}}=515 \mathrm{~nm}$. For Time dependent fluorescence spectral changes, $\lambda_{\mathrm{ex}}=495$ and $\lambda_{\mathrm{em}}=515$. Enhancement factor (EF) is the response of 3.1+ analyte divided by 1 . When EF $<\mathbf{3 . 1}$ quenching is observed, while when $\mathrm{EF}>\mathbf{3 . 1}$ enhancement is observed. The vertical line in the enhancement factor plots is the experimentally determined optimal excitation wavelength of $495 \mathrm{~nm}$. At pH 6.0 (b inset), excitation at 495 results in enhancement for Hcy but no enhancement for Cys in response to 3.1. 


\subsection{Conclusion}

In conclusion, a new approach for the selective detection of Hcy using fluorescein aldehyde-based probes has been developed. This method is based on intrinsic differences between the $\mathrm{p} K_{\mathrm{a}}$ of 5- and 6-membered thiazolidines and thiazinanes formed upon reaction with the aldehyde-bearing probes. At an optimum $\mathrm{pH}(6.0)$, amine of Hcyderived thiazinane is protonated to a greater extent ( $\mathrm{pKa}$ 6.7) causing PET inhibition and fluorescence enhancement. Due to lower $\mathrm{pKa}$ value $(\sim 5.7)$ of the protonated amine of the Cys-derived thiazolidine, at $\mathrm{pH}$ 6.0, amine and ammonium ion species were seen in equal quantity and therefore, no optical response was observed.

\subsection{Experimental section}

\subsubsection{Materials}

All chemicals were purchased from Sigma Aldrich and used as received. Ultrapure water obtained from a Milli-Q direct water purification system was used to prepare all aqueous solutions. All spectroscopic measurements were carried out in DMSO:buffer (1:99) solutions. All experiments were performed at room temperature.

\subsubsection{Methods}

${ }^{1} \mathrm{H}$ NMR and ${ }^{13} \mathrm{C}$ NMR were recorded on an ARX-400 Advance Bruker spectrometer performing at $400.13 \mathrm{MHz}\left({ }^{1} \mathrm{H}\right)$ and $100.61 \mathrm{MHz}\left({ }^{13} \mathrm{C}\right)$. All chemical shifts $(\delta)$ were reported in ppm relative to DMSO- $d_{6}\left(2.50 \mathrm{ppm},{ }^{1} \mathrm{H} ; 39.52 \mathrm{ppm},{ }^{13} \mathrm{C}\right)$ unless otherwise indicated. For the study of stability of $\mathbf{4 . 1}$ and $\mathbf{4 . 3}$ in aqueous media, ${ }^{1} \mathrm{H}$ NMR experiment was conducted in $\mathrm{H}_{2} \mathrm{O}: \mathrm{D}_{2} \mathrm{O}$ mixture (9:1) using DSS (sodium 2, 2-dimetyl-2- 
silapentane-5-sulfonate) as an internal standard $(\delta=0.000)$. ESI-HRMS (high resolution mass spectrometry) were recorded at the PSU Bioanalytical Mass Spectrometry Facility on a ThermoElectron LTQ-Orbitrap high resolution mass spectrometer. IR spectrum was obtained by Fourier transform infrared (FT-IR) spectroscopy operated on a Thermo Scientific Nicolet iS10 spectrophotometer equipped with a single-bounce diamond ATR attachment.

\subsubsection{Spectrophotometric measurement}

Fluorescence spectra were obtained on a Cary Eclipse fluorescence spectrophotometer (Agilent Technologies) with slit widths set at $5 \mathrm{~nm}$ for both excitation and emission, respectively. Fluorescence spectra were corrected for the wavelength dependent response of the R928 photomultiplier tube with the help of a manufacturer generated correction file.

\subsection{4 $\mathrm{p} K_{\mathrm{a}}$ measurements}

$\mathrm{pKa}$ values of the amine of 2-substituted thiazolidines/thiazinane $S$-4-carboxylic acids, 4.1, 4.3, 4.5, 4.2, 4.4, and 4.6 were obtained by the titration of their aqueous solutions with $0.01 \mathrm{M} \mathrm{NaOH}$ by following the procedure reported in the literature [126]. In the case of 4.1 and 4.2, 0.1 $\mathrm{M} \mathrm{NaOH}$ was used. The $\mathrm{pH}$ measurements were conducted using an Orion 410A pH meter, which was standardized with Scientific Products potassium hydrogen phthalate $\mathrm{pH} 4.00$ buffer, $\mathrm{BDH} \mathrm{pH} 7.00$ and Scientific Products boric acid/potassium hydroxide $\mathrm{pH} 10.00$ buffer. All pH titrations were conducted in triplicates and their average was reported. 


\subsubsection{Synthesis of compounds $4.1,4.2,4.3,4.4,4.5$ and 4.6}

Scheme 4-1. Synthetic route of $4.1,4.3$ and 4.5

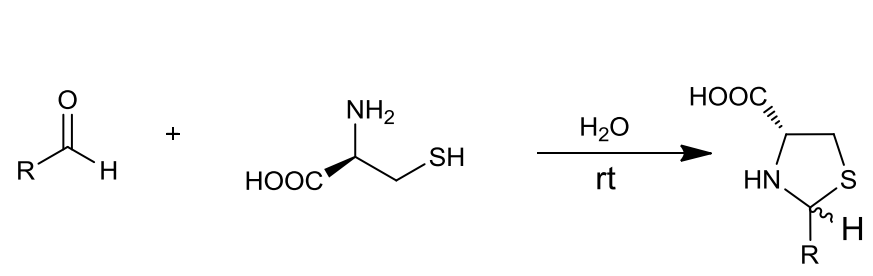<smiles></smiles>
4.6: $\mathrm{R}=\mathrm{H}$

Scheme 4-2. Synthetic route of 4.2, 4.4 and 4.6

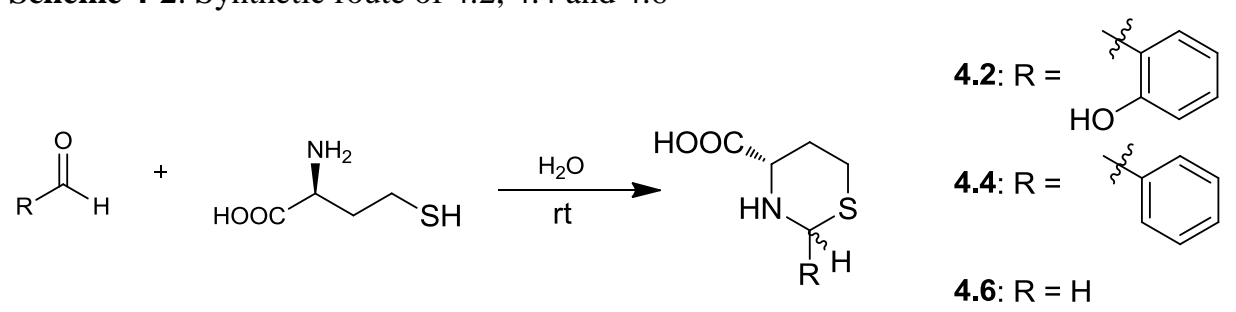

$(2 S, 4 R)$ and $(2 R, 4 R)-2-(2-h y d r o x y$ phenyl) thiazolidine-4-carboxylic acid (4.1)

L-Cys $(1.67 \mathrm{mmol})$ and salicylaldehyde $(1.67 \mathrm{mmol})$ were added in $5 \mathrm{~mL}$ of $\mathrm{DI}_{2} \mathrm{O}$. Reaction mixture was stirred at RT for $2 \mathrm{~h}$. The precipitates from the reaction mixture were filtered, washed with ice cold $\mathrm{H}_{2} \mathrm{O}$ and dried under vacuum to yield $\mathbf{4 . 1}$ as a mixture of distereoisomers, colourless solid $(307 \mathrm{mg}, 83 \%) ; v_{\max }($ film $) / \mathrm{cm}^{1} 1738 \quad(\mathrm{C}=\mathrm{O})$ ; M.P.180-181 C; ${ }^{1} \mathrm{H}$ NMR (400 MHz, DMSO) $\delta 7.49$ (m, 1H, Ar), 7. (m, 1H, Ar), 6.91 $(\mathrm{m}, 2 \mathrm{H}, \mathrm{Ar}), 5.84$ (s, 1H, Ar-CH), $5.65(\mathrm{~s}, 1 \mathrm{H}, \operatorname{Ar}-\mathrm{CH}), 4.26 \quad(\mathrm{~m}, 1 \mathrm{H}, \mathrm{NH}-$ $\mathrm{CH}), 3.82\left(\mathrm{~m}, 1 \mathrm{H}, \mathrm{S}-\mathrm{CH}_{2}\right), 3.11\left(\mathrm{~m}, 1 \mathrm{H}, \mathrm{S}-\mathrm{CH}_{2}\right) ;{ }^{13} \mathrm{C}$ NMR (101 MHz, DMSO) 172.9$172.4(\mathrm{C}=\mathrm{O}), 155.1,154.5,129.00,128.2,126.00,124.2,119.00,118.7,115.6,115.00$, 67.6, 66.6, 63.2 , 38.00, 37.00; Electrospray ionization (ESI) mass spectrometry (positive electron ionization) $m / z: 226.05602\left([\mathrm{M}+\mathrm{H}]^{+}, 100 \%\right)$, calculated for $\mathrm{C}_{10} \mathrm{H}_{11} \mathrm{NO}_{3} \mathrm{~S}, \mathrm{~m} / z$ $: 225.04596$. 


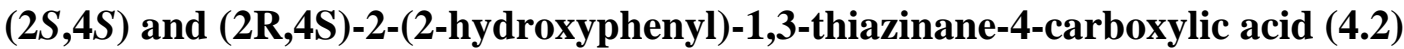

L-Hcy $(1.88 \mathrm{mmol})$ and salicylaldehyde $(1.88 \mathrm{mmol})$ were added in a mixture of $6 \mathrm{~mL}$ of distilled water and $0.25 \mathrm{~mL}$ of ethanol. Reaction mixture was stirred at RT for $48 \mathrm{hrs}$. The resultant precipitates were filtered, washed with ice cold $\mathrm{H}_{2} \mathrm{O}$ and dried under vacuum to yield $\mathbf{4 . 2}$ as a mixture of distereoisomers, colourless solid.

(322 mg, 82\%); $v_{\max }\left(\right.$ film) $/ \mathrm{cm}^{1} 1738(\mathrm{C}=\mathrm{O}) ;$ M.P.131-132 ${ }^{\circ} \mathrm{C} ; \quad{ }^{1} \mathrm{H}-\mathrm{NMR} \quad(400 \mathrm{MHz}$, DMSO- $\left.d_{6}\right) ; \delta$ (ppm): 7.35 (m, 1H, Ar), 7.15 (m, 1H, Ar), 6.87 (m, 2H, Ar), 5.43 (s, 1H, Ar- $\mathrm{CH}), 3.59(\mathrm{~m}, 1 \mathrm{H}, \mathrm{COCH}), 3.22\left(\mathrm{~m}, \mathrm{~Hz}, 1 \mathrm{H}, \mathrm{S}-\mathrm{CH}_{2}\right), 2.89\left(\mathrm{~m}, 1 \mathrm{H}, \mathrm{S}-\mathrm{CH}_{2}\right), 2.08(\mathrm{~m}$, $\left.1 \mathrm{H}, \mathrm{CH}-\mathrm{CH}_{2}\right), 1.50\left(\mathrm{~m}, 1 \mathrm{H}, \mathrm{CH}-\mathrm{CH}_{2}\right) ;{ }^{13} \mathrm{C}-\mathrm{NMR}(101 \mathrm{MHz}, \mathrm{DMSO}) 173.49(\mathrm{C}=\mathrm{O})$, $155.2,154.1,128.7,127.8,126.4,125.8,125.8,118.9,115.6,59.3,56.1,54.8,54.50,28.7$ 7, 27.9, 26.4, 25.3 ; Electrospray ionization (ESI) mass spectrometry (positive electron io nization) $m / z: 240.07182\left([\mathrm{M}+\mathrm{H}]^{+}, 100 \%\right)$, calculated for $\mathrm{C}_{11} \mathrm{H}_{13} \mathrm{NO}_{3} \mathrm{~S}, \mathrm{~m} / z, 239.06161$.

\section{$(2 S, 4 R)$ and $(2 R, 4 R)-2$-phenylthiazolidine-4-carboxylic acid (4.3)}

The synthesis of compound $\mathbf{4 . 3}$ has been reported in the literature [133]. Here an improved and simpler procedure has been used for its synthesis. Compound $\mathbf{4 . 3}$ was prepared according to the procedure described for 4.1. L-Cys $(1.67 \mathrm{mmol})$ and $(1.67$ mmol) benzaldehyde were added in $5 \mathrm{~mL}$ of $\mathrm{DI} \mathrm{H}_{2} \mathrm{O}$. Reaction mixture was stirred at $\mathrm{RT}$ for $2 \mathrm{~h}$. The precipitates from the reaction mixture were filtered, washed with ice cold $\mathrm{H}_{2} \mathrm{O}$ and dried under vacuum. Compound 4.3 was obtained as a mixture of distereoisome rs, colourless solid (488 mg, 99\%); $v_{\max }\left(\right.$ film) $/ \mathrm{cm}^{1} 1668(\mathrm{C}=\mathrm{O})$; M.P.175-176 ${ }^{\circ} \mathrm{C}$;

${ }^{1} \mathrm{HMNR}$ resonance for the major isomer are shown here, ${ }^{1} \mathrm{H}-\mathrm{NMR}$ (400 MHz, DMSO- 
$\left.d_{6}\right) \delta(\mathrm{ppm}) 7.4(\mathrm{~m}, 5 \mathrm{H}, \mathrm{Ar}) 5.67(\mathrm{~s}, 1 \mathrm{H}, \mathrm{Ar}-\mathrm{C} H), 4.24\left(\mathrm{q},{ }^{3} J_{\mathrm{H}-\mathrm{H}}=5 \mathrm{~Hz}, 1 \mathrm{H}, \mathrm{CO}-\mathrm{CH}\right)$, $3.80\left(\mathrm{~m}, 1 \mathrm{H}, \mathrm{CH}-\mathrm{CH}_{2}\right), 3.15\left(\mathrm{~m}, 1 \mathrm{H}, \mathrm{CH}-\mathrm{CH}_{2}\right) ;{ }^{13} \mathrm{CNMR}\left(101 \mathrm{MHz}, \mathrm{DMSO}-d_{6}\right) \quad$ (ppm) $172.95,172.19(\mathrm{C}=\mathrm{O}), 141.18,139.91,128.31,127.25,127.57,126.91,71.73,71.06,654$ 0, 64.85, 38.39, 37.94; Electrospray ionization (ESI) mass spectrometry (positive electro n ionization) $m / z: 210.06017\left([\mathrm{M}+\mathrm{H}]^{+}, 100 \%\right)$, calculated for $\mathrm{C}_{10} \mathrm{H}_{11} \mathrm{NO}_{2} \mathrm{~S}, \mathrm{~m} / z$ 209.05105.

\section{$(2 S, 4 S)$ and $(2 R, 4 S)$-2-phenyl-1,3-thiazinane-4-carboxylic acid (4.4)}

L-Hcy $(1.88 \mathrm{mmol})$ and benzaldehyde $(1.88 \mathrm{mmol})$ were added in $6 \mathrm{~mL}$ of DI water. Reaction mixture was stirred at RT for $72 \mathrm{hrs}$. The resultant precipitates were filtered washed with ice cold $\mathrm{H}_{2} \mathrm{O}$ and dried under vacuum. Compound 4.4 was obtained as a mixture of distereoisomers, colorless solid (273 mg, 65\%); $v_{\max }(\mathrm{film}) / \mathrm{cm}^{1} 1738(\mathrm{C}=\mathrm{O})$; M.P.177-178 C; ${ }^{\circ} \mathrm{H}-\mathrm{NMR}\left(400 \mathrm{MHz}, \mathrm{DMSO}-d_{6}\right) \delta(\mathrm{ppm}) 7.55$ (m, 5H, Ar), 5.27 (s, $1 \mathrm{H}$, $\operatorname{Ar}-\mathrm{CH}), 3.60\left(\mathrm{dd},{ }^{3} J_{\mathrm{H}-\mathrm{H}}=9,3 \mathrm{~Hz}, 1 \mathrm{H}, \mathrm{CO}-\mathrm{CH}\right), 3.28\left(\mathrm{td},{ }^{3} J_{\mathrm{H}-\mathrm{H}}=11,3 \mathrm{~Hz}\right.$ $\left.1 \mathrm{H}, \mathrm{S}-\mathrm{CH}_{2},\right), 2.91\left(\mathrm{dt},{ }^{3} \mathrm{~J}_{\mathrm{H}-\mathrm{H}}=10,4 \mathrm{~Hz}, 1 \mathrm{H}, \mathrm{S}-\mathrm{CH}_{2}\right), 2.10\left(\mathrm{dq},{ }^{3} J_{\mathrm{H}-\mathrm{H}}=7.0,3 \mathrm{~Hz}, 1 \mathrm{H}, \mathrm{CH}-\right.$ $\left.\mathrm{CH}_{2}\right), 1.51\left(\mathrm{qd},{ }^{3} J_{\mathrm{H}-\mathrm{H}}=9,4 \mathrm{~Hz}, 1 \mathrm{H}, \mathrm{CH}-\mathrm{CH}_{2}\right) ;{ }^{13} \mathrm{CNMR},\left(101 \mathrm{MHz}, \mathrm{DMSO} d_{6}\right) \delta(\mathrm{ppm})$ $173.5(\mathrm{C}=\mathrm{O}), 140.8,128.3$ (overlapping), 127.8, 126.5, 64.1, 59.2, 28.9, 27.7; Electrospr ay ionization (ESI) mass spectrometry (positive electron ionization) $\mathrm{m} / \mathrm{z}: 224.07707$ ([M+ $\mathrm{H}]^{+}, 100 \%$ ) calculated for $\mathrm{C}_{11} \mathrm{H}_{13} \mathrm{NO}_{2} \mathrm{~S}, \mathrm{~m} / 2$ 223.06670.

\section{(R)-thiazolidine-4-carboxylic acid (4.5)}

Synthesis of compound 4.5 has been reported in the literature, but for this work a modified and simpler procedure was used [126, 127]. Compound 4.5 was prepared by 
following the procedure described for 4.1. Formaldehyde was used as the starting material instead of salicylaldehyde. Compound 4.5 was obtained as a mixture of distereoi somers, colourless solid. $(152 \mathrm{mg}, 68.5 \%) . v_{\max }(\mathrm{film}) / \mathrm{cm}^{1} 1617$ (C=O); M.P.181-182 C; ${ }^{1} \mathrm{H}$ NMR (400 MHz, D2O) $\delta 4.52\left(\mathrm{~m}, 1 \mathrm{H} \mathrm{CO} \mathrm{CH}\right.$ and $\left.2 \mathrm{H}, \mathrm{NH}_{2} \mathrm{CH}_{2}\right), 3.47(\mathrm{~m}, 2 \mathrm{H}$, CH-CH$) .{ }^{13} \mathrm{CNMR}\left(101 \mathrm{MHz}, \mathrm{D}_{2} \mathrm{O}\right) \delta(\mathrm{ppm}) 171.9(\mathrm{C}=\mathrm{O}), 63.9,48.6,32.9$.Electrospray ionization (ESI) mass spectrometry (positive electron ionization) $\mathrm{m} / \mathrm{z}: 134.0252([\mathrm{M}+\mathrm{H}]$ ${ }^{+}, 100 \%$ ), calculated for $\mathrm{C}_{4} \mathrm{H}_{7} \mathrm{NO}_{2} \mathrm{~S}, m / z, 133.01975$.

\section{(S)-1,3-thiazinane-4-carboxylic acid (4.6)}

The synthesis of compound $\mathbf{4 . 6}$ has been reported in the literature [134]. Herein, a modified procedure to synthesize $\mathbf{4 . 6}$ has been used for the synthesis. L-Hcy (1.67 mmol) and formaldehyde $(1.67 \mathrm{mmol})$ were added in $6 \mathrm{~mL}$ of DI water. The reaction mixture was stirred at RT for $48 \mathrm{~h}$. The precipitates from the reaction mixture were filtered. Ethanol was added to the filtrate. The solution was kept at RT for $24 \mathrm{hrs}$. Transparent shiny crystal formation in the filtrate was observed. Crystals were filtered, washed with ice cold ethanol and dried under vacuum to yield $\mathbf{4 . 6}$ as colorless shiny crystals (135mg, $55 \%){ }^{1} \mathrm{H}$ NMR $\left(400 \mathrm{MHz}, \mathrm{D}_{2} \mathrm{O}\right) \delta 4.29\left(\mathrm{~m}, 2 \mathrm{H}, \mathrm{NH}-\mathrm{CH}_{2}-\mathrm{S}\right), 3.68\left(\mathrm{dd},{ }^{3} \mathrm{~J}_{\mathrm{H}-\mathrm{H}}=10,3 \mathrm{~Hz}\right.$, $1 \mathrm{H}, \mathrm{CO}-\mathrm{CH}), 3.05\left(\mathrm{~m}, 1 \mathrm{H}, \mathrm{S}-\mathrm{CH}_{2}-\mathrm{CH}_{2}\right), 2.89\left(\mathrm{~m}, 1 \mathrm{H}, \mathrm{S}-\mathrm{CH}_{2}-\mathrm{CH}_{2}\right), 2.56 \quad(\mathrm{~m}, \quad 1 \mathrm{H}, \quad \mathrm{CH}-$ $\left.\mathrm{CH}_{2}\right), 2.04\left(\mathrm{qd},{ }^{3} J_{\mathrm{H}-\mathrm{H}}=10,3 \mathrm{~Hz}, 1 \mathrm{H}, \mathrm{CHCH}_{2}\right) ;{ }^{13} \mathrm{CNMR}\left(101 \mathrm{MHZ}, \mathrm{D}_{2} \mathrm{O}\right) 173.3$ $(\mathrm{C}=\mathrm{O}), 59.4,45.1,28.1,26.0$; Electrospray ionization (ESI) mass spectrometry (positive electron ionization) $\mathrm{m} / \mathrm{z}: 148.04422\left([\mathrm{M}+\mathrm{H}]^{+}, 100 \%\right)$, calculated for $\mathrm{C}_{5} \mathrm{H}_{9} \mathrm{NO}_{2} \mathrm{~S}, \mathrm{~m} / \mathrm{z}$ 147.03540. 


\section{CHAPTER 5 SYNTHESIS OF FLUORESCEIN TRI ALDEHDYE AND ITS APPLICATION IN THE DETECTION OF HCY}

\subsection{Introduction}

In previous chapters, optimum conditions for the detection of Hcy using 3.1 (FMA) and 3.3 (FDA) have been discussed. The mechanism behind this selectivity is based on differences in the basicity of Hcy and Cys derived heterocycles was also described. Based on this mechanism, the next goal was to design a more sensitive aldehyde-bearing fluorophore that can detect Hcy at its physiological levels in biological media. Compounds 3.1 and 3.3 didn't exhibit an sufficiently low detection limit for an appreciable response from Hcy at concentrations below $\sim 50 \mu \mathrm{M}$ in plasma (Figure 3-17). To achieve this goal fluorophore reactivity was increased by adding another reactive moiety and rendering the fluorophore ring more electrophilic. To implement this plan, it was decided to increase the number of aldehyde moieties on the fluorescein scaffold. As noticed before, the sensitivity of $\mathbf{3 . 3}$ was found to be twice of the sensitivity of $\mathbf{3 . 1}$. Therefore it seemed reasonable that to improve the sensitivity of fluorophore, the number of aldehyde moieties should be increased. Based on this concept, fluorophore, fluorescein trialdehyde was designed.

\subsection{Duff reaction and its application}

Several methods have been reported in the literature for the formylation of aromatic compounds [135, 136]. For example, the Riemer Tiemann reaction [137], Gatterman reaction, Gattermann-Koch reaction [138], Vilsmeier-Haack reaction [139], and Duff 
reaction [140] are well known name reactions for the formylation of aromatic compounds. The Riemer Tiemann reaction was applied towards the synthesis of $\mathbf{3 . 1}$ and 3.2. Both were obtained from the same reaction via a separation, unlike the long synthesis reported by Lippard et al. [141] where at first, 4,5-dimethyl fluorescein was synthesized from the reaction of 2-methyl resorcinol and phthalic anhydride, later hydroxyl groups of 4,5-dimethyl fluorescein were protected with the help of benzoic anhydride. In the next step, Bromination of 4,5-dimethyl groups was carried out over a period of more than 7 days. Finally, bromo-methyl groups were converted to aldehyde groups by Swern oxidation to yield 3.2 with $36 \%$ yield [141].

To synthesize fluorescein trialdehyde, a new synthetic strategy was used for the diformylation of the phenolic ring. Previously, ortho (to a hydroxyl) diformylation using The Duff reaction had been published [142] by Grylo et al. using a diverse range of phenols as shown in Scheme 5-1. The Duff reaction also has some advantages including relative simplicity and inexpensive, stable and relatively nontoxic reagents.

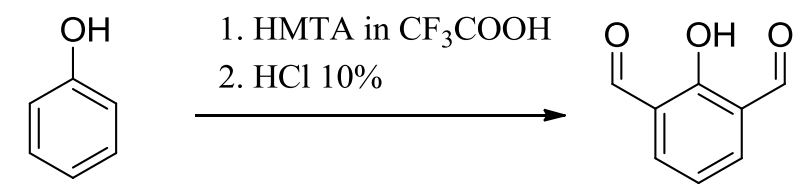

Scheme 5-1. Duff formylation of phenol

In 1934, An English scientist James Cooper Duff found that the reaction of hexamethylenetetramine with phenolic compound in acetic acid yielded a Schiff base, which upon hydrolysis in acidic medium, resulted in the ortho formyl product $[143,144]$. 
Since then The Duff reaction has been utilized for the direct diformylation of aromatic compounds in the synthesis of various drugs [145, 146], sensors [147, 148], and receptors [149] with some modifications. In the present work, the main focus was on the first application of The Duff reaction for the formylation of fluorescein to produce fluorescein trialdehyde. Attempts for the Synthesis of fluorescein tetra aldehyde were also made.

\subsection{Result and discussion}

Under The Duff reaction conditions, formylation of commercially available fluorescein was carried out by the reaction of fluorescein with hexamethylenetetramine in trifluoroacetic acid under an inert atmosphere followed by acid hydrolysis to afford $\mathbf{5 . 1}$ i.e. fluorescein tri aldehyde (FTA) in a single step (Scheme 5.2)

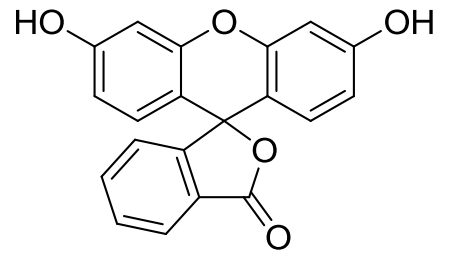

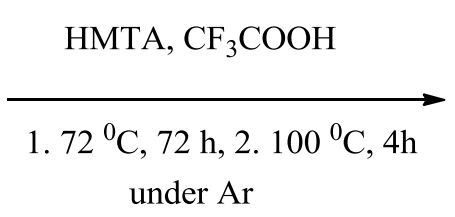

3. $10 \% \mathrm{HCl}, 100{ }^{\circ} \mathrm{C}, 1 \mathrm{~h}$

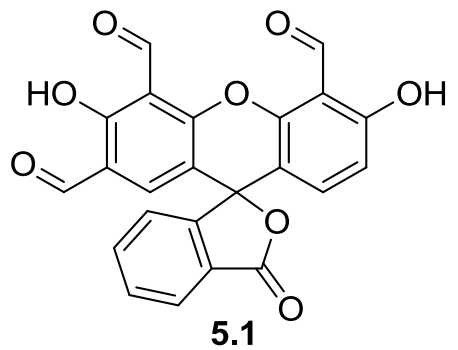

$2 \%$

Scheme 5-2. Synthesis of fluorescein tri aldehyde (5.1)

Fluorescein tri aldehyde was obtained in $2 \%$ yield. The reason for the small yield was that, with the insertion of electron withdrawing aldehyde group in the fluorescein scaffold the nucleophilicity of the fluorophore decreases. Therefore the reactivity of the molecule towards electrophilic aromatic substitution for further formylation also reduces. As a result small yield of $\mathbf{5 . 1}$ was obtained and fluorescein tetra aldehyde could not be synthesized. Synthesis of 5.1, under The Duff reaction was attempted several times by 
changing the number of equivalents of reactants and duration of the reaction. It was found that the ratio of fluorescein to HMTA (1:10 eqv) and duration of reaction i.e. $72 \mathrm{hrs}$ were the best parameters to synthesize 5.1.

Before the application of The Duff reaction, for the synthesis of fluorescein tri and tetra aldehyde, different reaction routes were also implemented. Formylation of tetra bromo fluorescein in THF with butyl lithium and DMF under various reaction conditions did not yield the desired product. formylation of tetra bromo fluorescein by isopropyl bromide and DMF under different reaction conditions did not produce 5.1 either. Later, hydroxyl groups of tetra bromofluorescein were protected by benzoyl chloride . OHprotected tetra bromofluorescein was subjected to formylation by isopropyl bromide and DMF. However this reaction did not succeed to give desired product. Finally, phosphoryl chloride and DMF were used for the formylation of fluorescein under a number of different reaction conditions but none of them could produce formylated product.

\section{Study of response of Hey and Cys towards 5.1}

To examine the sensitivity of this newly synthesized fluorophore 5.1, the reaction of Hcy and Cys with 5.1 was studied at pH 6.0 (Figure 5-1). As expected, in response to Hcy, a high fluorescence enhancement ( $\sim 7$ fold) was observed, whereas Cys didn’t show any appreciable change in the fluorescence. Later, the magnitude of the response towards Hcy with 3.1 and 3.3 (i.e. FMA and FDA) was also compared. The magnitude of fluorescence response of $\mathbf{5 . 1}$ towards Hcy was found to be more than higher than that of $\mathbf{3 . 1}$ and $\mathbf{3 . 3}$ (Figure 5-2). 

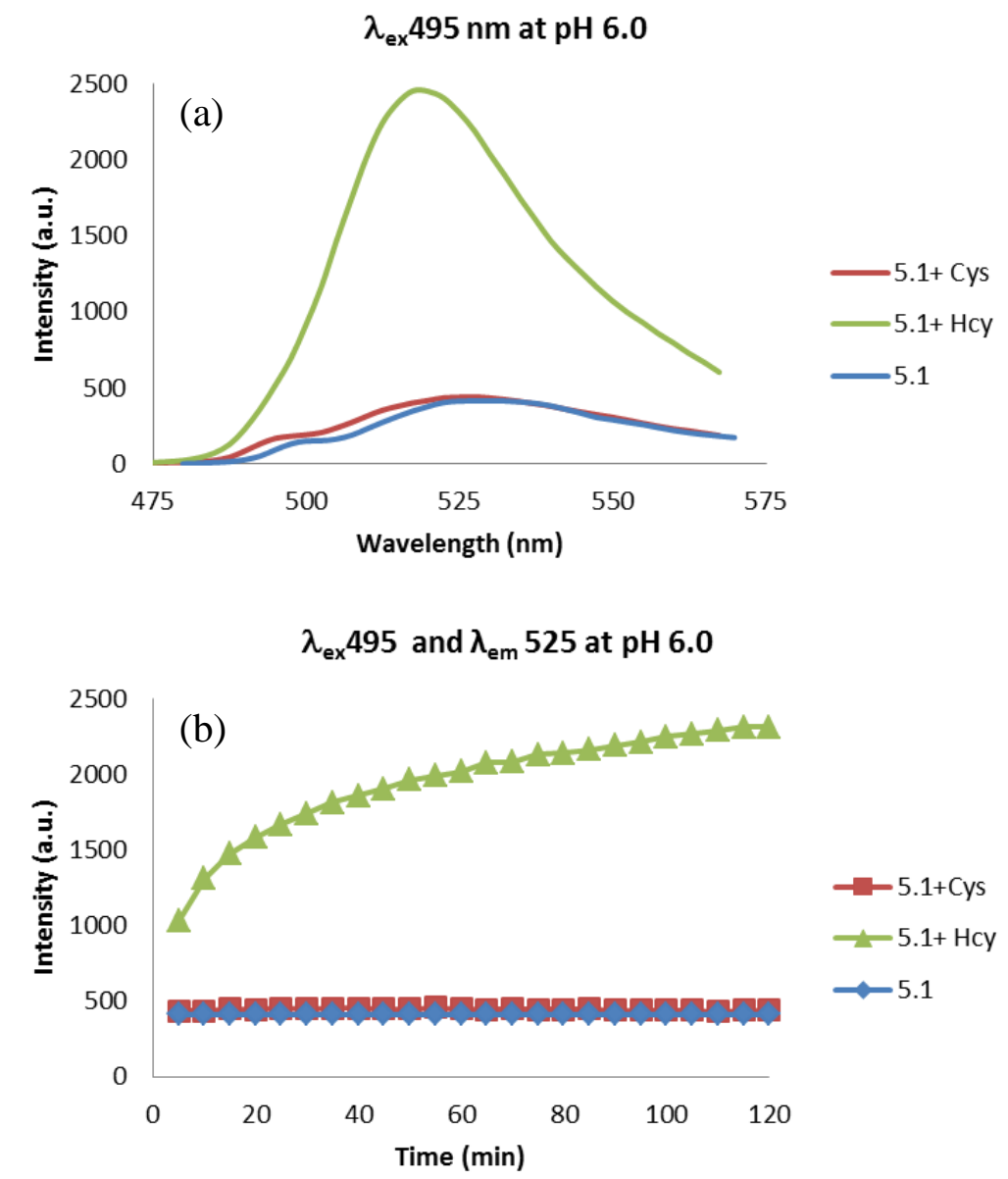

Figure 5-1. Optical sensing behavior of 5.1 towards Hcy and Cys at $\mathrm{pH}$ 6.0.

(a) Fluorescence spectral changes of $\mathbf{5 . 1}$ with Hcy and Cys after 2h. (b) Time dependent fluorescence spectral changes of $\mathbf{5 . 1}$ with Hcy and Cys. Solutions are composed of $4 \mu \mathrm{M}$ of $\mathbf{5 . 1}$ with $1 \mathrm{mM}$ of analyte in phosphate buffer (100 mM, pH 6.0) DMSO 99:1 at $20^{\circ} \mathrm{C}, \lambda_{\mathrm{ex}}=495 \mathrm{~nm}$ and $\lambda_{\mathrm{em}}=595 \mathrm{~nm}$. 

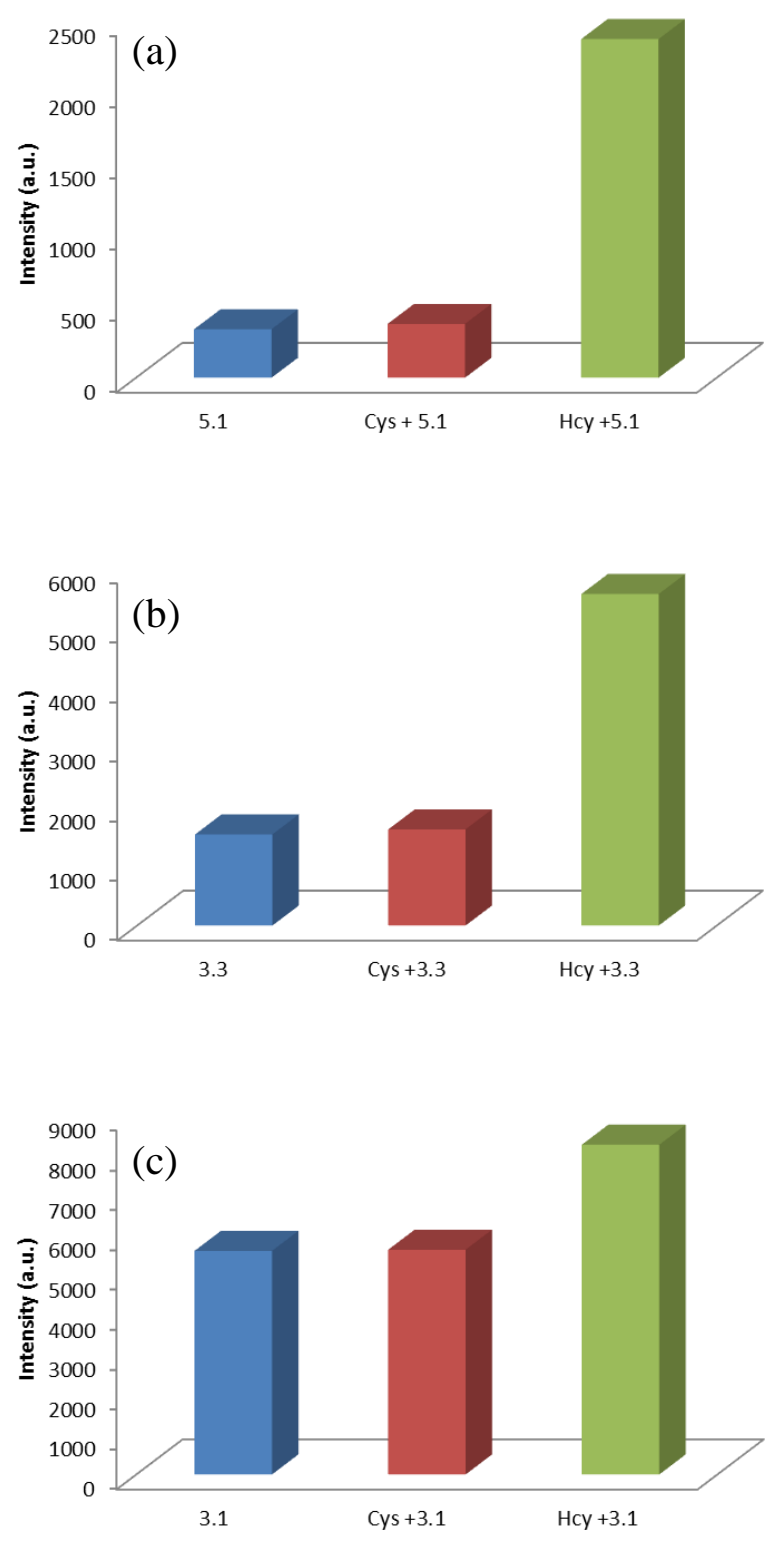

Figure 5-2. Comparison of magnitude of response of Hcy towards (a) 5.1, (b) 3.3, (c) 3.1.

Solutions are composed of $4 \mu \mathrm{M}$ of probe with $1 \mathrm{mM}$ of analyte in phosphate buffer (100 mM, pH 6.0) DMSO 99:1 at $20^{\circ} \mathrm{C}, \lambda_{\mathrm{ex}}=495 \mathrm{~nm}$ and $\lambda_{\mathrm{em}}=515 \mathrm{~nm}$

After investigating the relative magnitude of the signal in the detection of Hcy with 5.1, its behavior towards Hcy and Cys was evaluated at physiologically relevant levels. On adding Hcy $(15 \mu \mathrm{M})$ in the presence of Cys $(250 \mu \mathrm{M})$ to a solution of 5.1, an 
enhancement in the fluorescence $(\sim 1.5$ fold $)$ was obtained. Cys at $250 \mu \mathrm{M}$ does not produce a change in the optical response of 5.1., as shown in the Figure 5-3.
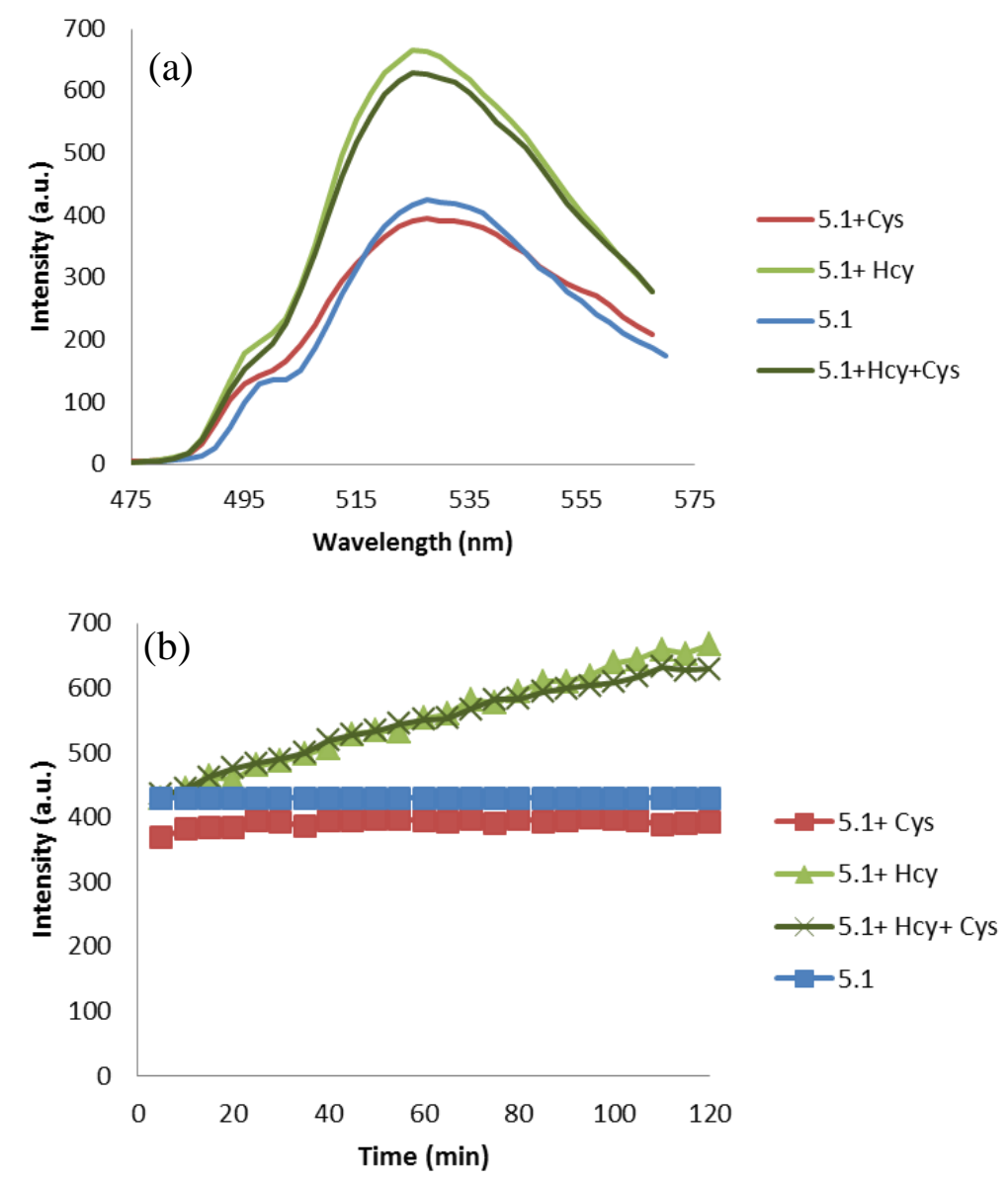

Figure 5-3. Optical sensing behavior of 5.1 towards Cys and Hcy at their biological concentrations at $\mathrm{pH}$ 6.0 .

(a) Fluorescence spectra of $\mathbf{5 . 1}$ with Cys and Hcy after two hours. Solutions are composed of $30 \mu \mathrm{M}$ of $\mathbf{3 . 3}$ with $250 \mu \mathrm{M}$ of Cys and $15 \mu \mathrm{M}$ of Hcy in phosphate buffer (100 mM, pH 6.0):DMSO 99:1 at $20^{\circ} \mathrm{C}, \lambda_{\mathrm{ex}}=$ $494 \mathrm{~nm}$ and $\lambda_{\mathrm{em}}=525 \mathrm{~nm}$.

The response to Hcy was also investigated in the presence of various amino acids (Gly, Ala, Met, Gln, Glu, and Asp) along with Cys. Figure 5-4 shows that Hcy produces a distinct response in the presence of these related amino acid analytes. Other amino acids 
and Cys produced a very small quenching in the fluorescence of 5.1. Whereas, Hcy produced almost 3 folds enhancement in the fluorescence. That shows the specificity of Hcy over other amino acids and Cys towards 5.1. Glutathione (GSH) produced no significant change in the fluorescence signal (Figure 5-4). Overall, these results demonstrated that $\mathbf{5 . 1}$ exhibited a distinct selectivity for Hcy.

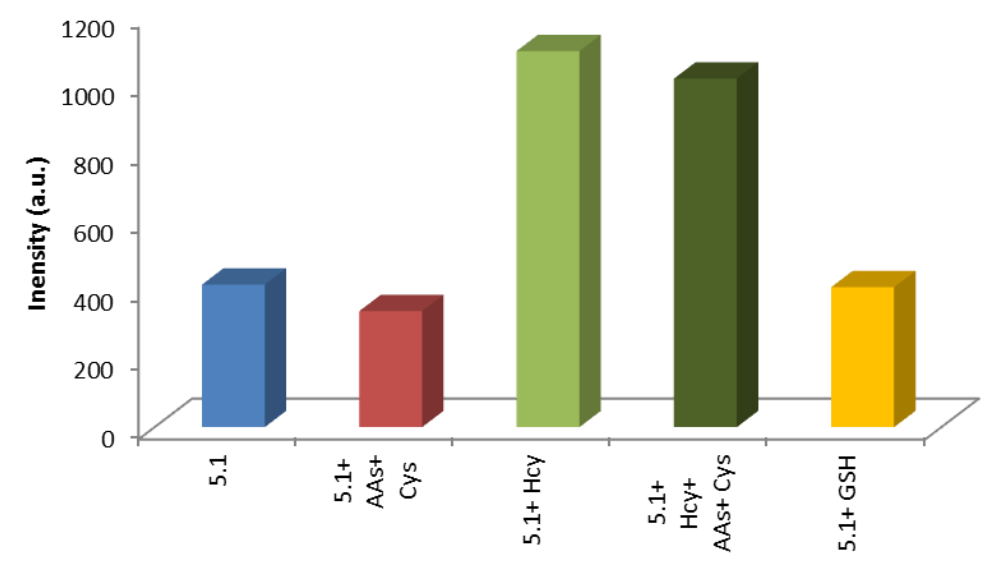

Figure 5-4. Optical sensing behavior of $\mathbf{5 . 1}$ towards Hcy and Cys with and without amino acids and GSH at $\mathrm{pH} 6.0$

fluorescence emission of 1 with Cys and Hcy in presence and absence of amino acids and GSH after $2 \mathrm{~h}$. Solutions are composed of $4 \mu \mathrm{M}$ of $\mathbf{5 . 1}$ with $50 \mu \mathrm{M}$ of each analyte in phosphate buffer (100 mM, pH 6.0):DMSO 99:1 at $20^{\circ} \mathrm{C}, \lambda_{\mathrm{ex}}=495 \mathrm{~nm}$ 

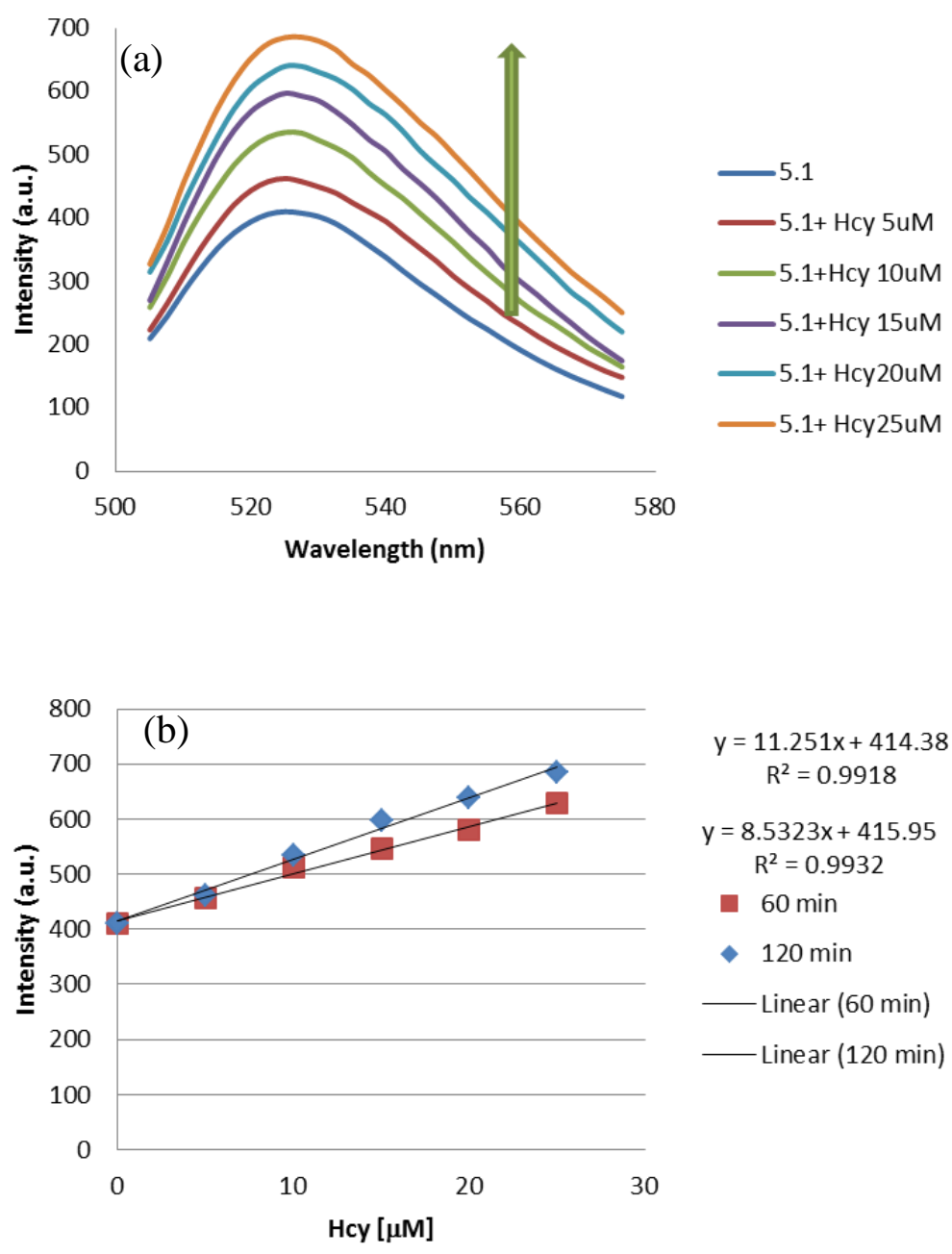

Figure 5-5. (a) and (b)- Spectral response of $\mathbf{5 . 1}$ towards increasing levels of Hcy in phosphate buffer (100 $\mathrm{mM}, \mathrm{pH} 6.0$ at $2 \mathrm{~h}$ ).

Solutions are composed of $4 \mu \mathrm{M}$ of $\mathbf{5 . 1}$ with $0-25 \mu \mathrm{M}$ of Hcy in phosphate buffer (100 mM, pH 6.0):DMSO 99:1 at $20{ }^{\circ} \mathrm{C}, \lambda_{\mathrm{ex}}=495 \mathrm{~nm}$ and $\lambda_{\mathrm{ex}}=525 \mathrm{~nm}$

A concentration dependent experiment was also performed which indicated that the fluorescence response of $\mathbf{5 . 1}$ increased linearly with a limit of detection at $1.88 \mu \mathrm{M}$ as shown in Figure 5-5. LOD was calculated with the help of standard error, slope and intercept from the calibration curve graph. Standard error was obtained from the regression analysis in Microsoft Excel 2010. 
Further, at the physiological levels of thiols, the response of $\mathbf{5 . 1}$ towards Hcy and Cys was investigated in deproteinized plasma. Results show that probe $\mathbf{5 . 1}$ was also capable of detecting Hcy in biological media. To measure the known amount of Hcy, deproteinized plasma was spiked with the known concentration of Hcy. In deproteinized plasma, addition of Hcy to a solution of $\mathbf{5 . 1}$ enhances the fluorescence. In contrast, no significant change in the emission intensity was observed upon addition of Cys. (Figure 5-6) With an increase in the concentration of Hcy, increase in the fluorescence emission was also observed in deproteinized plasma, as shown in Figure 5-7.

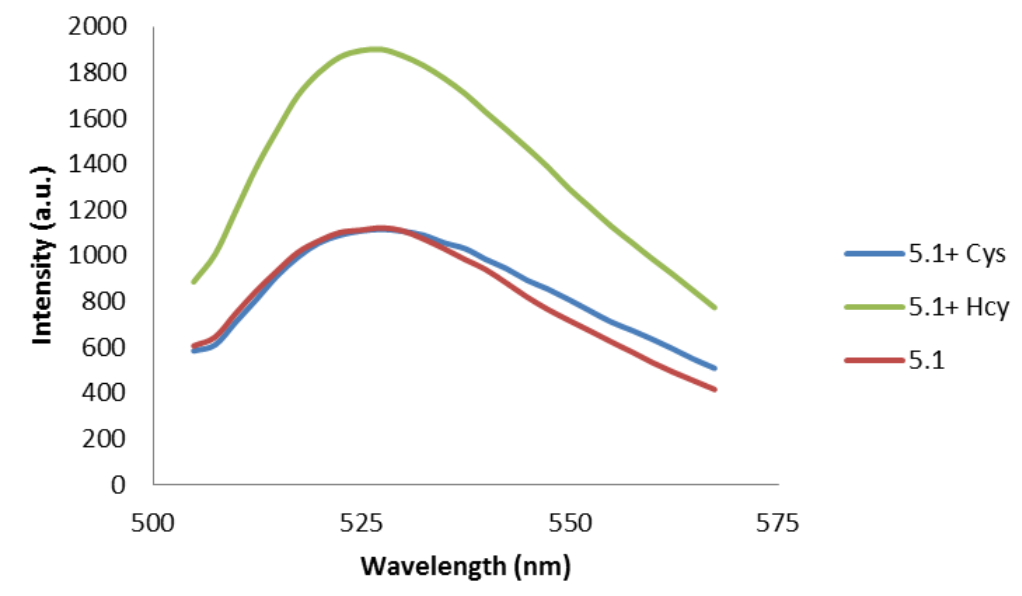

Figure 5-6. Optical sensing behavior of $\mathbf{5 . 1}$ towards Cys and Hcy in deproteinized plasma at pH 6.0.after $2 \mathrm{~h}$.

Solutions are composed of $20 \mu \mathrm{M}$ of 5.1 with $250 \mu \mathrm{M}$ of Cys and $15 \mu \mathrm{M}$ of Hcy in phosphate buffer (100 $\mathrm{mM}, \mathrm{pH}$ 6.0):DMSO 99:1 at $20{ }^{\circ} \mathrm{C}, \lambda_{\mathrm{ex}}=495 \mathrm{~nm}$ 


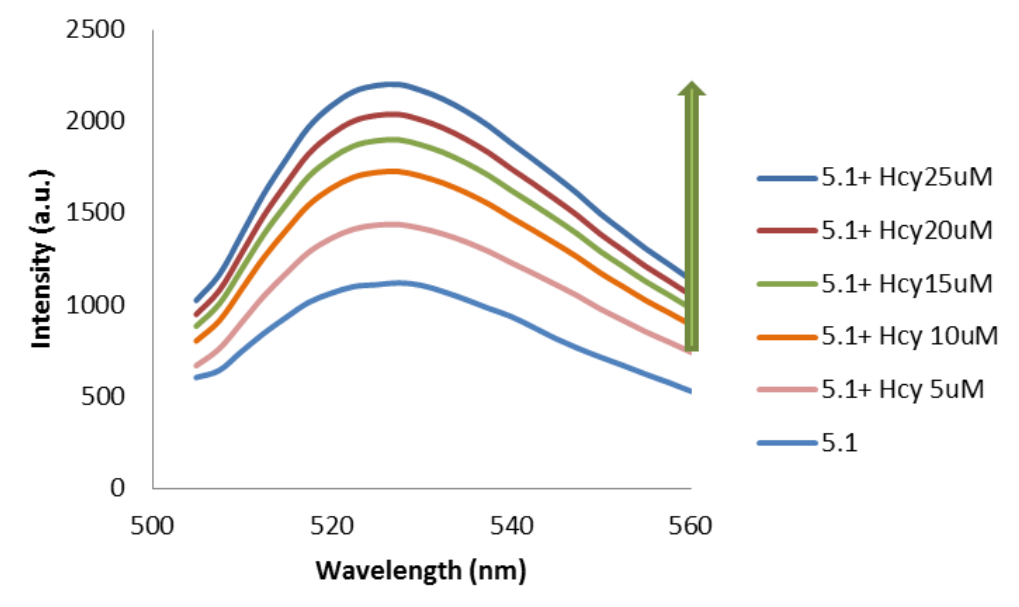

Figure 5-7. Optical sensing behavior of $\mathbf{5 . 1}$ towards Cys and Hcy in deproteinized plasma at $\mathrm{pH}$ 6.0.after $2 \mathrm{~h}$.

Solutions are composed of $20 \mu \mathrm{M}$ of $\mathbf{5 . 1}$ with 5,10, 15, 20 and $25 \mu \mathrm{M}$ of Hcy in phosphate buffer $(100 \mathrm{mM}$, pH 6.0):DMSO 99:1 at $20{ }^{\circ} \mathrm{C}, \lambda_{\text {ex }}=495 \mathrm{~nm}$

As previously explained fluorescence enhancement of $\mathbf{5 . 1}$ by the addition of Hcy was due to the formation of thiazinane-4-carboxylic acid, and subsequent protonation of the amine, producing an ammnonium species at $\mathrm{pH} 6.0$ to inhibit PET. To confirm the PET inhibition based response of Hcy to 5.1, the reaction of Hcy and Cys was studied at lower $\mathrm{pH}(5.0)$, intermediate $\mathrm{pH}$ (6.0) and higher $\mathrm{pH}$ (9.5). In Figure 5-8, it is evident that at lower $\mathrm{pH}(5.0)$, the thiazinane and thiazolidines are in the ammonium form, since fluorescent enhancement occurs. Conversely, at $\mathrm{pH} 6.0$, the ammonium of the thiazinane is the predominant species in contrast to Cys-derived thiazolidine, wherein the ammonium and amine species exist in nearly equal amounts. At higher $\mathrm{pH}(9.5)$, the amine of both heterocycles have their lone pairs available for PET quenching. 

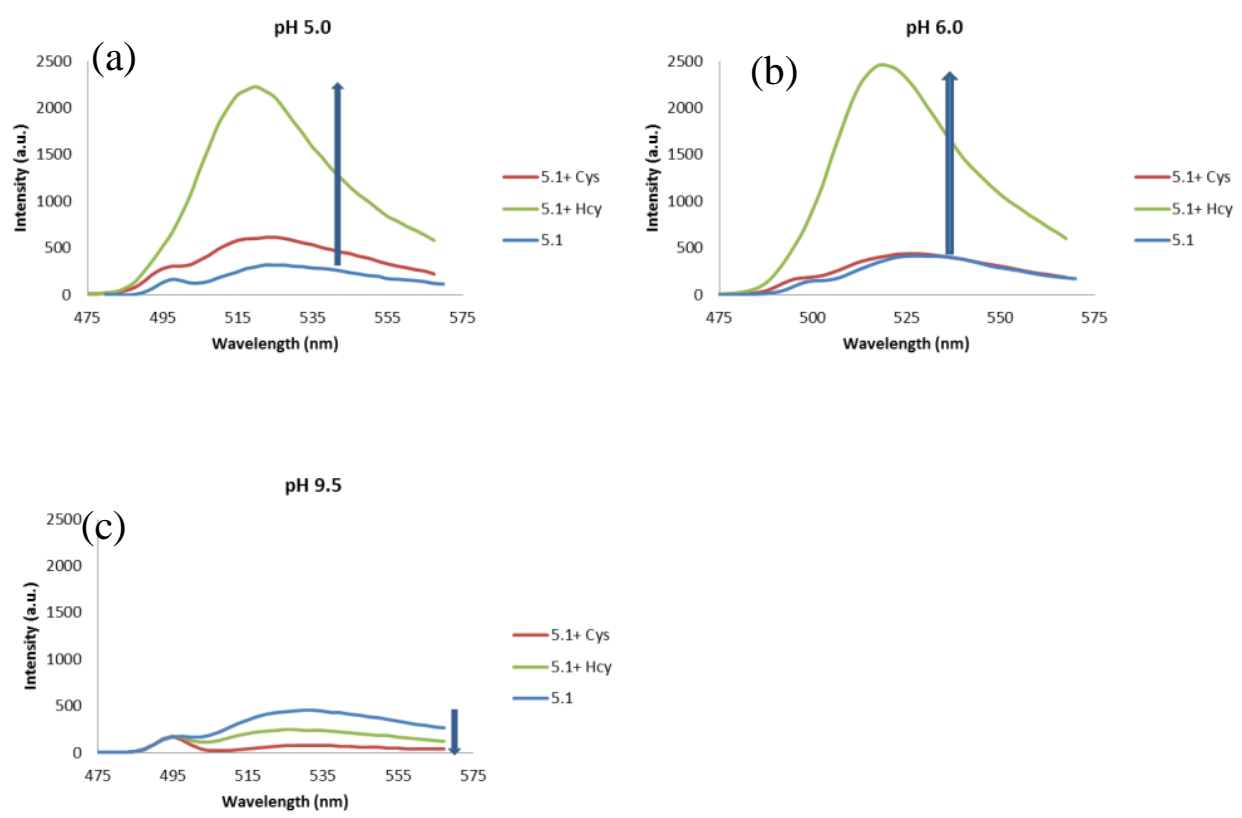

Figure 5-8. Optical sensing behavior of $\mathbf{5 . 1}$ towards Cys and Hcy in buffer at different $\mathrm{pH}$, after $2 \mathrm{~h}$. Fluorescence spectra of $\mathbf{5 . 1}$ with Cys and Hcy (a) at pH 5.5 in phosphate buffer, (b) at pH 6.0 in phosphate buffer, (c) at pH 9.5 in carbonate buffer .Solutions are composed of $4 \mu \mathrm{M}$ of $\mathbf{5 . 1}$ with $1 \mathrm{mM}$ of analyte in $100 \mathrm{mM}$ buffer solution: $\operatorname{DMSO}(99: 1)$ at $20^{\circ} \mathrm{C}, \lambda_{\mathrm{ex}}=495 \mathrm{~nm}$

Apart from being selective, the enhanced sensitivity of the probe $\mathbf{5 . 1}$ is due to the presence of three electron withdrawing aldehyde groups that makes the fluorophore scaffold more electrophilic and reactive. Previously, Huang et al. calculated the surface charges based on density functional theory (DFT) for an aldehyde-bearing iridium (III) complex. They found that charges on the $\mathrm{N}$ and $\mathrm{S}$ atoms of thiazolidine are more negative than the charges on the $\mathrm{N}$ and $\mathrm{S}$ atoms of thiazinane. According to them, higher negative charges on the thiazolidine can result in an intramolecular electron-transfer process from the thiazolidine group to the excited complex, causing a weak photoluminescence of the probe-Cys complex [109].

In the current case, as shown in Table 5.1, the Mulliken charges on the $\mathrm{N}$ and $\mathrm{S}$ 
atoms for Cys-derived thiazolidine are more negative ( $\mathrm{N},-0.650223$ and $\mathrm{S},-0.384138)$ when compared to the $\mathrm{N}$ and $\mathrm{S}$ atoms of Hcy-derived thiazinane $(\mathrm{N},-0.399059$ and $\mathrm{S},-$ 0.078137). This is in agreement with the results reported by Huang et al. for the intramolecular electron transfer process from the thiazolidine group resulting in fluorescence quenching or weak enhancement [109].

Table 5.1 Comparison Mulliken charges on the ' $N$ ' and ' $S$ ' of Cys and Hcy derived heterocycles formed upon reaction with $\mathbf{5 . 1}$

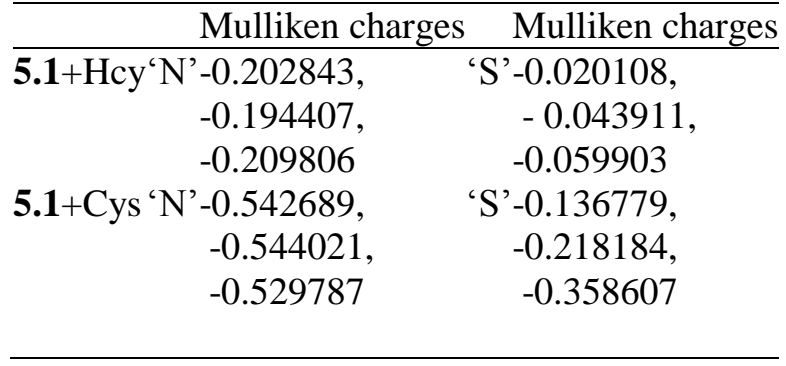

Further, the selective signaling for Hcy in terms of ionic charges can also be explained. From the Mulliken charge calculations, it was found that the phenolate anion and the ether oxygen of the thiazinane (Hcy)-dye adduct bear higher negative charges ($0.729,-0.686$ and -0.326 , respectively) than of the Cys-derived thiazolidine $(-0.508$, 0.621 and -0.280 , respectively) and $5.1(-0.659,-0.576$ and -0.261 , respectively, Table 5.2 and Figure 5-9). The development of enhanced negative charge density on the fluorophore phenolate oxygen upon formation of the Hcy-derived thiazinane results in an increase in fluorescence emission. 


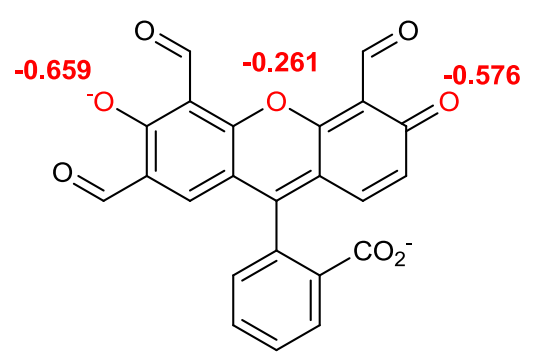

5.1

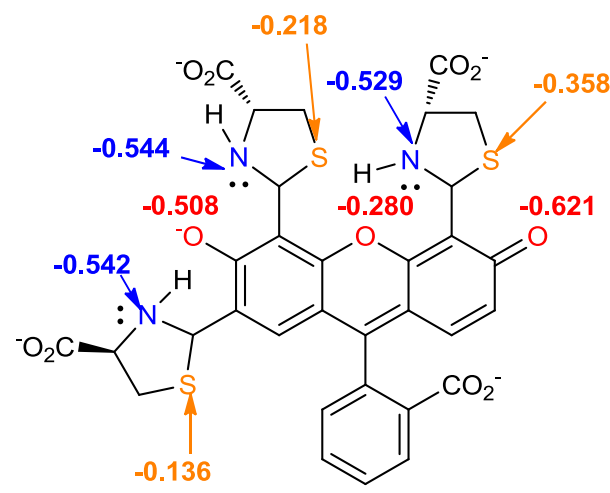

$5.1 \mathrm{a}$

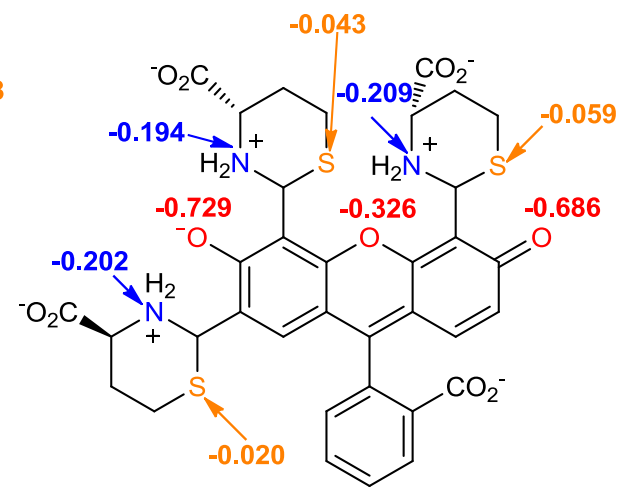

5.1b

Figure 5-9. Predominant species of compounds 5.1, 5.1a and 5.1b at $\mathrm{pH}$ 6.0. Calculated Mulliken charges are shown for the oxygen atoms in the fused ring system.

Table 5.2 Comparison Mulliken charges on the phenolate ' $\mathrm{O}$ ' and ether ' $\mathrm{O}$ ' of $\mathbf{5 . 1}$ and Cys and Hcy derived heterocycles formed upon reaction with $\mathbf{5 . 1}$

\begin{tabular}{|c|c|c|}
\hline & & Iulliken charges \\
\hline 5.1 & $\begin{array}{l}\text { Phenolate oxygen, } \\
\text { ether oxygen }\end{array}$ & $\begin{array}{l}-0.65882,-0.575738, \\
-0.261133\end{array}$ \\
\hline $5.1+$ Hcy & $\begin{array}{l}\text { Phenolate oxygen, } \\
\text { ether oxygen }\end{array}$ & $\begin{array}{l}-0.729433,-0.686371, \\
-0.325709\end{array}$ \\
\hline $5.1+$ Cys & $\begin{array}{l}\text { Phenolate oxygen, } \\
\text { ether oxygen }\end{array}$ & $\begin{array}{l}-0.508089,-0.620732 \\
-0.280251\end{array}$ \\
\hline
\end{tabular}

\subsection{Conclusion}

In conclusion, a highly selective fluorescein trialdehyde for the detection of Hcy at its 
physiological level in biological media has been developed. At $\mathrm{pH} 6.0$, protonation of the amine of the Hcy-derived thiazinane takes place due to its higher basicity compared to the amine of the Cys-derived thiazolidne. The protonation results in inhibition of PET quenching and selective signaling for Hcy. The presence of three electron-withdrawing aldehyde groups makes the fluorophore highly reactive and enhances the Hcy detection limit. Mulliken charge calculations reveal that the Hcy-derived thiazinane renders the fluorophore phenoxide oxygen more electron-rich leading to fluorescence enhancement as compared to the Cys-derived thiazolidine.

\subsection{Experimental section}

\subsubsection{Materials}

All chemicals were purchased from Sigma Aldrich and used as received. Ultra-pure water $\left(18.2 \mathrm{M} \Omega \cdot \mathrm{cm}\right.$ at $\left.25^{\circ} \mathrm{C}\right)$ obtained from a Milli-Q direct water purification system was utilized to prepare all aqueous solutions. All spectroscopic measurements were conducted in DMSO:buffer (1:99) solutions.

\subsubsection{Methods}

${ }^{1} \mathrm{H}$ NMR and ${ }^{13} \mathrm{C}-\mathrm{NMR}$ were recorded on a ARX-400 Advance Bruker spectrometer performing at $400.13 \mathrm{MHz}\left({ }^{1} \mathrm{H}\right)$ and $100.61 \mathrm{MHz}\left({ }^{13} \mathrm{C}\right)$. All chemical shifts chemical shifts $(\delta)$ were reported in ppm using DSS (sodium 2, 2-dimetyl-2-silapentane-5sulfonate) as an internal standard $(\delta=0.000)$ for ${ }^{1} \mathrm{H}$ NMR studies. $\mathrm{CF}_{3} \mathrm{COOD}$ was used as a NMR solvent to record ${ }^{1} \mathrm{H}$ NMR spectra. ${ }^{13} \mathrm{C}$ NMR of $\mathbf{5 . 1}$ was obtained in $\mathrm{CDCl}_{3}$ and $\mathrm{CF}_{3} \mathrm{COOD}(1: 8)$ solvent system . ESI-HRMS (high resolution mass spectrometry) spectra 
was recorded at the PSU Bioanalytical Mass Spectrometry Facility on a ThermoElectron LTQ-Orbitrap high resolution mass spectrometer. IR spectrum was obtained by Fourier transform infrared (FT-IR) spectroscopy operated on a Thermo Scientific Nicolet iS10 spectrophotometer equipped with a single-bounce diamond ATR attachment.

\subsubsection{Spectrophotometric measurement}

UV-visible spectra were recorded on a Cary $50 \mathrm{UV}$-Vis spectrophotometer (Agilent Technologies). Fluorescence spectra were recorded on a Cary Eclipse fluorescence spectrophotometer (Agilent Technologies) with slit widths set at $5 \mathrm{~nm}$ for both excitation and emission, respectively. Fluorescence spectra were corrected for the wavelength dependent response of the R928 photomultiplier tube with the help of a manufacturer generated correction file. All spectrophotometric measurements were conducted at room temperature.

\subsubsection{Deproteinization of plasma}

Deproteinization of plasma was carried out by following the procedure described in the section 3.6.4.

\subsubsection{Mulliken charges calculation}

Molecular models of compounds 5.1, 5.1a and 5.1b were built and subjected to geometry optimization and Mulliken population analysis using the PM7 hamiltonian in MOPAC2012 [150, 151].

\subsubsection{Synthesis of 5.1}

Fluorescein (1 eqv, $7.52 \mathrm{mmol}$ ) was dissolved in a minimum amount of trifluoroacetic 
acid. Hexamethylene tetraamine (10 eqv, $75.23 \mathrm{mmol}$ ) was added slowly to the fluorescein solution under $\mathrm{Ar}$ atmosphere at RT. Reaction mixture was stirred at $70^{\circ} \mathrm{C}$ for $72 \mathrm{hrs}$ under $\mathrm{Ar}$ and then at $100^{\circ} \mathrm{C}$ for extra $4 \mathrm{hrs}$. Afterward, $30 \mathrm{~mL}$ of $1 \mathrm{~N} \mathrm{HCl}$ was added to the reaction mixture and stirred at $100{ }^{\circ} \mathrm{C}$ for additional $1 \mathrm{hr}$. This resulted in the formation of orange precipitates. The reaction mixture was left at RT for $15 \mathrm{hrs}$. Orange precipitates were filtered, washed with water and dried under vacuum. Later, probe $\mathbf{5 . 1}$ was separated by column chromatography $\left(\mathrm{CHCl}_{3}: \mathrm{MeOH}, 98: 2\right.$ and DCM: EtOAc 97:3). Product was obtained as colorless solid with $2 \%$ yield $(62 \mathrm{mg}) . R_{\mathrm{f}}=0.3$ (3\% Ethyl acetate in dichloromethane, $\mathrm{SiO}_{2}$ ); M.P. > $200{ }^{\circ} \mathrm{C} ;{ }^{1} \mathrm{H}$ NMR $\left(400 \mathrm{MHz}, \mathrm{CDCl}_{3}\right) \delta 10.74$

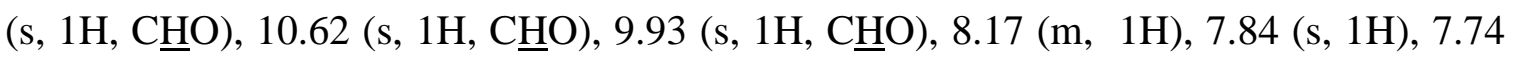
$(\mathrm{m}, 2 \mathrm{H}), 7.25(\mathrm{~m}, 2 \mathrm{H}), 6.94(\mathrm{~m}, 1 \mathrm{H}) ;{ }^{13} \mathrm{C} \mathrm{NMR}\left(101 \mathrm{MHz}, \mathrm{CDCl}_{3}\right) \delta 189.7$ (CHO), 187.6(overlapping, $\mathrm{CHO}), 166.3(\mathrm{COOH}), 153.7,152.8,137.9,133.6,131.9,127.8$, 125.1, 122.4, 122, $120.8,117.9,115.5,111.9,110.8,109.6$-108 (overlapping), 104.4; $v_{\max }($ film $) / \mathrm{cm}^{1} 1738(\mathrm{C}=\mathrm{O})$;. Electrospray ionization (ESI) mass spectrometry (negative electron ionization) $m / z: 415.04610\left(100 \%(\mathrm{M}-\mathrm{H}]^{+}\right.$, calculated for $\mathrm{C}_{23} \mathrm{H}_{12} \mathrm{O}_{8} \mathrm{~m} / z$ : $416.05322(100.0 \%)$. 


\section{REFERENCES}

1. Carmel, R.; Jacobsen, D. W.; Editors, Homocysteine in health and disease. Cambridge University Press: 2001; p 510 pp.

2. Refsum, H.; Smith, A. D.; Ueland, P. M.; Nexo, E.; Clarke, R.; McPartlin, J.; Johnston, C.; Engbaek, F.; Schneede, J.; McPartlin, C.; Scott, J. M., Facts and recommendations about total homocysteine determinations: an expert opinion. Clin. Chem. 2004, 50, (1), 3-32.

3. Boldyrev, A., Molecular Mechanisms of Homocysteine Toxicity and Possible Protection Against Hyperhomocysteinemia. Free Radic. Biol. Med. 2009, 47, S137-S138.

4. Ferin, R.; Pavao, M. L.; Baptista, J., Methodology for a rapid and simultaneous determination of total cysteine, homocysteine, cysteinylglycine and glutathione in plasma by isocratic RP-HPLC. J. Chromatogr. B Analyt. Technol. Biomed. Life. Sci. 2012, 911, 15-20.

5. Kleinman, W. A.; Richie Jr, J. P., Status of glutathione and other thiols and disulfides in human plasma. Biochem. Pharmacol. 2000, 60, (1), 19-29.

6. Paulsen, C. E.; Carroll, K. S., Cysteine-mediated redox signaling: chemistry, biology, and tools for discovery. Chem. Rev. 2013, 113, (7), 4633-79.

7. Reddie, K. G.; Carroll, K. S., Expanding the functional diversity of proteins through cysteine oxidation. Curr. Opin. Chem. Biol. 2008, 12, (6), 746-54.

8. Forman, H. J.; Zhang, H.; Rinna, A., Glutathione: Overview of its protective roles, measurement, and biosynthesis. Mol. Asp. Med. 2009, 30, (1-2), 1-12.

9. Miller, A. L., The methionine-homocysteine cycle and its effects on cognitive diseases. Altern. Med. Rev. 2003, 8, (1), 7-19.

10. Finkelstein, J. D., Methionine metabolism in mammals. J. Nutr. Biochem. 1990, 1, (5), 228-37.

11. Selhub, J., Homocysteine metabolism. Annu. Rev. Nutr. 1999, 19, (1), 217-246.

12. Solanky, N.; Requena Jimenez, A.; D'Souza, S. W.; Sibley, C. P.; Glazier, J. D., Expression of folate transporters in human placenta and implications for homocysteine metabolism. Placenta 2010, 31, (2), 134-43.

13. Finkelstein, J. D., The metabolism of homocysteine: pathways and regulation. Eur. J. Pediatr. 1998, 157 Suppl 2, S40-4.

14. Fowler, B., Homocysteine: overview of biochemistry, molecular biology, and role in disease processes. Semin Vasc Med 2005, 5, (2), 77-86.

15. Mudd, S. H.; Poole, J. R., Labile methyl balances for normal humans on various dietary regimens. Metabolism. 1975, 24, (6), 721-735.

16. Stipanuk, M. H.; Ueki, I., Dealing with methionine/homocysteine sulfur: cysteine metabolism to taurine and inorganic sulfur. J. Inherit. Metab. Dis. 2011, 34, (1), 17-32.

17. Alvarez, L.; Corrales, F.; Martin-Duce, A.; Mato, J. M., Characterization of a fulllength cDNA encoding human liver S-adenosylmethionine synthetase: tissuespecific gene expression and mRNA levels in hepatopathies. Biochem. J. 1993, 293 ( Pt 2), 481-6. 
18. Utley, C. S.; Marcell, P. D.; Allen, R. H.; Antony, A. C.; Kolhouse, J. F., Isolation and characterization of methionine synthetase from human placenta. J. Biol. Chem. 1985, 260, (25), 13656-65.

19. Refsum, H.; Ueland, P. M.; Nygard, O.; Vollset, S. E., Homocysteine and cardiovascular disease. Annu. Rev. Med. 1998, 49, 31-62.

20. Seshadri, S.; Beiser, A.; Selhub, J.; Jacques, P. F.; Rosenberg, I. H.; D'Agostino, R. B.; Wilson, P. W. F.; Wolf, P. A., Plasma homocysteine as a risk factor for dementia and Alzheimer's disease. N. Engl. J. Med. 2002, 346, (7), 476-483.

21. Mills, J. L.; Scott, J. M.; Kirke, P. N.; McPartlin, J. M.; Conley, M. R.; Weir, D. G.; Molloy, A. M.; Lee, Y. J., Homocysteine and neural tube defects. J. Nutr. 1996, 126, (3), S756-S760.

22. Herrmann, M.; Widmann, T.; Herrmann, W., Homocysteine--a newly recognised risk factor for osteoporosis. Clin. Chem. Lab. Med. 2005, 43, (10), 1111-7.

23. Bernasconi, A. R.; Liste, A.; Del Pino, N.; Rosa Diez, G. J.; Heguilen, R. M., Folic acid 5 or $15 \mathrm{mg} / \mathrm{d}$ similarly reduces plasma homocysteine in patients with moderate-advanced chronic renal failure. Nephrology (Carlton) 2006, 11, (2), 137-41.

24. Ozkan, Y.; Yardim-Akaydin, S.; Firat, H.; Caliskan-Can, E.; Ardic, S.; Simsek, B., Usefulness of homocysteine as a cancer marker: total thiol compounds and folate levels in untreated lung cancer patients. Anticancer Res. 2007, 27, 11851189.

25. Oldenburg, B.; Fijnheer, R.; van der Griend, R.; vanBerge-Henegouwen, G. P.; Koningsberger, J. C., Homocysteine in inflammatory bowel disease: a risk factor for thromboembolic complications? Am. J. Gastroenterol. 2000, 95, (10), 282530 .

26. Guthikonda, S.; Haynes, W. G., Homocysteine: role and implications in atherosclerosis. Curr. Atheroscler. Rep. 2006, 8, (2), 100-6.

27. Eleftheriadou, I.; Grigoropoulou, P.; Moyssakis, I.; Kokkinos, A.; Perrea, D.; Toutouzas, K.; Katsilambros, N.; Tentolouris, N., The effect of hyperhomocysteinemia on aortic distensibility in healthy individuals. Nutrition 2013, 29, (6), 876-80.

28. Bostom, A. G.; Silbershatz, H.; Rosenberg, I. H.; Selhub, J.; D'Agostino, R. B.; Wolf, P. A.; Jacques, P. F.; Wilson, P. W., Nonfasting plasma total homocysteine levels and all-cause and cardiovascular disease mortality in elderly Framingham men and women. Arch. Intern. Med. 1999, 159, (10), 1077-80.

29. Jacobsen, D. W., Homocysteine and vitamins in cardiovascular disease. Clin. Chem. 1998, 44, (8), 1833-1843.

30. Strain, J.; Dowey, L.; Ward, M.; Pentieva, K.; McNulty, H., B-vitamins, homocysteine metabolism and CVD. Proc. Nutr. Soc. 2004, 63, (4), 597-604.

31. McCully, K. S., Vascular pathology of homocysteinemia: implications for the pathogenesis of arteriosclerosis. Am. J. Pathol. 1969, 56, (1), 111-28.

32. Wald, D. S.; Law, M.; Morris, J. K., Homocysteine and cardiovascular disease: evidence on causality from a meta-analysis. Br. Med. J. 2002, 325, (7374), 1202$1206 \mathrm{~K}$. 
33. Boushey, C. J.; Beresford, S. A.; Omenn, G. S.; Motulsky, A. G., A quantitative assessment of plasma homocysteine as a risk factor for vascular disease: probable benefits of increasing folic acid intakes. JAMA 1995, 274, (13), 1049-1057.

34. Nygård, O.; Nordrehaug, J. E.; Refsum, H.; Ueland, P. M.; Farstad, M.; Vollset, S. E., Plasma homocysteine levels and mortality in patients with coronary artery disease. N. Engl. J. Med. 1997, 337, (4), 230-237.

35. Demuth, K.; Drunat, S.; Girerd, X.; Moatti, N.; Paul, J.-L.; Safar, M.; Boutouyrie, P., Homocysteine is the only plasma thiol associated with carotid artery remodeling. Atherosclerosis 2002, 165, (1), 167-174.

36. Page, J. H.; Ma, J.; Chiuve, S. E.; Stampfer, M. J.; Selhub, J.; Manson, J. E.; Rimm, E. B., Plasma total cysteine and total homocysteine and risk of myocardial infarction in women: a prospective study. Am. Heart J. 2010, 159, (4), 599-604.

37. Morris, M. S.; Jacques, P. F.; Rosenberg, I. H.; Selhub, J., Hyperhomocysteinemia associated with poor recall in the third National Health and Nutrition Examination Survey. Am. J. Clin. Nutr. 2001, 73, (5), 927-33.

38. Ravaglia, G.; Forti, P.; Maioli, F.; Martelli, M.; Servadei, L.; Brunetti, N.; Porcellini, E.; Licastro, F., Homocysteine and folate as risk factors for dementia and Alzheimer disease. Am. J. Clin. Nutr. 2005, 82, (3), 636-643.

39. Lehmann, M.; Gottfries, C.; Regland, B.; rn, o., Identification of cognitive impairment in the elderly: homocysteine is an early marker. Dement. Geriatr. Cogn. Disord. 1998, 10, (1), 12-20.

40. Clarke, R.; Smith, A. D.; Jobst, K. A.; Refsum, H.; Sutton, L.; Ueland, P. M., Folate, vitamin B12, and serum total homocysteine levels in confirmed Alzheimer disease. Arch. Neurol. 1998, 55, (11), 1449-1455.

41. Kirke, P.; Molloy, A.; Daly, L.; Burke, H.; Weir, D.; Scott, J., Maternal plasma folate and vitamin B12 are independent risk factors for neural tube defects. QJM 1993, 86, (11), 703-708.

42. Mills, J. L.; Scott, J. M.; Kirke, P. N.; McPartlin, J.; Conley, M.; Weir, D., Homocysteine and neural tube defects. 1. In Nutr: 1996.

43. Mills, J. L.; Lee, Y. J.; Conley, M. R.; Kirke, P. N.; McPartlin, J. M.; Weir, D. G.; Scott, J. M., Homocysteine metabolism in pregnancies complicated by neuraltube defects. The Lancet 1995, 345, (8943), 149-151.

44. van der Put, N. M.; van Straaten, H. W.; Trijbels, F. J.; Blom, H. J., Folate, homocysteine and neural tube defects: an overview. Exp. Biol. Med. 2001, 226, (4), 243-270.

45. Mudd, S. H.; Skovby, F.; Levy, H. L.; Pettigrew, K. D.; Wilcken, B.; Pyeritz, R. E.; Andria, G.; Boers, G. H.; Bromberg, I. L.; Cerone, R.; et, a., The natural history of homocystinuria due to cystathionine beta-synthase deficiency. Am. J. Hum. Genet. 1985, 37, 1-31.

46. van Meurs, J. B.; Dhonukshe-Rutten, R. A.; Pluijm, S. M.; van der Klift, M.; de Jonge, R.; Lindemans, J.; de Groot, L. C.; Hofman, A.; Witteman, J. C.; van Leeuwen, J. P.; Breteler, M. M.; Lips, P.; Pols, H. A.; Uitterlinden, A. G., Homocysteine levels and the risk of osteoporotic fracture. N. Engl. J. Med. 2004, $350,(20), 2033-41$. 
47. McLean, R. R.; Jacques, P. F.; Selhub, J.; Tucker, K. L.; Samelson, E. J.; Broe, K. E.; Hannan, M. T.; Cupples, L. A.; Kiel, D. P., Homocysteine as a predictive factor for hip fracture in older persons. N. Engl. J. Med. 2004, 350, (20), 20422049.

48. Grahame, R., Heritable disorders of connective tissue. Baillieres Best Pract. Res. Clin. Rheumatol. 2000, 14, (2), 345-61.

49. Kraus, J. P.; Janosik, M.; Kozich, V.; Mandell, R.; Shih, V.; Sperandeo, M. P.; Sebastio, G.; de Franchis, R.; Andria, G.; Kluijtmans, L. A.; Blom, H.; Boers, G. H.; Gordon, R. B.; Kamoun, P.; Tsai, M. Y.; Kruger, W. D.; Koch, H. G.; Ohura, T.; Gaustadnes, M., Cystathionine beta-synthase mutations in homocystinuria. Hum. Mutat. 1999, 13, (5), 362-75.

50. Schedewie, H.; Willich, E.; Gröbe, H.; Schmidt, H.; Müller, K., Skeletal findings in homocystinuria: a collaborative study. Pediatr. Radiol. 1973, 1, (1), 12-23.

51. Sato, Y.; Honda, Y.; Iwamoto, J.; Kanoko, T.; Satoh, K., Effect of folate and mecobalamin on hip fractures in patients with stroke: a randomized controlled trial. JAMA 2005, 293, (9), 1082-1088.

52. Agullo-Ortuno, M. T.; Albaladejo, M. D.; Parra, S.; Rodriguez-Manotas, M.; Fenollar, M.; Ruiz-Espejo, F.; Tebar, J.; Martinez, P., Plasmatic homocysteine concentration and its relationship with complications associated to diabetes mellitus. Clin. Chim. Acta 2002, 326, (1-2), 105-12.

53. Ueland, P. M.; Refsum, H.; Beresford, S. A.; Vollset, S. E., The controversy over homocysteine and cardiovascular risk. Am. J. Clin. Nutr. 2000, 72, (2), 324-32.

54. Huo, Y.; Qin, X.; Wang, J.; Sun, N.; Zeng, Q.; Xu, X.; Liu, L.; Wang, X., Efficacy of folic acid supplementation in stroke prevention: new insight from a meta-analysis. Int. J. Clin. Pract. 2012, 66, (6), 544-51.

55. Schnyder, G.; Roffi, M.; Flammer, Y.; Pin, R.; Hess, O. M., Effect of homocysteine-lowering therapy with folic acid, vitamin B12, and vitamin B6 on clinical outcome after percutaneous coronary intervention: the Swiss Heart study: a randomized controlled trial. JAMA 2002, 288, (8), 973-979.

56. Yang, Q.; Botto, L. D.; Erickson, J. D.; Berry, R. J.; Sambell, C.; Johansen, H.; Friedman, J. M., Improvement in stroke mortality in Canada and the United States, 1990 to 2002. Circulation 2006, 113, (10), 1335-43.

57. Lee, M.; Hong, K. S.; Chang, S. C.; Saver, J. L., Efficacy of homocysteinelowering therapy with folic Acid in stroke prevention: a meta-analysis. Stroke 2010, 41, (6), 1205-12.

58. Saposnik, G.; Ray, J. G.; Sheridan, P.; McQueen, M.; Lonn, E., Homocysteinelowering therapy and stroke risk, severity, and disability: additional findings from the HOPE 2 trial. Stroke 2009, 40, (4), 1365-72.

59. Bonaa, K. H.; Njolstad, I.; Ueland, P. M.; Schirmer, H.; Tverdal, A.; Steigen, T.; Wang, H.; Nordrehaug, J. E.; Arnesen, E.; Rasmussen, K., Homocysteine lowering and cardiovascular events after acute myocardial infarction. N. Engl. J. Med. 2006, 354, (15), 1578-88.

60. Ebbing, M.; Bleie, O.; Ueland, P. M.; Nordrehaug, J. E.; Nilsen, D. W.; Vollset, S. E.; Refsum, H.; Pedersen, E. K.; Nygard, O., Mortality and cardiovascular 
events in patients treated with homocysteine-lowering B vitamins after coronary angiography: a randomized controlled trial. JAMA 2008, 300, (7), 795-804.

61. Smulders, Y. M.; Blom, H. J., The homocysteine controversy. J. Inherit. Metab. Dis. 2011, 34, (1), 93-9.

62. Nekrassova, O.; Lawrence, N. S.; Compton, R. G., Analytical determination of homocysteine: a review. Talanta 2003, 60, (6), 1085-95.

63. Reddy, M. N.; Behnke, C., A Rapid and Simple Assay to Determine Total Homocysteine and Other Thiols in Pediatric Samples by High Pressure Liquid Chromatography and Fluorescence Detection. J. Liq. Chromatogr. Relat. Technol. 1997, 20, (9), 1391-1408.

64. Melnyk, S., A new HPLC method for the simultaneous determination of oxidized and reduced plasma aminothiols using coulometric electrochemical detection. The Journal of Nutritional Biochemistry 1999, 10, (8), 490-497.

65. Lu, C.; Zu, Y.; Yam, V. W., Specific postcolumn detection method for HPLC assay of homocysteine based on aggregation of fluorosurfactant-capped gold nanoparticles. Anal. Chem. 2007, 79, (2), 666-72.

66. Guan, X.; Hoffman, B.; Dwivedi, C.; Matthees, D. P., A simultaneous liquid chromatography/mass spectrometric assay of glutathione, cysteine, homocysteine and their disulfides in biological samples. J. Pharm. Biomed. Anal. 2003, 31, (2), 251-261.

67. Nelson, B. C.; Pfeiffer, C. M.; Sniegoski, L. T.; Satterfield, M. B., Development and evaluation of an isotope dilution LC/MS method for the determination of total homocysteine in human plasma. Anal. Chem. 2003, 75, (4), 775-84.

68. Lee, P. T.; Lowinsohn, D.; Compton, R. G., The selective electrochemical detection of homocysteine in the presence of glutathione, cysteine, and ascorbic acid using carbon electrodes. Analyst 2014, 139, (15), 3755-62.

69. Lee, P. T.; Lowinsohn, D.; Compton, R. G., Simultaneous Detection of Homocysteine and Cysteine in the Presence of Ascorbic Acid and Glutathione Using a Nanocarbon Modified Electrode. Electroanalysis 2014, 26, (7), 14881496.

70. Chen, Z.; Zu, Y., Electrochemical recognition of single-methylene difference between cysteine and homocysteine. J. Electroanal. Chem. 2008, 624, (1-2), 9-13.

71. Zappacosta, B.; Persichilli, S.; Minucci, A.; Scribano, D.; Baroni, S.; Fasanella, S.; Neri, P.; Daloiso, P. D.; Giardina, B.; De Sole, P., Evaluation of a new enzymatic method for homocysteine measurement. Clin. Biochem. 2006, 39, (1), 62-6.

72. La'ulu, S. L.; Rawlins, M. L.; Pfeiffer, C. M.; Zhang, M. D.; Roberts, W. L., Performance Characteristics of Six Homocysteine Assays. Am. J. Clin. Pathol. 2008, 130, (6), 969-975.

73. Zappacosta, B.; Persichilli, S.; Minucci, A.; Scribano, D.; Antenucci, M.; Fasanella, S.; Neri, P.; Giardina, B.; De Sole, P., Analytical evaluation of a new immunonephelometric method for homocysteine measurement. Clin. Chim. Acta 2007, 375, (1-2), 165-8. 
74. Peng, H.; Chen, W.; Cheng, Y.; Hakuna, L.; Strongin, R.; Wang, B., Thiol reactive probes and chemosensors. Sensors (Basel) 2012, 12, (11), 15907-46.

75. Jung, H. S.; Chen, X.; Kim, J. S.; Yoon, J., Recent progress in luminescent and colorimetric chemosensors for detection of thiols. Chem. Soc. Rev. 2013, 42, (14), 6019-31.

76. Rusin, O.; St Luce, N. N.; Agbaria, R. A.; Escobedo, J. O.; Jiang, S.; Warner, I. M.; Dawan, F. B.; Lian, K.; Strongin, R. M., Visual detection of cysteine and homocysteine. J. Am. Chem. Soc. 2004, 126, (2), 438-439.

77. Wang, W. H.; Rusin, O.; Xu, X. Y.; Kim, K. K.; Escobedo, J. O.; Fakayode, S. O.; Fletcher, K. A.; Lowry, M.; Schowalter, C. M.; Lawrence, C. M.; Fronczek, F. R.; Warner, I. M.; Strongin, R. M., Detection of homocysteine and cysteine. $J$. Am. Chem. Soc. 2005, 127, (45), 15949-15958.

78. Lim, S.; Escobedo, J. O.; Lowry, M.; Xu, X.; Strongin, R., Selective fluorescence detection of cysteine and N-terminal cysteine peptide residues. Chem. Commun. 2010, 46, (31), 5707-9.

79. Escobedo, J. O.; Rusin, O.; Wang, W.; Alpturk, O.; Kim, K. K.; Xu, X.; Strongin, R. M., Detection of biological thiols. In Reviews in Fluorescence 2006, Geddes, C. D.; Lakowicz, J. R., Eds. Springer: US, 2006; Vol. 3, pp 139-162.

80. Ma, L.; He, J.; Zhang, X.; Cui, Y.; Gao, J.; Tang, X.; Ding, M., Determination of total, free, and reduced homocysteine and related aminothiols in uremic patients undergoing hemodialysis by precolumn derivatization HPLC with fluorescence detection. RSC Adv. 2014, 4, (102), 58412-58416.

81. Alcaide, P.; Krijt, J.; Ruiz-Sala, P.; Ješina, P.; Ugarte, M.; Kožich, V.; Merinero, B., Enzymatic diagnosis of homocystinuria by determination of cystathionine- 3 synthase activity in plasma using LC-MS/MS. Clin. Chim. Acta 2015, 438, 261265.

82. Dillon, M. C.; Opris, D. C.; Kopanczyk, R.; Lickliter, J.; Cornwell, H. N.; Bridges, E. G.; Nazar, A. M.; Bridges, K. G., Detection of homocysteine and Creactive protein in the saliva of healthy adults: comparison with blood levels. Biomark Insights 2010, 5, 57-61.

83. Newton, L. A.; Sandhu, K.; Livingstone, C.; Leslie, R.; Davis, J., Clinical diagnostics for homocysteine: a rogue amino acid? Expert Rev. Mol. Diagn. 2010, 10, (4), 489-500.

84. Huijgen, H. J.; Tegelaers, F. P.; Schoenmakers, C. H.; Pronk-Admiraal, C. J.; Ekema, S., Multicenter analytical evaluation of an enzymatic method for the measurement of plasma homocysteine and comparison with HPLC and immunochemistry. Clin. Chem. 2004, 50, (5), 937-940.

85. Zighetti, M. L.; Chantarangkul, V.; Tripodi, A.; Mannucci, P. M.; Cattaneo, M., Determination of total homocysteine in plasma: comparison of the Abbott IMx immunoassay with high performance liquid chromatography. Haematologica 2002, 87, (1), 89-94.

86. Donnelly, J. G.; Pronovost, C., Evaluation of the Abbott IMxTM fluorescence polarization immunoassay and the Bio-Rad enzyme immunoassay for 
homocysteine: comparison with high-performance liquid chromatography. Ann. Clin. Biochem. 2000, 37, (2), 194-198.

87. Frantzen, F.; Faaren, A. L.; Alfheim, I.; Nordhei, A. K., Enzyme conversion immunoassay for determining total homocysteine in plasma or serum. Clin. Chem. 1998, 44, (2), 311-316.

88. Lawrence, N. S.; Deo, R. P.; Wang, J., Detection of homocysteine at carbon nanotube paste electrodes. Talanta 2004, 63, 443-449.

89. Chwatko, G.; Bald, E., Determination of different species of homocysteine in human plasma by high-performance liquid chromatography with ultraviolet detection. J. Chromatogr. B 2002, 949, (1-2), 141-151.

90. Valente, A.; Bronze, M. R.; Bicho, M.; Duarte, R.; Costa, H. S., Validation and clinical application of an UHPLC method for simultaneous analysis of total homocysteine and cysteine in human plasma. J. Sep. Sci. 2012, 35, 3427-3433.

91. Su, C.-L.; Tseng, W.-L., Selective detection of homocysteine by laser desorption/ionization mass spectrometry. Rapid Commun. Mass Spectrom. 2006, 20, 3303-3308.

92. Shipchandler, M. T.; Moore, E. G., Rapid, fully automated measurement of plasma homocyst(e)ine with the Abbott IMx analyzer. Clin. Chem. 1995, 41, (7), 991-4.

93. Ducros, V.; Demuth, K.; Sauvant, M. P.; Quillard, M.; Causse, E.; Candito, M.; Read, M. H.; Drai, J.; Garcia, I.; Gerhardt, M. F., Methods for homocysteine analysis and biological relevance of the results. J. Chromatogr. B Analyt. Technol. Biomed. Life. Sci. 2002, 781, (1-2), 207-26.

94. Tate, J.; Ward, G., Interferences in immunoassay. The Clinical biochemist. Reviews / Australian Association of Clinical Biochemists 2004, 25, (2), 105-20.

95. Schiettecatte, J.; Anckaert, E.; Smitz, J., Interferences in immunoassays. Adv Immunoass Technol 2012.

96. Bock, J. L., The new era of automated immunoassay. Am. J. Clin. Pathol. 2000, 113, (5), 628-646.

97. Ji, J. Z.; Meng, Q. H., Evaluation of the interference of hemoglobin, bilirubin, and lipids on Roche Cobas 6000 assays. Clin. Chim. Acta 2011, 412, (17-18), 1550-3.

98. Hanson, N. Q.; Eckfeldt, J. H.; Schwichtenberg, K.; Aras, O.; Tsai, M. Y., Interlaboratory variation of plasma total homocysteine measurements: results of three successive homocysteine proficiency testing surveys. Clin. Chem. 2002, 48, (9), 1539-45.

99. Sun, S. K.; Wang, H. F.; Yan, X. P., A sensitive and selective resonance light scattering bioassay for homocysteine in biological fluids based on target-involved assembly of polyethyleneimine-capped Ag-nanoclusters. Chem. Commun. 2011, 47, (13), 3817-9.

100. Hung, V. W.-S.; Kerman, K., Gold electrodeposition on carbon nanotubes for the enhanced electrochemical detection of homocysteine. Electrochem. Commun. 2011, 13, (4), 328-330. 
101. Pasas, S. A.; Lacher, N. A.; Davies, M. I.; Lunte, S. M., Detection of homocysteine by conventional and microchip capillary electrophoresis/electrochemistry. Electrophoresis 2002, 23, (5), 759-66.

102. Yu, C.; Zeng, F.; Luo, M.; Wu, S., A silica nanoparticle-based sensor for selective fluorescent detection of homocysteine via interaction differences between thiols and particle-surface-bound polymers. Nanotechnology 2012, 23, (30), 305503.

103. Xiao, Q.; Zhang, L.; Lu, C., Resonance light scattering technique for simultaneous determination of cysteine and homocysteine using fluorosurfactantcapped gold nanoparticles. Sensors and Actuators B: Chemical 2012, 166-167, 650-657.

104. Ching, C. T.-S.; Chang, J.-W.; Sun, T.-P.; Shieh, H.-L.; Tsai, C.-L.; Huang, H.W.; Liu, W.-H.; Liu, C.-M.; Yeh, W.-C.; Li, J.-H., An amperometric biosensor array for precise determination of homocysteine. Sensors and Actuators B: Chemical 2011, 152, (1), 94-98.

105. Lee, H. Y.; Choi, Y. P.; Kim, S.; Yoon, T.; Guo, Z.; Lee, S.; Swamy, K. M.; Kim, G.; Lee, J. Y.; Shin, I.; Yoon, J., Selective homocysteine turn-on fluorescent probes and their bioimaging applications. Chem. Commun. 2014, 50, (53), 69679.

106. Escobedo, J. O.; Wang, W.; Strongin, R. M., Use of a commercially available reagent for the selective detection of homocysteine in plasma. Nat. Protoc. 2006, 1, (6), 2759-62.

107. Hakuna, L.; Escobedo, J. O.; Lowry, M.; Barve, A.; McCallum, N.; Strongin, R. M., A photochemical method for determining plasma homocysteine with limited sample processing. Chem. Commun. 2014.

108. Peng, H.; Wang, K.; Dai, C.; Williamson, S.; Wang, B., Redox-based selective fluorometric detection of homocysteine. Chem. Commun. 2014, 50, (89), 1366871.

109. Chen, H.; Zhao, Q.; Wu, Y.; Li, F.; Yang, H.; Yi, T.; Huang, C., Selective phosphorescence chemosensor for homocysteine based on an iridium(III) complex. Inorg. Chem. 2007, 46, (26), 11075-81.

110. Zhang, J.; Jiang, X.-D.; Shao, X.; Zhao, J.; Su, Y.; Xi, D.; Yu, H.; Yue, S.; Xiao, L.-j.; Zhao, W., A turn-on NIR fluorescent probe for the detection of homocysteine over cysteine. RSC Adv. 2014, 4, (96), 54080-54083.

111. Schubert, M. P., Reactions of semimercaptals with amino compounds. J. Biol. Chem. 1937, 121, 539-48.

112. Feuster, E. K.; Glass, T. E., Detection of amines and unprotected amino acids in aqueous conditions by formation of highly fluorescent iminium ions. J. Am. Chem. Soc. 2003, 125, (52), 16174-5.

113. Kim, T.-K.; Lee, D.-N.; Kim, H.-J., Highly selective fluorescent sensor for homocysteine and cysteine. Tetrahedron Lett. 2008, 49, (33), 4879-4881.

114. Lee, K. S.; Kim, T. K.; Lee, J. H.; Kim, H. J.; Hong, J. I., Fluorescence turn-on probe for homocysteine and cysteine in water. Chem. Commun. 2008, (46), 61735. 
115. Kim, T.-R.; Yun, S.-J.; Park, B.-B., Kinetics and Thermodynamic Studies on the Reaction of Cysteine with Cinnamaldehyde. Bull. Korean Chem. Soc. 1986, 7, (1), 25-29.

116. Wang, Y.; Xiao, J.; Wang, S.; Yang, B.; Ba, X., Tunable fluorescent sensing of cysteine and homocysteine by intramolecular charge transfer. Supramol. Chem. 2010, 22, (6), 380-386.

117. Lim, S.; Escobedo, J. O.; Lowry, M.; Strongin, R. M., Detecting specific saccharides via a single indicator. Chem. Commun. 2011, 47, (29), 8295-7.

118. Lee, H. Y.; Choi, Y. P.; Kim, S.; Yoon, T.; Guo, Z.; Lee, S.; Swamy, K. M. K.; Kim, G.; Lee, J. Y.; Shin, I.; Yoon, J., Selective homocysteine turn-on fluorescent probes and their bioimaging applications. Chem. Commun. 2014.

119. Pesek, J. J.; Frost, J. H., Nuclear magnetic resonance spectroscopy of schiff bases. I. Imines in Aqueous Solution. J. Magn. Reson. (1969) 1974, 15, (3), 520-528.

120. Yoshikawa, K.; Hashimoto, M.; Morishima, I., Photoelectron spectroscopic study of cyclic amines. Relation between ionization potentials, basicities, and $\mathrm{s}$ character of the nitrogen lone pair electrons. J. Am. Chem. Soc. 1974, 96, (1), 288289.

121. Ohwada, T.; Hirao, H.; Ogawa, A., Theoretical analysis of Lewis basicity based on local electron-donating ability. Origin of basic strength of cyclic amines. $J$. Org. Chem. 2004, 69, (22), 7486-94.

122. Radić, N.; Despotović, I.; Vianello, R., Ring Strain and Other Factors Governing the Basicity of Nitrogen Heterocycles - An Interpretation by Triadic Analysis. Croat. Chem. Acta 2012, 85, (4), 495-504.

123. Silva, A. P., Fluorescent PET (Photoinduced Electron Transfer) sensors as potent analytical tools. Analyst 2009, 134, (12), 2385-2393.

124. Shao, J.; Yu, X.; Xu, X.; Lin, H.; Cai, Z.; Lin, H., Colorimetric and fluorescent sensing of biologically important fluoride in physiological $\mathrm{pH}$ condition based on a positive homotropic allosteric system. Talanta 2009, 79, (2), 547-551.

125. Isik, M.; Ozdemir, T.; Turan, I. S.; Kolemen, S.; Akkaya, E. U., Chromogenic and fluorogenic sensing of biological thiols in aqueous solutions using BODIPYbased reagents. Org. Lett. 2012, 15, (1), 216-219.

126. Howard-Lock, H.; Lock, C.; Martins, M., Amino acid/zwitterion equilibria II: vibrational and NMR studies of substituted thiazolidine-4-carboxylic acids. Can. J. Chem. 1991, 69, (11), 1721-1727.

127. Ratner, S.; Clarke, H., The action of formaldehyde upon cysteine. J. Am. Chem. Soc. 1937, 59, (1), 200-206.

128. Butvin, P.; Al-Ja'Afreh, J.; Svetlik, J.; Havranek, E., Solubility, Stability, and Dissociation Constants of (2RS, 4R)-2-Substituted Thiazolidine-4-carboxylic Acids in Aqueous Solutions. Chem. Pap.-Chem. Zvesti 1999, 53, (5), 315-322.

129. Niazi, A.; Bozorghi, S. J.; Shargh, D. N., Prediction of acidity constants of thiazolidine-4-carboxylic acid derivatives using ab initio and genetic algorithmpartial least squares. Turk. J. Chem. 2006, 30, (5), 619-628. 
130. Butvin, P.; Al-Ja'Afreh, J.; Svetlik, J.; Havranek, E., Solubility, stability, and dissociation constants of (2RS,4R)-2-substituted thiazolidine-4-carboxylic acids in aqueous solutions. Chemical Papers-Chemicke Zvesti 1999, 53, (5), 315-322.

131. Howard-Lock, H. E.; Lock, C. J. L.; Martins, M. L., Amino acid/zwitterion equilibria II: vibrational and NMR studies of substituted thiazolidine-4-carboxylic acids. Can. J. Chem. 1991, 69, (11), 1721-1727.

132. Pesek, J. J.; Frost, J. H., Decomposition of thiazolidines in acidic and basic solution. Tetrahedron 1975, 31, (8), 907-913.

133. Refouvelet, B.; Pellegrini, N.; Robert, J. F.; Crini, G.; Blacque, O.; Kubicki, M. M., Synthesis and stereochemical studies of 2-substituted thiazolidine-4carboxamide derivatives. J. Heterocycl. Chem. 2000, 37, (6), 1425-1430.

134. Miyazaki, H.; Ohta, A.; Kawakatsu, N.; Waki, Y.; Gogun, Y.; Shiraiwa, T.; Kurokawa, H., Preparations of Optically Active Homocysteine and Homocystine by Asymmetric Transformation of (RS)-1, 3-Thiazane-4-carboxylic Acid. Bull. Chem. Soc. Jpn. 1993, 66, (2), 536-540.

135. Hofslokken, N. U.; Skattebol, L., Convenient Method for the ortho-Formylation. Acta Chem. Scand. 1999, 53, 258-262.

136. Wynberg, H.; Meijer, E. W., The Reimer-Tiemann Reaction. Organic Reactions 1982.

137. Wynberg, H., The Reimer-Tiemann Reaction. Chem. Rev. 1960, 60, (2), 169-184.

138. Crounse, N. N., The Gattermann-Koch Reaction. Organic Reactions 1949.

139. Kagal, S. A.; Madhavan Nair, P.; Venkataraman, K., A synthesis of isoflavones by a modified vilsmeier-haack reaction. Tetrahedron Lett. 1962, 3, (14), 593-597.

140. Smith, W. E., Formylation of aromatic compounds with hexamethylenetetramine and trifluoroacetic acid. The Journal of Organic Chemistry 1972, 37, (24), 39723973.

141. Burdette, S. C.; Walkup, G. K.; Spingler, B.; Tsien, R. Y.; Lippard, S. J., Fluorescent sensors for $\mathrm{Zn} 2+$ based on a fluorescein platform: synthesis, properties and intracellular distribution. J. Am. Chem. Soc. 2001, 123, (32), 78317841.

142. Skonieczny, K.; Charalambidis, G.; Tasior, M.; Krzeszewski, M.; Kalkan-Burat, A.; Coutsolelos, A. G.; Gryko, D. T., General and Efficient Protocol for Formylation of Aromatic and Heterocyclic Phenols. Synthesis 2012, 44, (23), 3683-3687.

143. Duff, J.; Bills, E., 282. Reactions between hexamethylenetetramine and phenolic compounds. Part II. Formation of phenolic aldehydes. Distinctive behaviour of pnitrophenol. J. Chem. Soc. 1934, 1305-1308.

144. Duff, J.; Bills, E., 273. Reactions between hexamethylenetetramine and phenolic compounds. Part I. A new method for the preparation of 3-and 5aldehydosalicylic acids. J. Chem. Soc. 1932, 1987-1988.

145. Masurier, N.; Moreau, E.; Lartigue, C.; Gaumet, V.; Chezal, J. M.; Heitz, A.; Teulade, J. C.; Chavignon, O., New opportunities with the Duff reaction. J. Org. Chem. 2008, 73, (15), 5989-92. 
146. Sashidhara, K. V.; Kumar, A.; Kumar, M.; Srivastava, A.; Puri, A., Synthesis and antihyperlipidemic activity of novel coumarin bisindole derivatives. Bioorg. Med. Chem. Lett. 2010, 20, (22), 6504-7.

147. Chen, W. H.; Xing, Y.; Pang, Y., A highly selective pyrophosphate sensor based on ESIPT turn-on in water. Org. Lett. 2011, 13, (6), 1362-5.

148. Dong, Y.; Li, J.; Jiang, X.; Song, F.; Cheng, Y.; Zhu, C., Na+ triggered fluorescence sensors for $\mathrm{Mg} 2+$ detection based on a coumarin salen moiety. Org. Lett. 2011, 13, (9), 2252-5.

149. Koralegedara, M. B.; Aw, H. W.; Burns, D. H., Initial structural studies of charged receptors that bind to inorganic phosphate anion and to an anionic phospholipid found in bacterial membranes. J. Org. Chem. 2011, 76, (6), 1930-3.

150. Stewart, J. J. P., MOPAC2012. Stewart Computational Chemistry, Version $14.335 \mathrm{~W}$

151. Maia, J. D. C., et al., J. Chem. Theory Comput. 2012, 8, 3072-3081. 


\section{APPENDIX A : CHARACTERIZATION OF COMPOUNDS 4.1 AND 4.2}
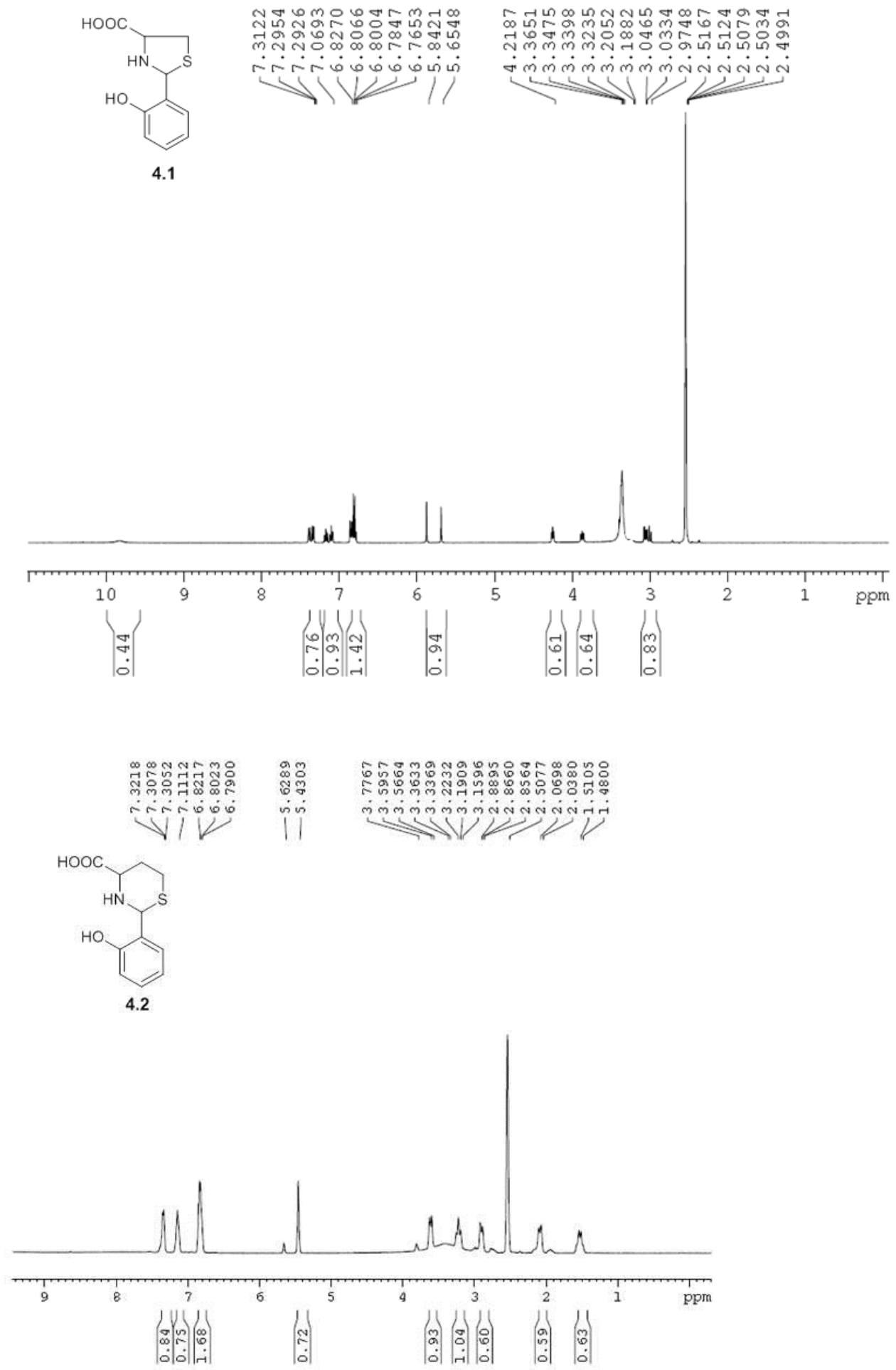

Figure A-1. ${ }^{1}$ HNMR of 4.1 and 4.2 


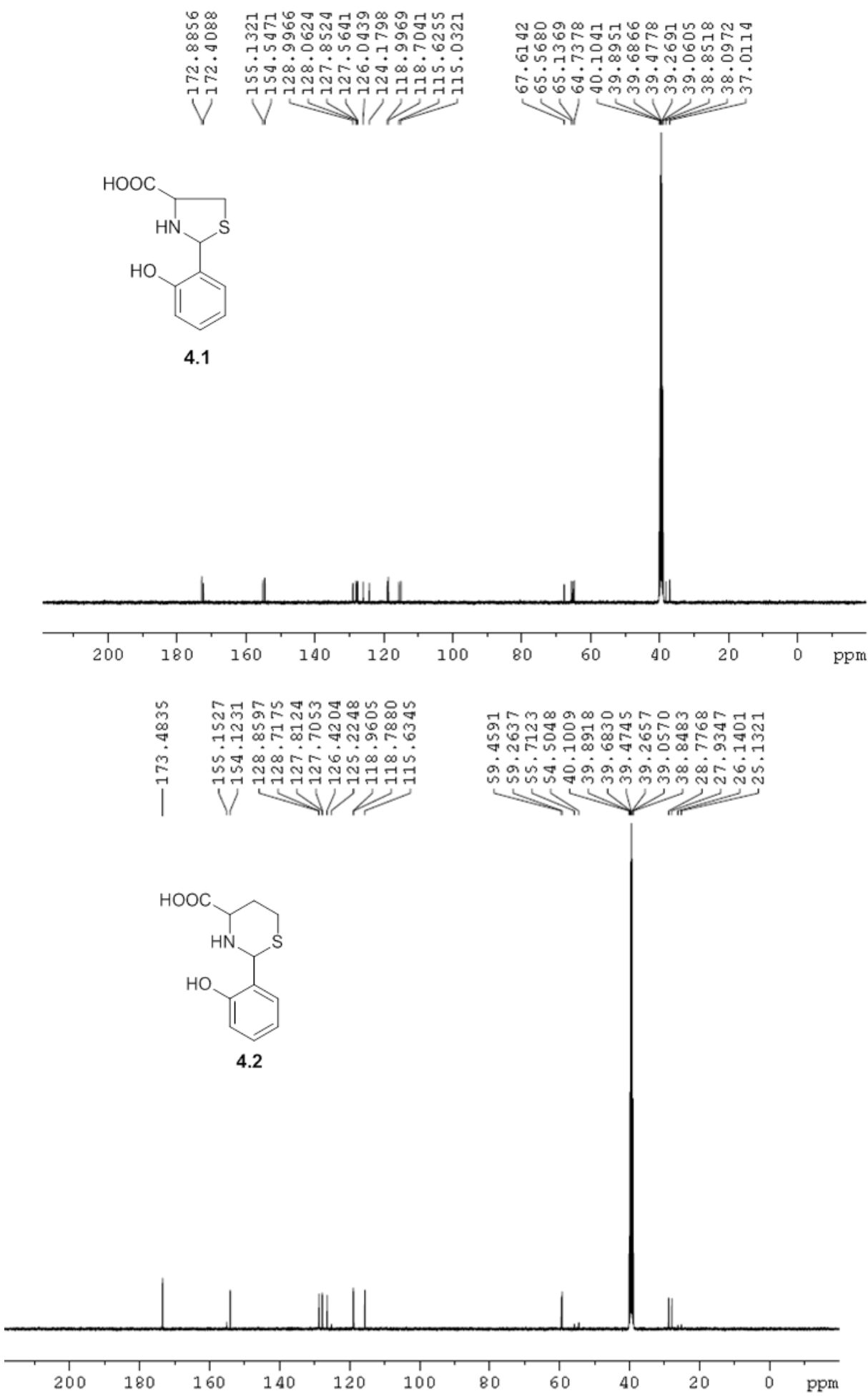

Figure A-2 ${ }^{13} \mathrm{CNMR}$ of $\mathbf{4 . 1}$ and $\mathbf{4 . 2}$ 


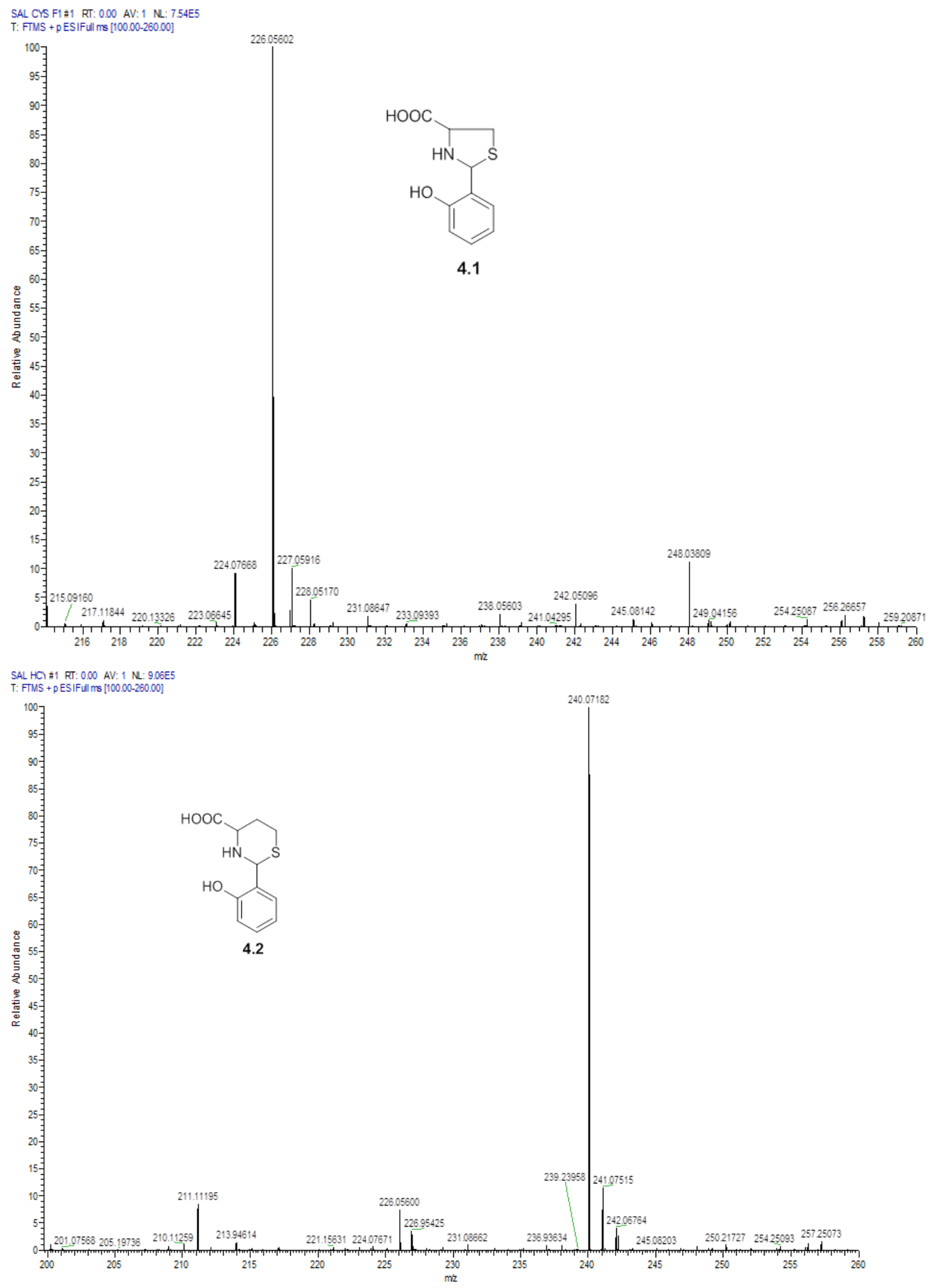

Figure A-3. Mass spectrum of 4.1 and 4.2 


\section{APPENDIX B : CHARACTERIZATION OF COMPOUND 4.3 AND 4.4}

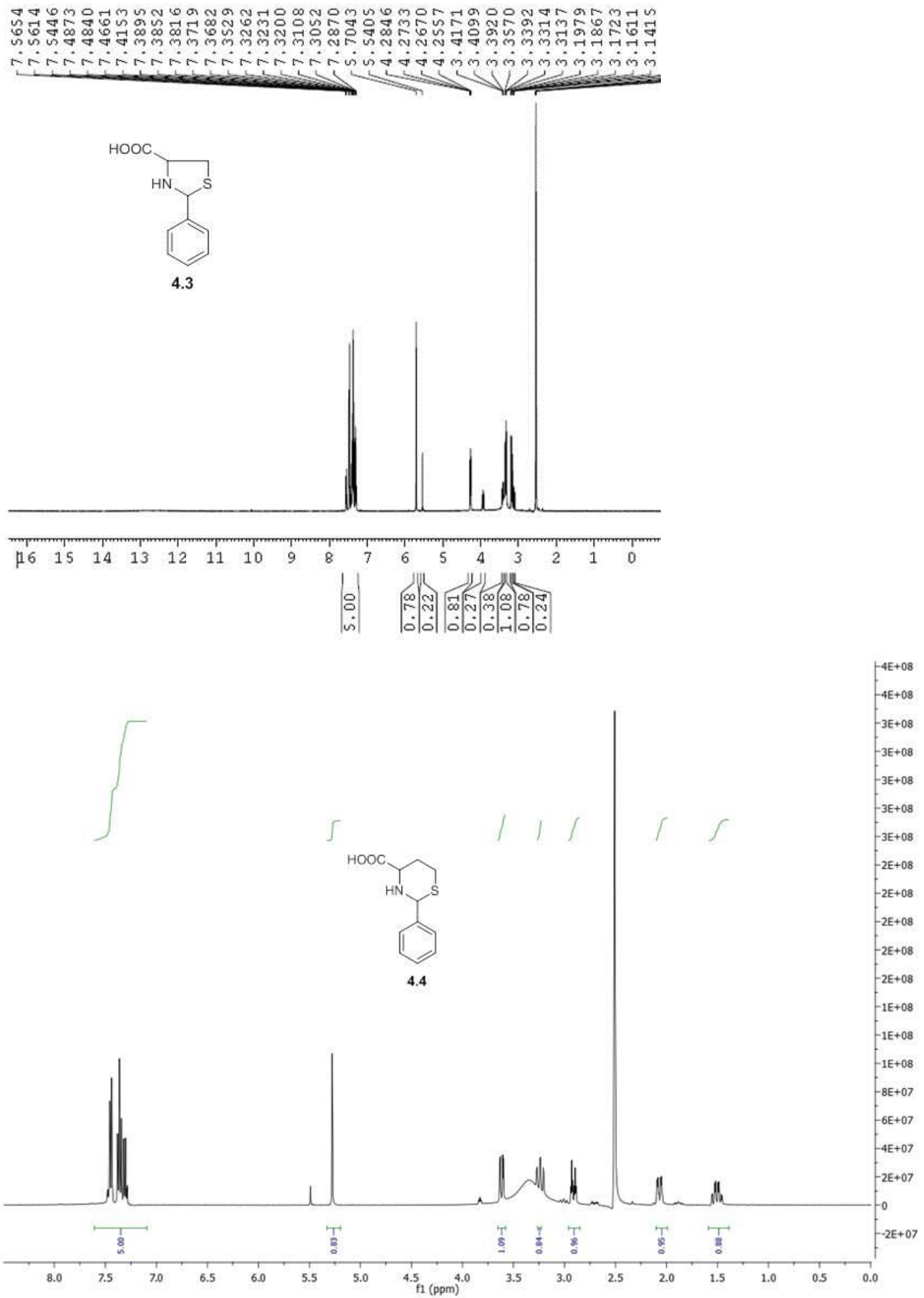

Figure B-1. ${ }^{1} \mathrm{HNMR}$ of $\mathbf{4 . 3}$ and $\mathbf{4 . 4}$ 


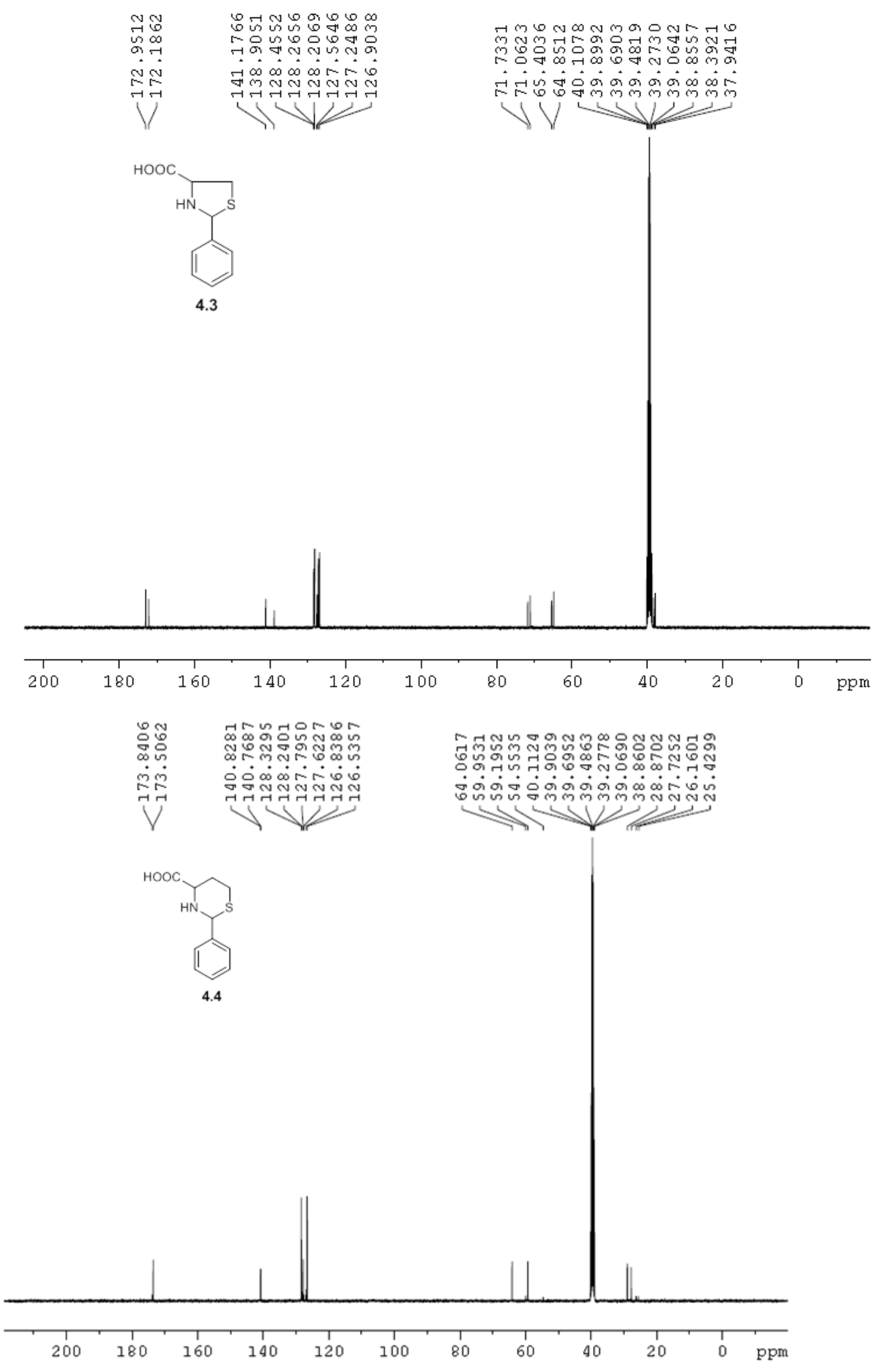

Figure B-2. ${ }^{13} \mathrm{CNMR}$ of $\mathbf{4 . 3}$ and $\mathbf{4 . 4}$ 


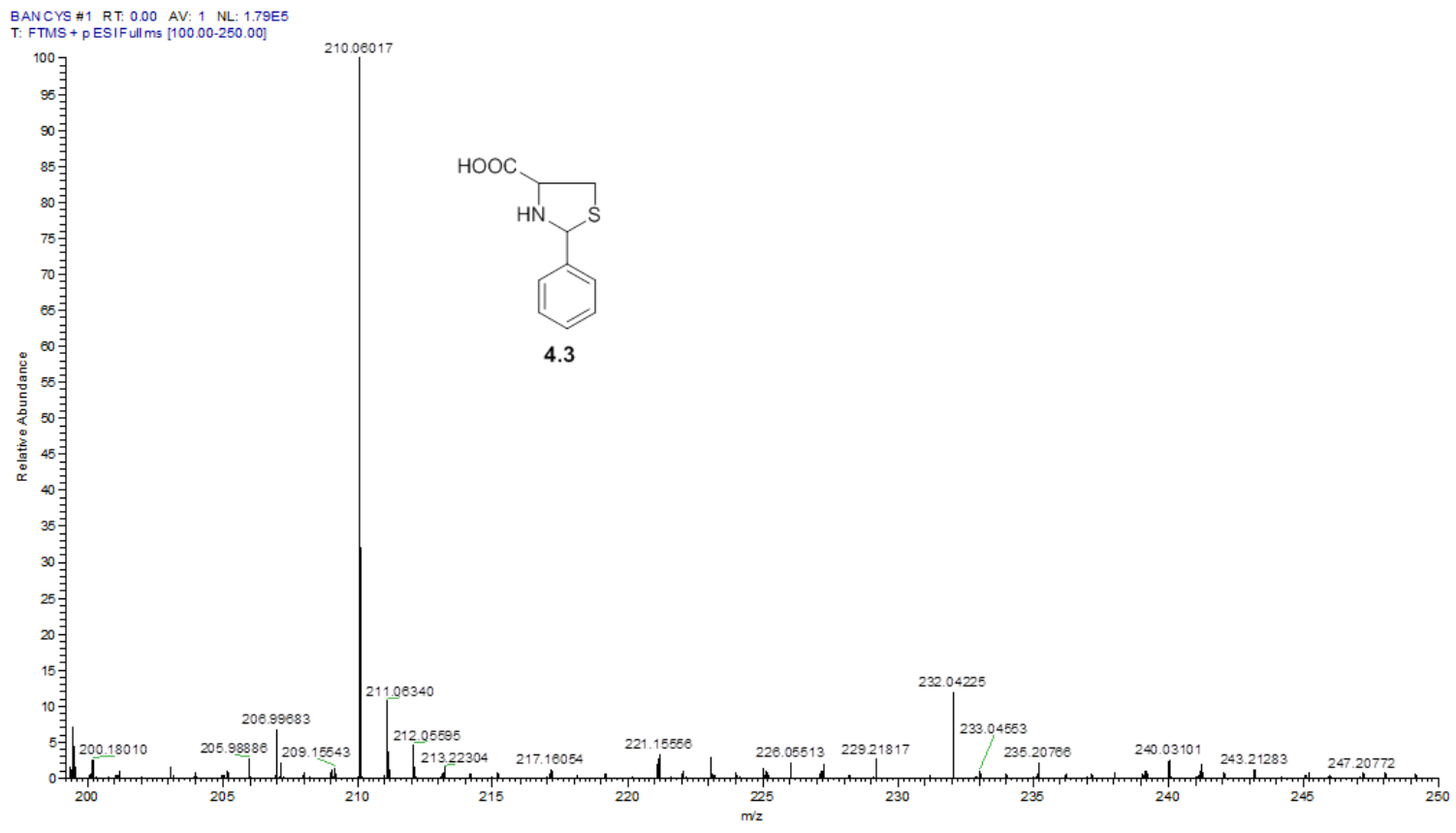

BAN HC) \#1 RT: 0.01 AV: 1 NL'· 3.79E5

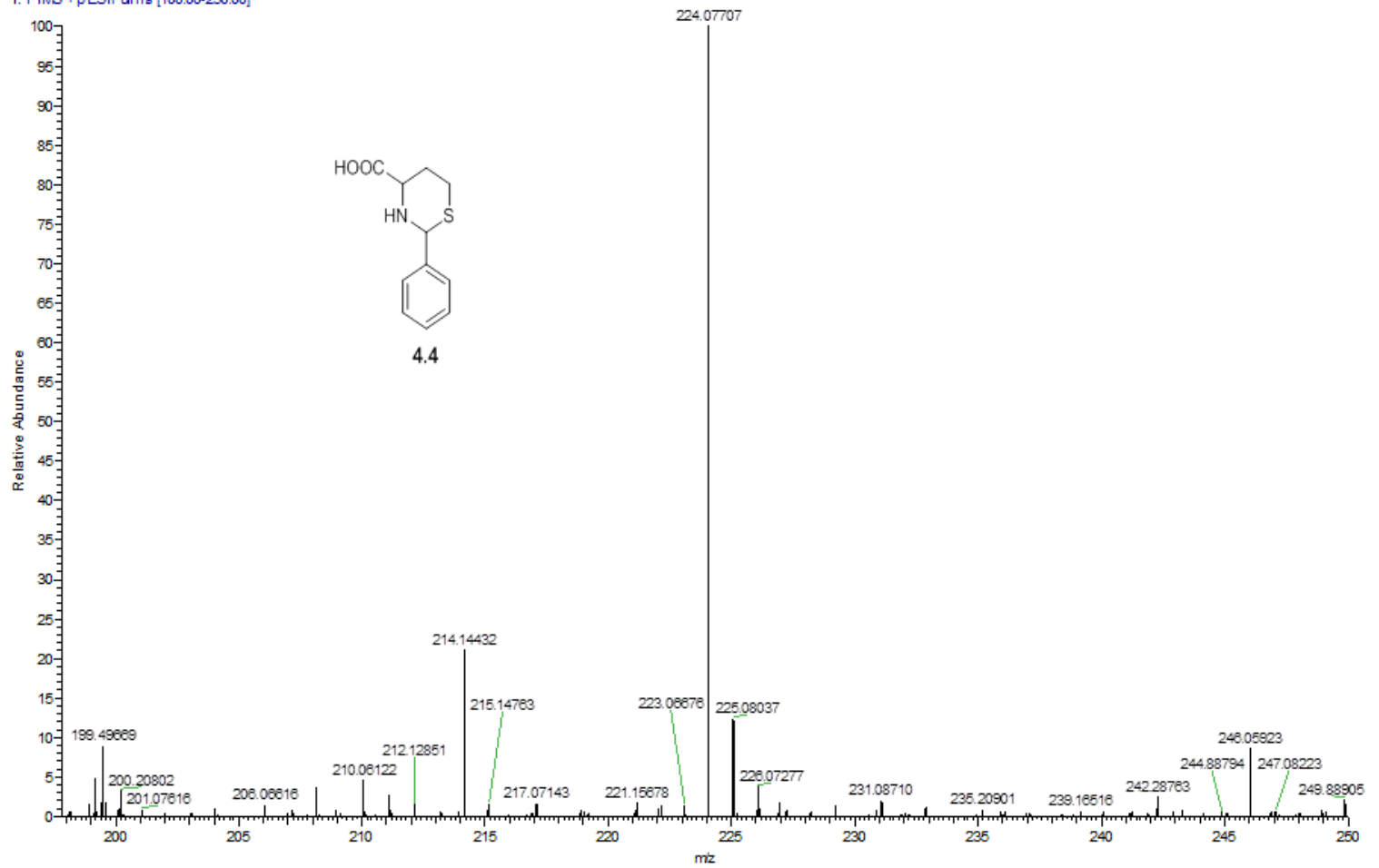

Figure B-3. Mass spectrum of 4.3. and 4.4 


\section{APPENDIX C : CHARACTERIZATION OF COMPOUND 4.5 AND 4.6}
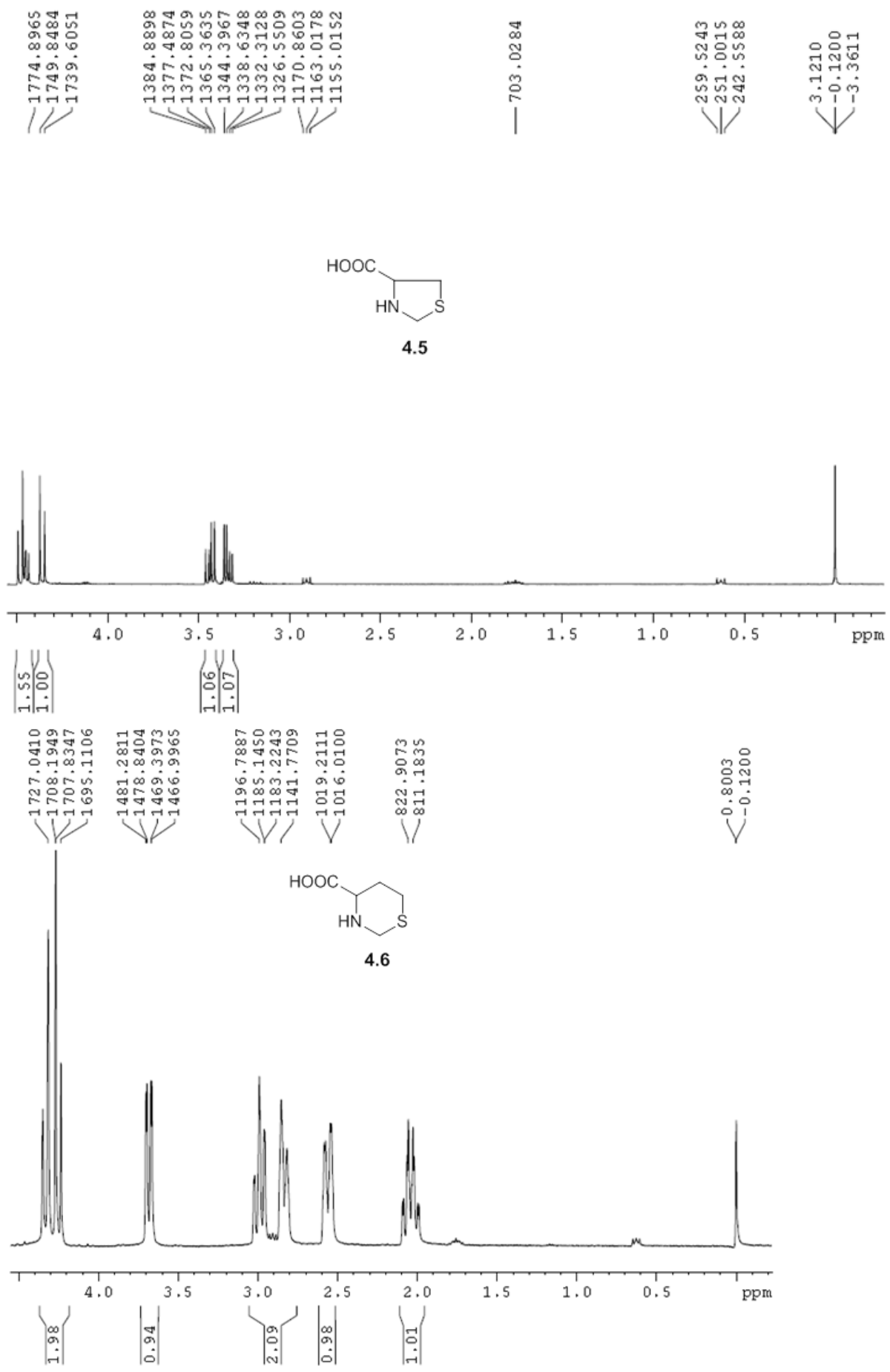

Figure C-1. ${ }^{1} \mathrm{HNMR}$ of $\mathbf{4 . 5}$ and $\mathbf{4 . 5}$ 

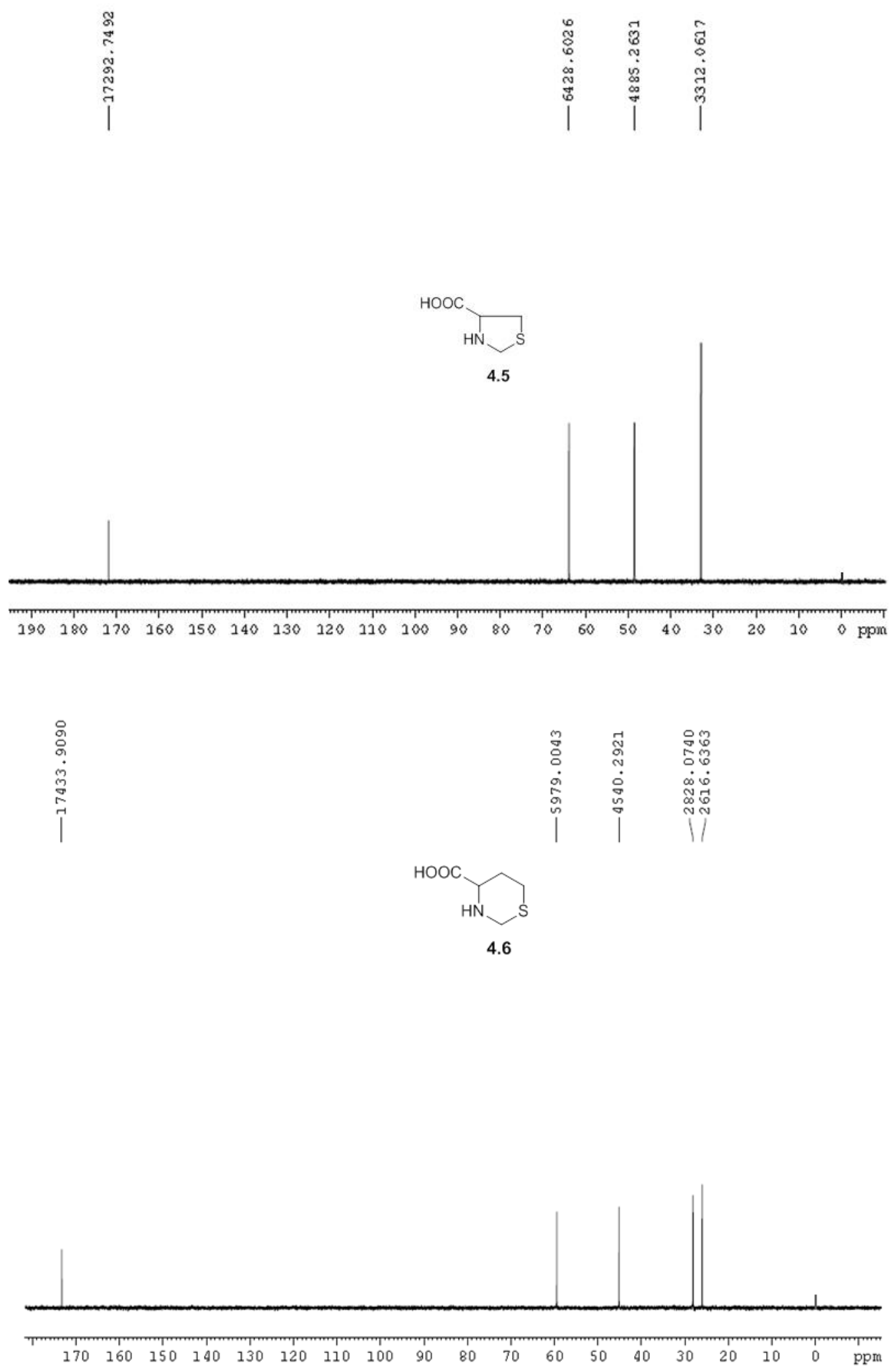

Figure C-2. ${ }^{13} \mathrm{CNMR}$ of $\mathbf{4 . 5}$ and $\mathbf{4 . 6}$ 


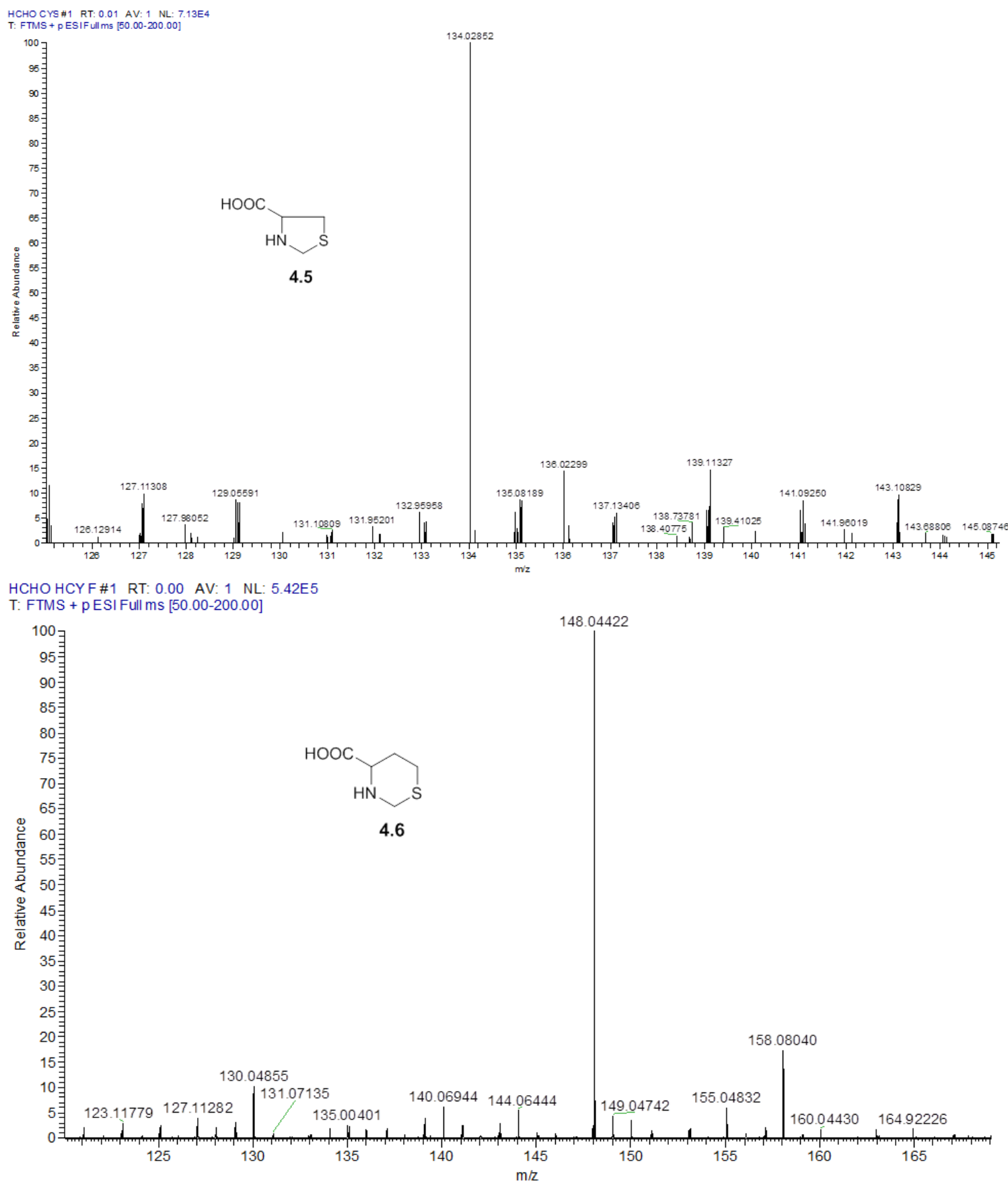

Figure C-3. Mass spectrum of 4.5 and 4.6 


\section{APPENDIX D : CHARACTERIZATION OF COMPOUNDS 5.1}

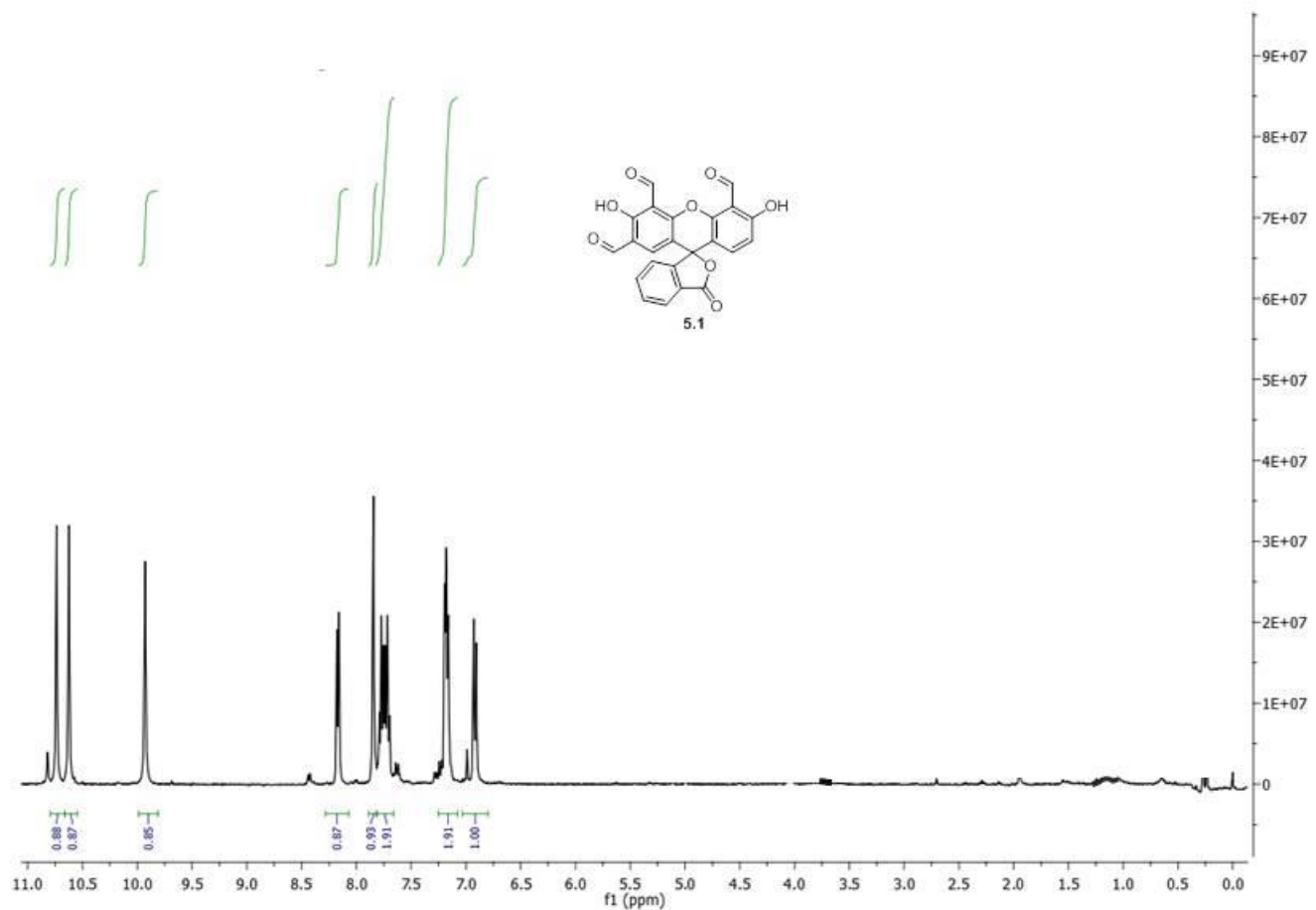

Figure D-1. ${ }^{1} \mathrm{HNMR}$ of $\mathbf{5 . 1}$

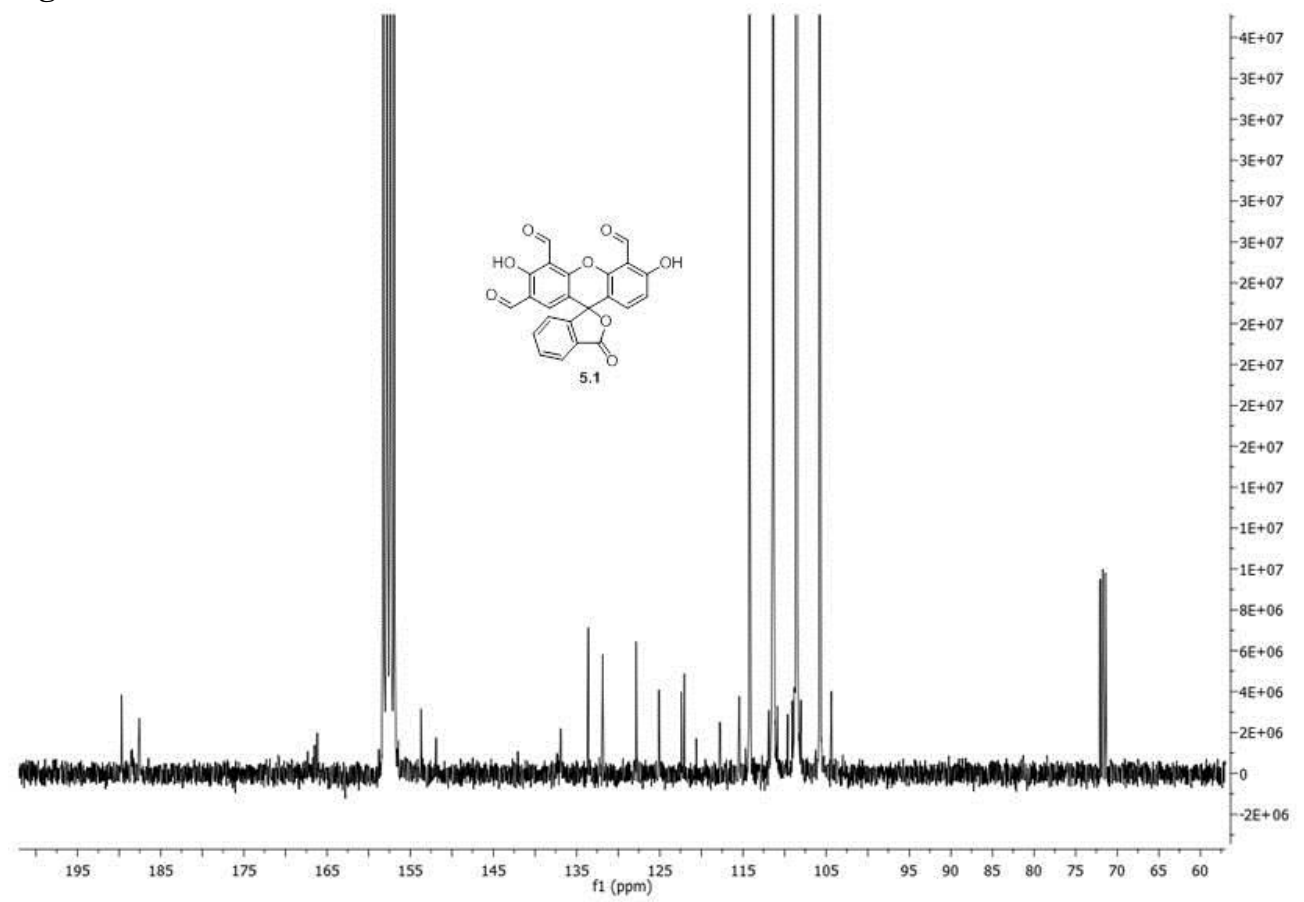

Figure D-2. ${ }^{13} \mathrm{NMR}$ of $\mathbf{5 . 1}$ 


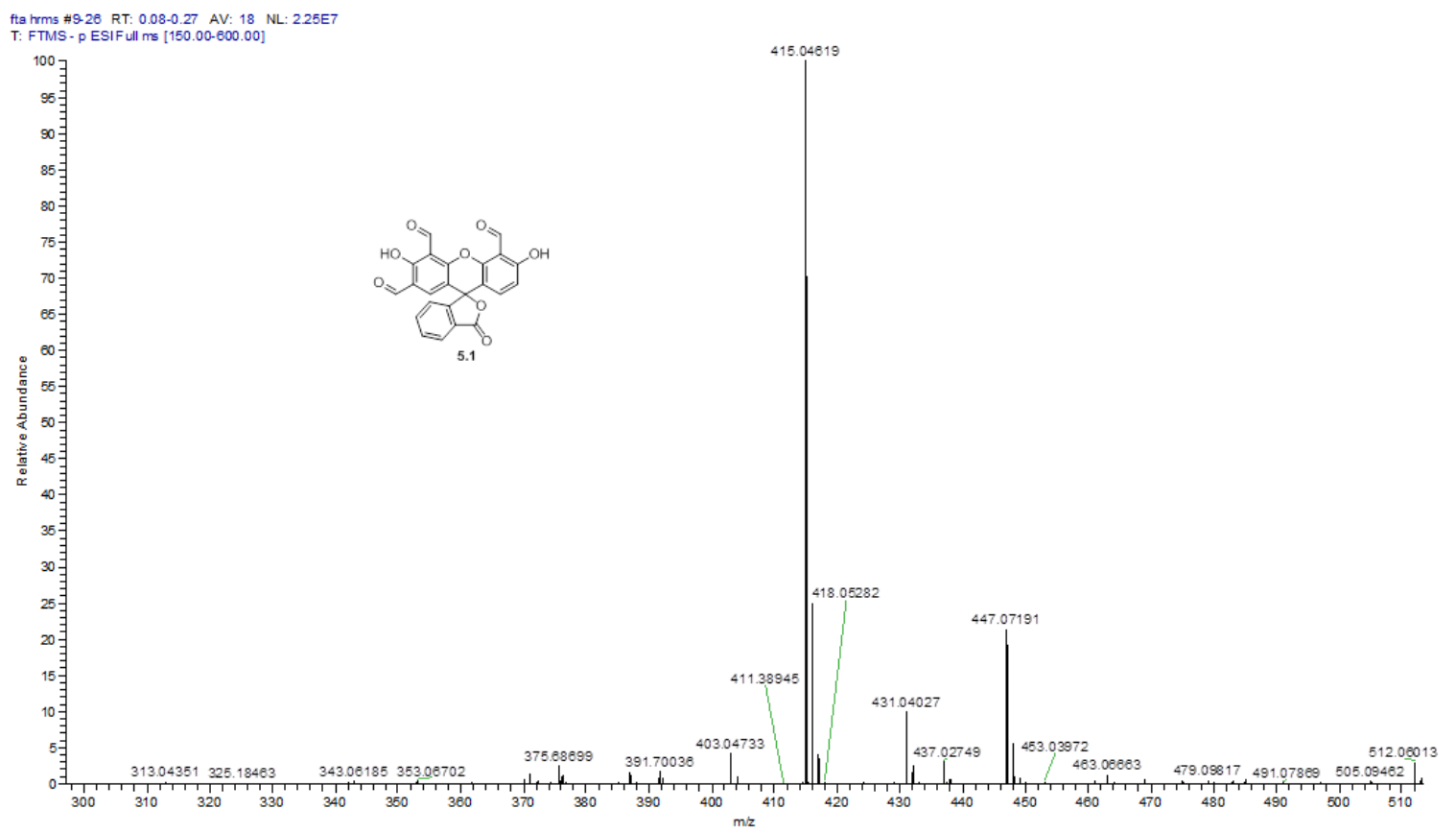

Figure D-3. Mass spectrum of $\mathbf{5 . 1}$ 


\section{APPENDIX E : COLORIMETRIC RESPONSE OF THIOLS TOWARDS 5.1}

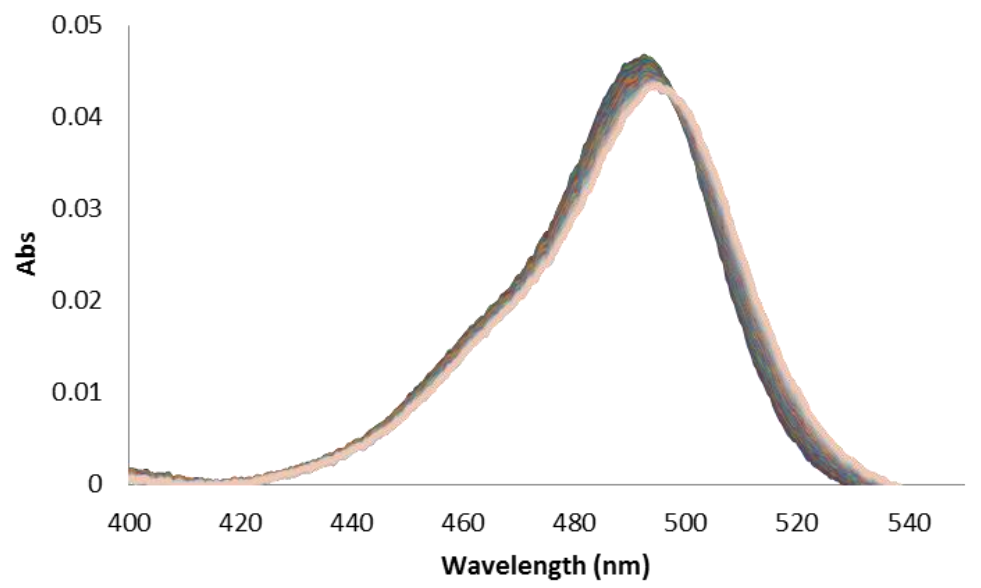

Figure E-1. Optical sensing behavior of $\mathbf{5 . 1}$ towards Hcy at $\mathrm{pH}$ 6.0, Time course absorbance spectral changes of $\mathbf{5 . 1}$ with Hcy, Solutions are composed of $4 \mu \mathrm{M}$ of $\mathbf{5 . 1}$ with $50 \mu \mathrm{M}$ of analyte in phosphate buffer (100 mM, pH 6.0):DMSO 99:1 at $20^{\circ} \mathrm{C}$

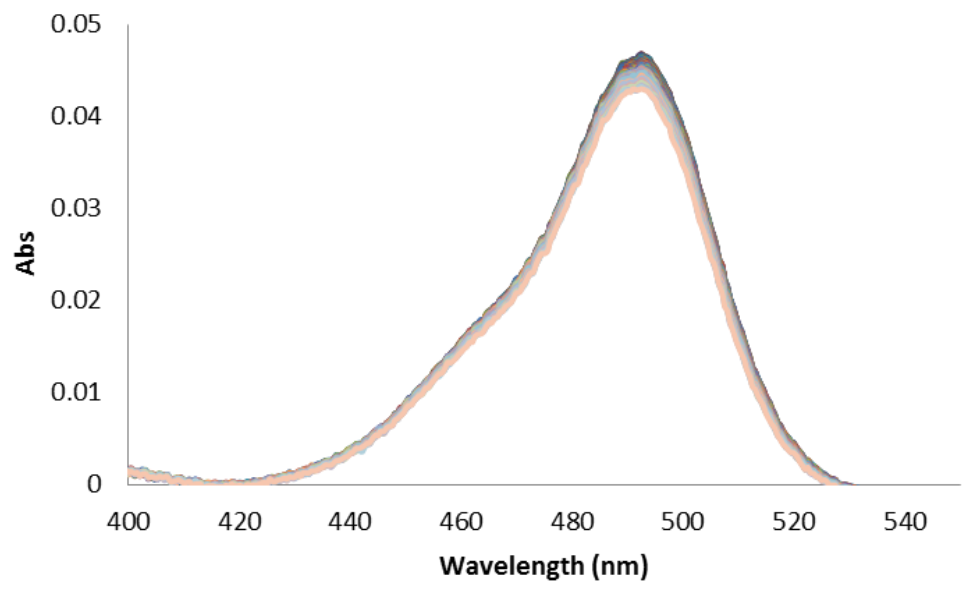

Figure E-2. Optical sensing behavior of $\mathbf{5 . 1}$ towards Cys at $\mathrm{pH}$ 6.0, Time course absorbance spectral changes of 5.1 with Cys, Solutions are composed of $4 \mu \mathrm{M}$ of $\mathbf{5 . 1}$ with $50 \mu \mathrm{M}$ of analyte in phosphate buffer (100 mM, pH 6.0):DMSO 99:1 at $20^{\circ} \mathrm{C}$ 


\section{APPENDIX F : ENERY MINIMIZED SIMULATED 3D STRUCTURE OF 5.1,}

\subsection{A AND 5.1B'}

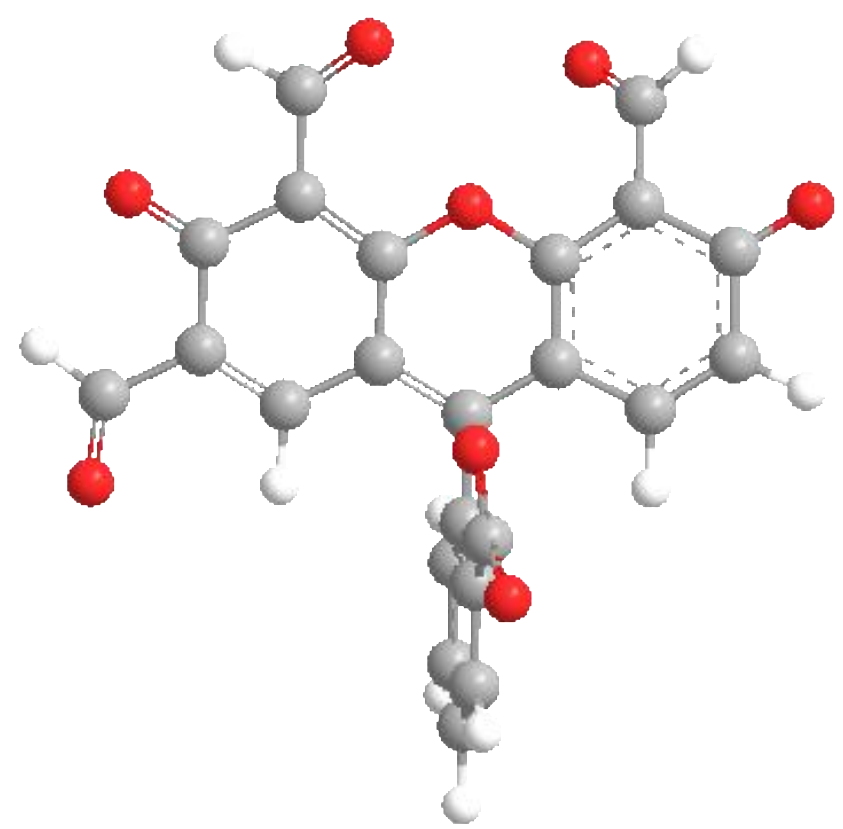

Figure F-1. Energy minimized 3D structure of $\mathbf{5 . 1}$

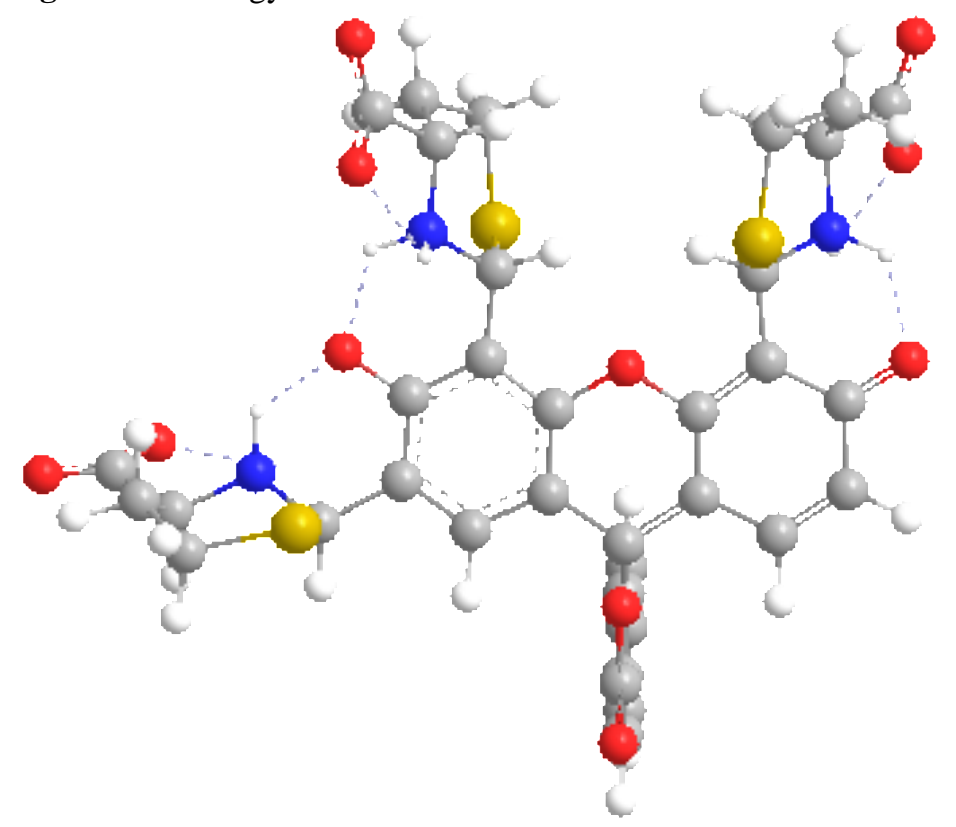

Figure F-2. Energy minimized 3D structure of 5.1b (Hcy-5.1) 


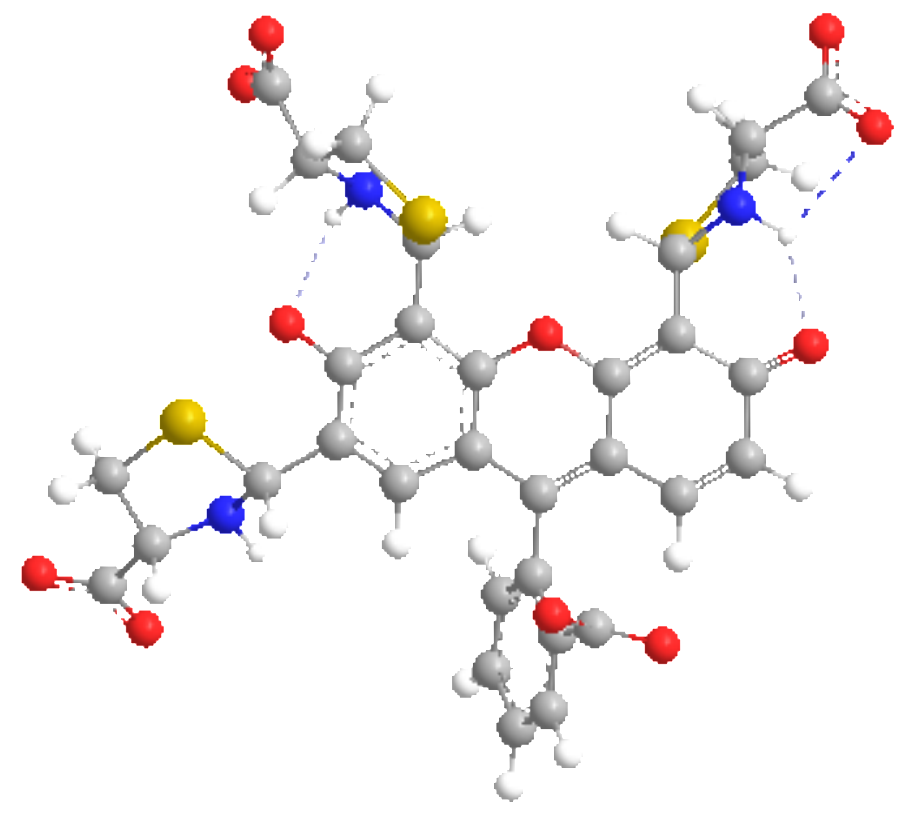

Figure F-3. Energy minimized 3D structure of 5.1a (Cys-5.1). 